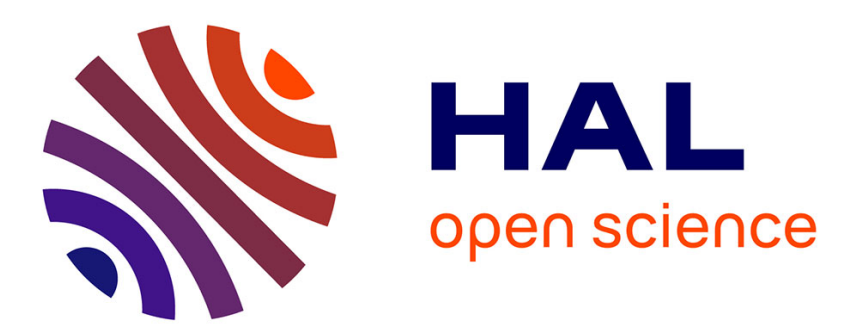

\title{
Des maisons en terre médiévales sur un îlot du quartier Saint-Mathieu, à Perpignan (Pyrénées-Orientales). Premiers éléments de réflexion.
}

Isabelle Rémy, Claire-Anne de Chazelles, Aymat Catafau, Patrice Alessandri

\section{- To cite this version:}

Isabelle Rémy, Claire-Anne de Chazelles, Aymat Catafau, Patrice Alessandri. Des maisons en terre médiévales sur un îlot du quartier Saint-Mathieu, à Perpignan (Pyrénées-Orientales). Premiers éléments de réflexion.. Archéologie du Midi Médiéval, 2010, 27, pp.53-95. halshs-00548019

\section{HAL Id: halshs-00548019 \\ https://shs.hal.science/halshs-00548019}

Submitted on 26 Aug 2016

HAL is a multi-disciplinary open access archive for the deposit and dissemination of scientific research documents, whether they are published or not. The documents may come from teaching and research institutions in France or abroad, or from public or private research centers.
L'archive ouverte pluridisciplinaire HAL, est destinée au dépôt et à la diffusion de documents scientifiques de niveau recherche, publiés ou non, émanant des établissements d'enseignement et de recherche français ou étrangers, des laboratoires publics ou privés. 


\title{
Des maisons en terre médiévales sur un îlot du quartier Saint-Mathieu, à Perpignan (Pyrénées-Orientales). Premiers éléments de réflexion
}

\author{
Isabelle RÉMY*, Claire-Anne de CHAZELLES**, Aymat CATAFAU*** \\ et Patrice ALESSANDRI****
}

L'étude du bâti d'un îlot complet, dans le faubourg Saint-Mathieu qui est situé en périphérie de la ville médiévale de Perpignan, a offert l'une des premières opportunités de rassembler des informations sur l'architecture de terre du XIII ${ }^{e}$ siècle. L'intérêt patrimonial des faubourgs médiévaux, déjà révélé peu avant par une opération archéologique d'urgence dans le quartier Saint-Jacques, tient de l'excellente conservation de leur parcellaire médiéval et de leur architecture des XIII ${ }^{\circ}$ et XIV ${ }^{e}$ siècles. Les maisons, conservées parfois jusqu'au fâite du toit, présentent la particularité d'être exclusivement construites en terre crue. Elles ont livré des informations capitales concernant la mise en œuvre du pisé, majoritairement représenté et déjà assez bien connu dans les faubourgs des villes de la région, mais aussi de la bauge. Le quartier comble donc ici un vide documentaire sur cette technique encore peu documentée.

The study of a complete block of buildings, in the Saint-Mathieu suburb on the outskirts of the medieval city of Perpignan, offered one of the first opportunities to gather information on earth architecture in the XIIIth century. The patrimonial interest of medieval suburbs, already revealed a little earlier by an emergency archaeological operation in the Saint-Jacques district, lies in the excellent preservation of their medieval land parcels and of their XIIIth and XIVth century architecture. Houses, some of which are preserved to the top of the roof, offer the particularity of being exclusively built in raw earth. They delivered major information concerning the implementation of pisé, mainly represented and already well-known in the suburbs of the cities of the region, and also of bauge. This district fills a documentary vacuum on a still little-documented technique.

Mots-clés : architecture civile urbaine, architecture de terre, bauge, pisé, Perpignan.

Key words : civil urban architecture, earth architecture, bauge, pisé, Perpignan.

L'étude des maisons médiévales en terre du quartier Saint-Mathieu, conduite en 2003, fait suite à une intervention réalisée en 2000 dans un autre quartier de Perpignan - celui de Saint-Jacques - dont elle corrobore et enrichit les acquis concernant les plans parcellaires et l'architecture civile de la fin du Moyen Âge. Ces deux quartiers, de même que celui de la Réal, se sont développés pendant la phase d'expansion urbaine qu'a connue Perpignan dans la seconde moitié du XIII' siècle. Ils en ont gardé, jusqu'à nos jours, la trame dessinée par des rues perpendiculaires qui délimitent des îlots découpés en lanières (fig. 1 et 2).
Au cours de l'année 2000, une intervention conduite par F. Guyonnet ${ }^{1}$ sur un groupe de maisons du quartier Saint-Jacques, à une centaine de mètres de la cathédrale et une vingtaine de mètres du couvent des Dominicains, avait, en effet, révélé un potentiel extraordinaire pour la connaissance de l'architecture médiévale de Perpignan, grâce à la découverte d'élévations en terre remarquablement conservées (Guyonnet 2001 ; Guyonnet, Catafau 2003). Ces vestiges, préservés en certains endroits jusqu'au faîte du toit, étaient majoritairement édifiés en bauge, à l'exception d'un tronçon de mur attestant aussi de l'emploi du pisé. Appartenant à la première phase de

\footnotetext{
*INRAP Méditerranée

**Chargée de recherche au CNRS, UMR 5140 Lattes

***Centre de Recherches Historiques sur les Sociétés Méditerranéenne - Université de perpignan

****INRAP Méditerranée

${ }^{1}$ Il s'agit d'une opération préventive (AFAN), réalisée durant 3 semaines par François Guyonnet et Richard Pellé. L'intervention était motivée par un projet de réhabilitation de plusieurs immeubles situés entre la rue de l'Anguille et la rue Joseph Denis.
} 


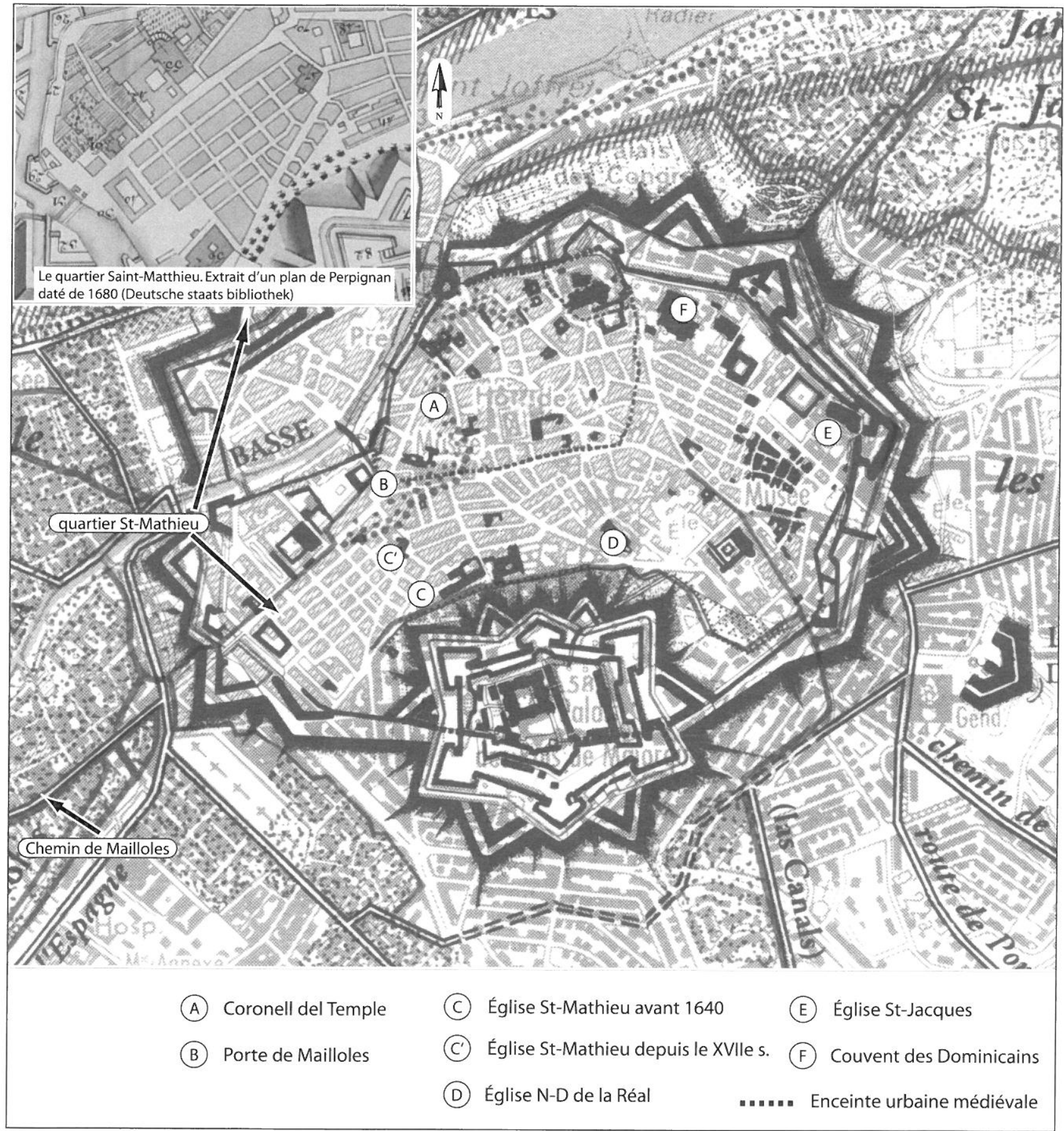

Fig. 1 : Localisation de quelques éléments topographiques sur le fond cadastral de la ville de Perpignan.

construction de l'îlot, ils pouvaient dater de la fin du XIII ${ }^{e}$ siècle ou du début du XIV ${ }^{\mathrm{e}}$ siècle. La mise en lumière de tels vestiges alertait sur le caractère particulièrement sensible de ces trois quartiers. Aussi, lorsqu'en 2003, la Ville de Perpignan projeta la destruction d'un carré de 16 maisons insalubres, délimité par les rues Arago, des Commères, de l'Hôpital et du Four-Saint-François, dans le quartier Saint-Mathieu, une intervention préventive fut-elle tout de suite envisagée ${ }^{2}$. Cet îlot d'habitation, situé à $150 \mathrm{~m}$ de l'église Saint-Mathieu du XVII ${ }^{\mathrm{c}}$ siècle, offrait l'opportunité de vérifier de manière systématique l'existence d'autres constructions en terre d'époque médiévale à Perpignan. Cet îlot-test devait permettre de confirmer le potentiel archéologique, et si tel était le cas,

${ }^{2}$ L'équipe se composait de deux personnes affectées au piquage et l'enregistrement des informations issues du diagnostic des maisons (Cécile FockChow-Tho, Isabelle Rémy). Ce travail a nécessité quatre semaines. Les sondages dans le sous-sol de 4 maisons ont été confiés à deux autres personnes (Patrice Alessandri, André Raux). Cette équipe d'agents de l'INRAP s'est complétée de deux chercheurs. Nous avons demandé l'aide de Claire-Anne de Chazelles, qui est intervenue durant 3 jours sur quelques murs en terre tandis qu'Aymat Catafau s'est chargé de la partie historique. 


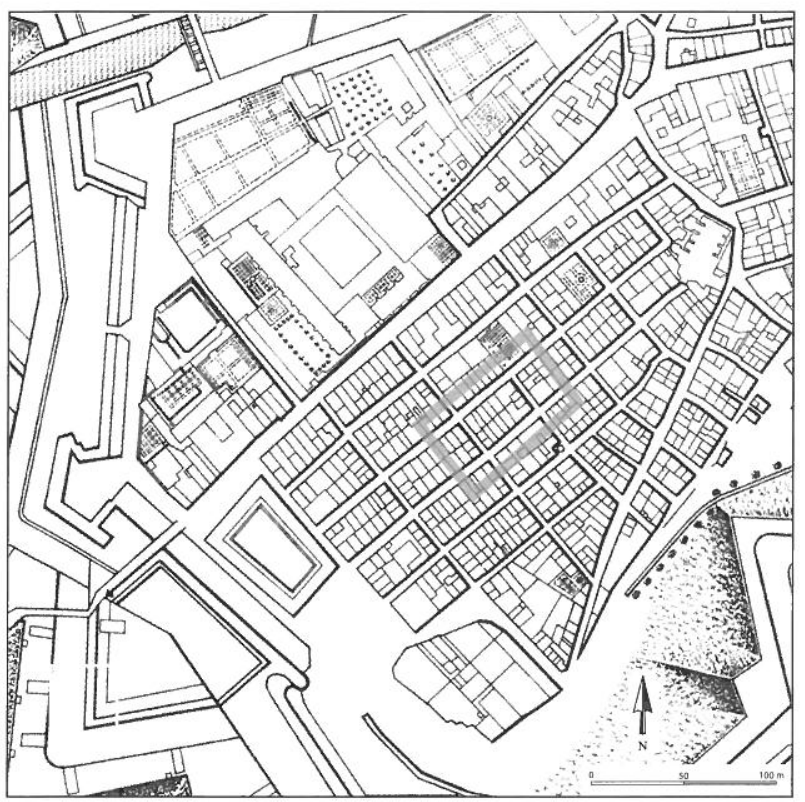

Fig. 2 : Localisation de l'îlot diagnostiqué. La trame régulière du quartier est caractéristique de certains programmes urbains du XIII ${ }^{e}$ siècle dans la région.

de définir les caractéristiques principales qui fourniraient autant de pistes de travail pour les interventions archéologiques à venir : métriques, architecture, techniques de construction, nature des matériaux mis en œuvre, histoire des bâtiments, etc.

Cependant, comme presque toute intervention préventive en archéologie du bâti, l'opération souffrait d'une réelle ambiguïté en ce qui concernait son « avenir », nous obligeant à réviser notre manière d'appréhender le chantier. En effet, pour différentes raisons, il est apparu assez clair que le diagnostic, initialement fixé sur 8 maisons, ne pourrait être poursuivi par une phase d'étude. Aussi avons-nous décidé de ménager des sondages plus étendus que ceux que l'on établit en général lors de ces premières phases d'intervention, dans le dessein d'obtenir un volant d'informations le plus large possible. En contrepartie, les phases de constructions les plus récentes ont dû être négligées au profit des élévations en terre médiévales. Il est évident que ce genre d'intervention - limitée par des contraintes techniques, mais aussi de temps et de sécurité - ne saurait remplacer une étude à part entière. Aussi de nombreux points sont-ils demeurés dans l'ombre ou ne peuvent être exposés que sous la forme d'interrogations. Néanmoins, le diagnostic, effectué finalement sur sept des immeubles, a parfaitement confirmé la légitimité d'une opération archéologique, en mettant en évidence de nombreuses parois en terre, parfois dans un exceptionnel état de conservation. Il a, entre autre, permis de recueillir de nombreuses informations concernant les aspects techniques et morphologiques de ces maisons dans leur état initial, contemporain de la première phase de lotissement du quartier.

\section{LE QUARTIER SAINT-MATHIEU : UN EXEMPLE D'URBANISME DES ANNÉES 1240-1280}

\section{Les éléments connus par les sources documentaires}

Il est peu de cas où la genèse médiévale d'un quartier urbain puisse être aussi bien connue que celle du quartier Saint-Mathieu de Perpignan. Entre le moment où les Templiers décident de lotir systématiquement leurs terrains « hors de la porte de Mailloles », en 1240, et celui où ce processus peut être considéré comme achevé, en 1280, ils enregistrent sur leur cartulaire pas moins de 311 actes de concession de terrains à bâtir concernant le quartier compris aujourd'hui entre les rues Grande-la-Monnaie, Maréchal Foch, Dugommier, Caserne Saint-Martin, soit une superficie totale d'environ 7 ha.

L'histoire des Templiers du Roussillon dispose d'une source privilégiée, le Llibre de la Creu, unique cartulaire ecclésiastique conservé pour le Roussillon médiéval, fort de 479 folii de parchemin contenant 844 actes (Tréton $2007)^{3}$. Il a été le support principal de deux importants travaux d'historiens, le DES de Robert Vinas (Vinas 1961 et 2001) et la thèse de Laure Verdon (Verdon 2001), qui en ont donné l'essentiel dans deux ouvrages parus en 2001. C'est sur leurs dépouillements et leurs écrits que s'appuie cette présentation, ainsi que sur un certain nombre de publications relatives à l'histoire de l'urbanisme ou de l'économie de Perpignan au Moyen Âge.

Il est sans doute possible d'aller plus loin dans l'analyse de ces actes et, à l'aide des confronts de parcelles à bâtir et de maisons louées, de tenter une restitution de l'occupation du sol à la fin de ce processus de lotissement, peut-être même de suivre les phases de son aménagement. Sans avoir mené cette étude de détail, les documents copiés au cartulaire des Templiers du Roussillon ont permis de dater et de décrire avec précision les étapes de la formation de ce quartier ${ }^{4}$.

Le quartier appelé « Saint-Mathieu » depuis le début du XIV ${ }^{\mathrm{e}}$ siècle, quand l'église du même nom y est bâtie, vers 1300 , se situe entre la «porte de Mailloles », au sud-ouest des remparts de la ville datant du milieu du XII ${ }^{e}$ siècle, et la « porte de Saint-Martin », à trois cent cinquante mètres de là, qui clôt les remparts dans leur extension du dernier quart du XIII' ${ }^{\mathrm{e}}$ siècle (fig. 1). Depuis cette porte, le « chemin de Mailloles » conduisait à l'ancien village de Mailloles, autour de son église Sainte-Marie, remontant à une origine attestée toponymiquement du haut Moyen Âge (Villa Gothorum) et sans doute d'époque antique (Alessandri 1993). Une partie des habitants du nouveau quartier (futur « Saint-Mathieu ») sont originaires de ce village (Verdon 1995) $)^{5}$, qui donne l'impression d'être en partie à

\footnotetext{
${ }^{3}$ Il s'agit d'une étude diplomatique et codicologique ainsi que d'une publication des actes réalisée dans le cadre d'une thèse sous la direction d'Olivier Guyotjeannin. J'emprunte ces informations sur le cartulaire.

${ }^{4}$ En plus des ouvrages déjà cités, se reporter à Verdon 2000.

${ }^{5}$ Laure Verdon cite Charles Higounet, qui remarquait, à Bordeaux au Moyen Âge : « les émigrants se sont établis dans les paroisses suburbaines où aboutissaient les chemins qu'ils empruntaient pour aller de leur région d'origine à la ville » (Verdon 1995, 262)
} 
l'abandon dès le milieu du XIII ${ }^{\mathrm{e}}$ siècle, dix ans après le début du lotissement des abords de la porte de Mailloles ${ }^{6}$.

Les Templiers disposent à la porte de Mailloles d'un ensemble de terrains, de moulins, fours et maisons qu'ils ont acquis progressivement, méthodiquement, échangeant parfois des biens situés ailleurs en Roussillon contre des propriétés foncières dans cet espace limitrophe des murs, continuant à acheter des terrains alors même qu'ils en attribuent d'autres à titre de concession viagère à des fins de construction. Cette préférence pour ce lieu repose sur des éléments objectifs : la proximité de la Basse et d'un canal, le rech comtal dit rech mitjà, ( « canal moyen » pour le distinguer du grand rech comtal venant de Vinça et passant par Thuir avant d'entrer à Perpignan par le sud), qui, dérivé de la Têt à Sainte-Eugénie, passe par Orle et Mailloles et alimente de nombreux moulins dans la périphérie immédiate de la ville ; un équipement artisanal et proto-industriel (mouture de la farine puis panification, ateliers de tanneurs et corroyeurs du cuir, ateliers de traitement du textile, scieries) en pleine expansion à la fin du XII ${ }^{e}$ et au début du XIII ${ }^{e}$ siècle à Perpignan. Mais des éléments plus conjoncturels et, dans une certaine mesure, plus propres aux Templiers, ont pu jouer leur rôle : l'espace du futur quartier Saint-Mathieu se trouve enclavé entre deux pôles majeurs de la présence templière dans la plaine du Roussillon. La maison des Templiers à l'intérieur des murs de Perpignan se trouve presque en bordure de la porte de Mailloles. Elle occupe tout un pâté de maisons, un coronell du Perpignan médiéval (pâté de maisons longtemps appelé coronell del Temple), délimité par les rues actuelles de la Cloche d'Or, de la Barre, Mailly et de l'Ange, ensemble à l'intérieur duquel on circule par une ruelle sans issue (actuelle impasse de la Division) et par d'autres ruelles disparues depuis (carrer de la Iglesia del Temple, 1247, carrer del Forn del Temple, 1275) où se trouvaient la maison fortifiée du Temple, l'église Sainte-Marie du Temple et le four du Temple. À l'opposé géographique, le terroir de Mailloles et son village sont depuis l'installation des Templiers en Roussillon un des points d'ancrage de leurs possessions foncières dans la plaine.

Dès 1172, dans le testament du dernier comte de Roussillon, Girard, les Templiers reçoivent en legs les moulins de la porte de Mailloles. Le Temple continue à acquérir des moulins à Mailloles, en 1199, et sur le rech comtal, près de la Basse, en 1232. L'Ordre veille à ses intérêts et élève une protestation lorsque la construction d'un barrage (une resclausa) risque de gêner ses moulins. Le terrain qui s'étend au pied de la porte est appelé dès cette époque la « condomine du Temple », bordée au nord par le chemin qui va à Mailloles. C'est juste au nord de ce chemin qu'est établi, légendairement en 1211, lors du passage de François d'Assise à Perpignan, en tout cas avant 1235 , date de sa première mention, le couvent des Franciscains. La chapelle Notre-Dame des Anges, ancienne chapelle du Tiers Ordre des Franciscains, et un pan muré du cloître cimetière en ont seuls été préservés, lors de l'installation d'un hôpital militaire au XVII siècle. En 1244 l'actuelle rue Foch, le chemin de Mailloles, est appelée carreria Sancti Francisci, après avoir porté aux premiers temps du lotissement le nom de via novella, carrer nou (« rue neuve »).

En 1215, les Templiers établissent trois actes de concessions de parcelles à bâtir en cet endroit. À un menuisier, ils donnent en acapte (bail à emphytéose) un patil ad faciendum domos in vinea Templi que est versus meridiem juxta portalem Perpiniani de Malleolis. La localisation est sans équivoque : au sud, contre la porte de Perpignan dite « de Mailloles ». L'espace à bâtir est un carré de 5 cannes de Montpellier de côté (environ $10 \mathrm{~m} \mathrm{x}$ $10 \mathrm{~m}$ ). Ces premières concessions ne sont pas suivies d'autres : pression démographique insuffisante, demande trop faible? Les raisons de l'arrêt de cette tentative restent inconnues. Pourtant le Temple met à profit les décennies suivantes pour acquérir encore des biens fonciers dans ce secteur : en 1232 tout un ensemble composé de terres, vignes, treilles, maisons, mas, ouvroirs (operatoria) est payé par eux 2600 sous de Melgueil. Même au plus fort de leurs concessions à bail, les Templiers continuent à y acheter des terres (en 1244 par exemple) ou à échanger des biens marginaux de leur patrimoine foncier contre des propriétés dans le quartier de «Sant Francesch », en 1272.

C'est en 1241 que commence le grand mouvement de concessions de terrains à bâtir : pour cette seule année ce sont 35 actes de ce type, concernant ce quartier, qui sont copiés dans le cartulaire, 33 pour 1246, en tout plus de 90 pour les années 1241-1249. Une nouvelle vague de concessions s'étend des années 1261 à 1280 , avec pour 1268,32 actes, en 1271, 75 (!), et 17 en 1280 (en tout, sur ces vingt années plus de 170 concessions). Entre 1251 et 1260 , les concessions sont presque inexistantes. Après 1280 , le mouvement est fini, les concessions retombent à quelques unités sur la décennie suivante.

Les concessions sont essentiellement des baux de terrains à bâtir : d'une superficie variable, le plus souvent d'une ou deux monallatas, c'est-à-dire probablement d'une ou deux fois $25 \mathrm{~m}^{2}$ (une monallata est la surface carrée d'un monall, une poutre, dont la longueur est évaluée par Jean-Auguste Brutails à $5 \mathrm{~m}$ ) (Brutails 1891) ${ }^{7}$. On trouve une concession de 6 (soit $150 \mathrm{~m}^{2}$ ), et même une de 12 monallatas $\left(300 \mathrm{~m}^{2}\right)$. Le terrain est donné contre un

\footnotetext{
${ }^{6}$ En effet, dès 1251 les Templiers concèdent un pati ...intus villam veteri de Malleolis, le qualificatif de « vieux » est le signe d'un déclin villageois, du début d'un processus d'abandon. En 1279, c'est un champ de fourrage qui est localisé « in terminis de Malleolis, in villa vetula », indicateur probable d'une déprise du bâti (Catafau, 1998,405).

7 « Pour mesurer les emplacements à bâtir on se servait de la monallata, carré déterminé par la portée d'un monall, ou poutre. Les Templiers firent à Perpignan, au XIII ${ }^{\mathrm{e}}$ siècle, de nombreuses concessions de terrains à bâtir, à raison de trois sterlings de cens annuel par monallata; or je trouve dans le cartulaire du temple, fol 306-307, une concession consentie pour ce prix d'un terrain de deux cannes et demie de Montpellier de côté, le 9 avril 1266 , j'ai lieu de croire qu'il s'agit d'une monallata et que cette mesure était un carré de $25 \mathrm{~m}$ de superficie environ (5 m x $5 \mathrm{~m}$ ) 》 (Brutails, 1891,58 , note 1).
} 
droit d'entrée (intrata) élevé, et un cens annuel assez faible au départ. Les tendances s'inversent par la suite, et la pression et la demande se faisant moins fortes, les Templiers concèdent des terrains contre un droit réduit, mais perçoivent des cens annuels plus élevés. À la fin de la période, les concessions de quelques maisons, propriétés du Temple, louées en emphytéose, suivent la même évolution. Les preneurs des terrains à bâtir ont pour seule obligation, mais impérative, au risque de se voir retirer la terre concédée, d'y construire « une ou des maisons » dans les deux ans suivant le passage de l'acte.

C'est de ce mouvement de construction que naît le quartier Saint-Mathieu : les rues parallèles (E-O) qui s'alignent sur la « rue Saint-François »; les actuelles rue de la Lanterne, Arago, du Four-Saint-François, du Puits des Chaînes, ou perpendiculaires (N-S) ; les actuelles rues Cimetière Saint-Mathieu, Pierre Trouée, des Commères, de 1'Hôpital, Dagobert, sont tracées préalablement à l'attribution des parcelles, dont beaucoup au moment de leur concession ne bordent qu'une rue d'un côté, et des trois autres la «terre du Temple », ou la «vigne du Temple ». Ce plan régulier n'est pas spontané, il est le résultat d'un arpentage et d'un découpage planifiés. C'est d'ailleurs ce que signifie le nom que donne à ce quartier le roi Jacques de Majorque dans l'acte du 28 août 1247, où il confirme au Temple la possession de tous les fours de Perpignan, y compris celui situé extra muros in populacione nova que est extra villam Perpiniani. La poblacio nova (populacio en latin) c'est le nom habituel dans les chartes catalanes des «villeneuves» ou «bastides » des pays languedociens ou aquitains.

Laure Verdon a bien montré dans ses travaux sur le quartier comment la première vague de lotissement s'ordonne sur un certain nombre de bâtiments très tôt construits, qui en forment l'armature, les pôles de cristallisation : le four, la rue nouvelle, face au couvent Saint-François, puis comment dans la seconde phase, et surtout dans la décennie 1270-1280, ce sont les espaces interstitiels, les patis, ou terrains à bâtir enclavés, qui sont systématiquement lotis, et finissent par donner l'image d'un quartier entièrement construit.

Elle a aussi montré comment le recrutement social de ce quartier affirme dès l'origine son activité artisanale : travail du cuir, du textile, du bois et activités de transport caractérisent ses habitants, avec l'inflexion, dans le dernier tiers du XIII ${ }^{\mathrm{e}}$ siècle vers une spécialisation textile et drapière de la ville de Perpignan, corroborée par les sources économiques (registres notariaux). Le Temple possède d'ailleurs ses propres moulins, mais aussi ses ateliers de tannerie, sur la rue Saint-François, et il tire une partie non négligeable de ses revenus des taxes levées sur le four à pain (qui donnera son nom à la rue du Four-Saint-François). Mais les archéologues noteront avec intérêt que le précepteur du Temple concède aussi, en 1250, extra portale de Malleolis, un four à tuiles dont le cens annuel s'élève à 31 sous 1 denier de Barcelone, soit 25 sous de Melgueil, ou plus simplement un demi-marc d'argent, que le preneur pourra régler sous forme de 1250 tuiles bien cuites, livrables à Pâques et à la Saint-Michel de septembre.
La confrontation avec le terrain ; les éléments de restitution des parcelles de l'îlot diagnostiqué

\section{L'implantation topographique}

L'étude des élévations était conjointe à une exploration du sous-sol, réalisée sur des surfaces limitées. Quatre sondages ont été ouverts dans quatre maisons : aux 5, rue de l'Hôpital, aux 31 et 35, rue du Four-Saint-François, au 33, rue Arago. Les emplacements des sondages étaient choisis en fonction de la possibilité de relier les études d'élévations à la stratigraphie présente dans le sous-sol. Leur réalisation avait un double objectif, qui était d'une part de renseigner sur l'état de conservation des vestiges des différentes périodes d'occupation dans l'îlot et d'autre part de préciser les relations entre la stratigraphie enfouie et les élévations de murs, notamment ceux montés en terre crue, en cherchant à apporter des informations en terme de chronologie absolue. De ces points de vue, les résultats sont contrastés. L'aménagement d'une cave moderne au 5, rue de l'Hôpital a détruit les occupations antérieures de l'espace et le sol naturel, largement entamé par ce creusement, n'a pas été observé. Au 31, de la rue du Four-Saint-François le terrain naturel apparaît immédiatement sous une couche d'occupation limoneuse vierge de tout mobilier archéologique. Au 35, de la rue du Four-Saint-François l'espace est occupé par un bassin d'époque moderne. Le terrain naturel apparaît sous deux couches d'occupation limoneuses dépourvues de mobilier archéologique. Enfin, au 33, rue Arago, c'est-à-dire au revers du sondage précédent, les sols d'époque contemporaine reposent sur une couche d'occupation limoneuse qui, ici aussi, n'a livré aucun mobilier.

Le premier constat qui frappe est que le terrain naturel est présent dans l'îlot à des cotes assez élevées. Elles apparaissent, en effet, immédiatement sous les niveaux d'occupation modernes et contemporains. Cette constatation induit deux interprétations possibles : la configuration actuelle de l'espace est celle, demeurée inchangée, mise en place dès l'implantation du quartier Saint-Mathieu bâti sur les terres à jardin situées hors les murs ; seuls quelques aménagements mineurs et tardifs, creusement d'une cave, reprise de murs en sous-œuvre, viennent modifier l'ordonnancement d'origine. Elle peut, sinon, résulter d'un réaménagement profond du secteur avant la construction du quartier en terre, impliquant une destruction totale de l'habitat plus ancien, une évacuation des matériaux de démolition et une réinstallation sur un terrain mis à nu jusqu'aux alluvions de la Basse.

\section{Restitution de l'îlot diagnostiqué}

Le quartier fait partie des trois extensions de Perpignan opérées au cours du XIII ${ }^{e}$ siècle, avec les quartiers Saint-Jacques et la Réal. Ils forment de grands lotissements, dont la genèse était raisonnée et contrôlée, comme en témoigne encore, à l'heure actuelle, la pérennité des structures urbaines et du parcellaire. Ces quartiers neufs s'organisent sur une trame orthogonale, dessinée par un réseau de rues perpendiculaires délimitant des îlots eux-mêmes divisés en parcelles rectangulaires. 
L'ensemble présente une morphologie qui appartient à la grande famille des villes neuves et des bastides, édifiées au cours du même siècle à l'initiative des rois d'Aragon, parmi lesquelles se comptent, entre autres exemples, la ville de Montpellier, qui connaît son propre projet de lotissement favorisé par Jacques I ${ }^{\mathrm{er}}$ (Fabre, Lochard 1992 : 151-152).

Aujourd'hui encore, le quartier Saint-Mathieu a conservé son organisation en îlots de plan assez régulier, aux angles orientés vers les quatre points cardinaux. Ils sont de taille assez modeste mais égale, d'une trentaine par une vingtaine de mètres. Ils sont découpés en double rangée de parcelles longues et étroites occupées par des maisons adossées, ce qui manifeste une remarquable pérennité. C'est globalement le cas de l'îlot concerné par le diagnostic, pour lequel il a été possible de constater la parfaite superposition des élévations en terre mises au jour avec une très grande partie du parcellaire actuel et présumé remonter au Moyen Âge. De fait, seules quelques anomalies, fruits de modifications ultérieures, brisent cette composition régulière (fig. 3 ).

L'extrémité nord-est de l'îlot est le premier secteur qui soulève des questions. Il est aujourd'hui occupé par quatre maisons organisées selon un plan soumis à une stricte symétrie : aux angles sont édifiés deux grands immeubles en L (les numéros 31 et 37), dans lesquels sont insérées deux petites maisons dont les façades sont orientées sur la rue des Commères ( $n^{\circ} 15$ et 17 ). La présence d'élévations en terre dans les murs de fond de deux d'entre elles démontre que cette organisation est le fruit de la réunion de deux séries de deux parcelles allongées et initialement alignées sur les rues Arago et du Four-Saint-François. Les quatre parcelles en lanières ont donc été unifiées en deux grandes unités occupant chacune un angle de l'îlot, auxquelles est soustraite une partie de la surface pour l'édification des deux petites maisons. Ce remembrement est accompagné de reconstructions importantes, qui n'ont toutefois pas effacé toutes les traces des unités initiales, conservées dans le cœur de l'îlot.

Le second secteur qui a subi un remembrement correspond aux maisons situées aux 33 et 33 bis de la rue Arago, qui formaient d'abord une seule unité, avant d'être divisée dans le sens de la longueur.

L'angle sud est le dernier secteur qui a visiblement fait l'objet de modifications importantes. Il est occupé par une unité dont la façade est orientée sur la rue de l'Hôpital (le $\mathrm{n}^{\circ} 5$ ), flanquée de deux plus petites situées dans l'angle ( $\mathrm{n}^{\circ} 7$ et 29 de la rue du Four-Saint-François). À l'exception de deux murs de terre, observés dans l'enveloppe de la maison sise au $n^{\circ} 5$, tous les murs mitoyens des trois maisons sont édifiés en maçonnerie, sans doute à la suite de reconstructions importantes. Il est possible de proposer deux hypothèses de restitution du découpage initial : la première, la plus proche de la configuration actuelle,

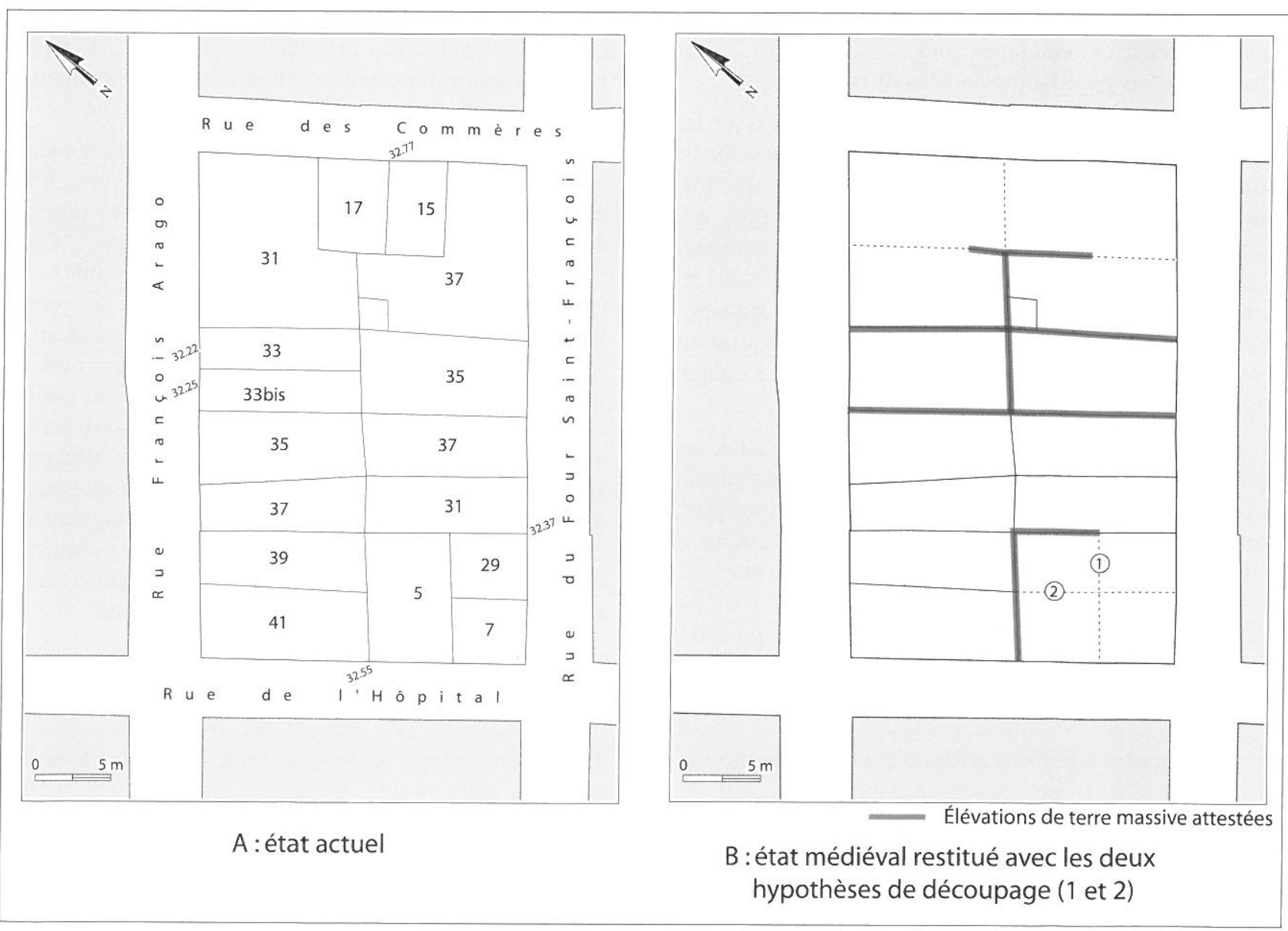

Fig. 3 : D'après l'état actuel (A), l'îlot a subi peu de modifications : il était initialement découpé en parcelles en lanières sur lesquelles se sont installées les maisons, adossées, les façades orientées sur les rues Arago et du Four Saint-François (B). 
consiste à proposer deux parcelles en lanières, de module légèrement inférieur à la moyenne, et orientées sur la rue de 1'Hôpital (fig. 3 : hypothèse 1). Les deux petites unités ( $\mathrm{n}^{\circ} 7$ et 29) seraient alors le résultat d'une division de la parcelle d'angle. Toutefois, la restitution de deux parcelles en lanière, mais orientées comme les unités voisines, c'est-à-dire sur la rue du Four-Saint-François, permettrait de conserver l'idée, plus satisfaisante, d'un découpage symétrique (fig. 3 : hypothèse 2). Dans cette hypothèse, la reconstruction de cet angle de l'îlot s'accompagnerait, dès lors, d'un remembrement qui se traduirait par un changement de l'orientation des parcelles. Malgré l'absence d'arguments matériels confortant l'une des deux propositions, c'est la seconde, la plus « simple » puisqu'elle reproduit le module et l'organisation du reste de l'îlot, qui semble la plus crédible. Dès lors, les éléments conservés et restitués permettraient de proposer un modèle parfaitement régulier d'îlot découpé en 14 parcelles adossées, de formes rectangulaires et orientées sur les rues Arago et du Four-Saint-François.

\section{LES PREMIERS ÉLÉMENTS D'UN MODÈLE DE LA MAISON MÉDIÉVALE}

\section{Le plan}

Les parcellaires médiévaux de type lotissement, comme c'est le cas à Saint-Mathieu, affectent fréquemment ce découpage en lanières, là où l'espace n'est pas rare. Le bâti adopte un plan de masse déterminé essentiellement par les dimensions du lot foncier. Les contraintes très fortes imposées par les limites de la parcelle imposent l'adoption du modèle courant au Moyen Âge de la «maison bloc » dessinant une barre étroite, perpendiculaire à la rue, se développant sur tout ou partie seulement de la longueur de la parcelle. Ce choix, explicable par ailleurs par des questions de redevances annuelles proportionnelles aux largeurs de façade, est caractéristique de ces périodes de densification de tissu bâti.

Dans ce cas de figure contraignant, les dimensions de la maison sont donc déterminées par la dimension de la parcelle. Le module de base mesure plus ou moins $50 \mathrm{~m}^{2}$, soit deux monallatas, ce qui correspond tout à fait aux dimensions standard des parcelles établies par les historiens à partir des documents (voir $\$ 1$ supra). Toutefois, dans le détail, il est possible de constater des variations, assez insignifiantes dans les longueurs, mais plus sensibles dans les largeurs des espaces bâtis. Celles-ci évoluent, en effet, entre $3,20 \mathrm{~m}$ et $6 \mathrm{~m}$ pour une profondeur oscillant entre $9,70 \mathrm{~m}$ et $10 \mathrm{~m}$. Une première explication est trouvée dans le tracé incertain des lignes directrices, comme en témoigne la forme souvent plutôt trapézoïdale des parcelles. Moins anecdotique, la corrélation de ces variations avec quelques chronologies relatives mises en évidence lors du diagnostic indique une construction non simultanée de ces habitations, ce qui n'est évidemment pas sans exercer une certaine influence sur les dimensions des maisons. Les écarts observés peuvent donc se justifier essentiellement dans l'ordre d'attribution des lots et des constructions où les dernières s'appuient contre les premières, leur permettant d'économiser l'espace correspondant à l'épaisseur d'un, parfois deux murs.

Les maisons de terre semblent occuper l'ensemble de la surface disponible. Cependant, deux des immeubles (le 31 rue du Four-Saint-François et le 33/33bis de la rue Arago) donnent matière à réflexion. En effet, tous les deux ont livré les témoins d'un premier état en terre, matérialisé par une pente de toit couverte d'un solin maçonné coiffant une élévation de pisé qui, dans les deux cas, ne semble pas se poursuivre jusqu'au mur de façade. En outre, le prolongement artificiel de la pente de toit conduirait à restituer une façade initiale d'une hauteur évoluant entre 1,50 m et 2,30 m environ, ce qui tendrait à argumenter en faveur d'un développement sur une longueur inférieure aux $10 \mathrm{~m}$ disponibles. Cette observation conduit à émettre l'hypothèse de l'existence, au moins sur ces deux parcelles, d'une première unité déjà édifiée en terre, mais de longueur plus réduite et occupant uniquement le fond de la parcelle. Quoi qu'il en soit, la première construction a été rapidement remplacée par des maisons respectant une morphologie générale apparemment semblable, mais occupant désormais l'ensemble de la parcelle (fig. 4).

\section{L'élévation}

La découverte de plusieurs traces de toiture sur les murs latéraux permet de restituer pour chaque maison de terre un toit à une seule pente, oscillant autour de $15^{\circ}$ (à l'exception d'un cas à $11^{\circ}$ au 35 rue du Four-Saint-François) et orienté vers la façade. Leur présence fournit une aide précieuse pour préciser l'importance des volumes, guidée par les niveaux d'occupation restituables grâce aux trous d'encastrement des poutres ou des solives de plancher. Les deux maisons témoignant d'un premier état présentaient donc une largeur de 3,20 m et 5,50 m pour une longueur estimée autour de $6 \mathrm{~m}$ et une hauteur maximale (au niveau du mur de fond) de $5 \mathrm{~m}$. Elles se développaient probablement sur deux niveaux, soit un rez-de-chaussée surmonté de combles, peut-être aménagés. Toutes les maisons, dans l'état qui correspond à l'occupation de la totalité de la parcelle, affichent des largeurs évoluant entre 3,20 m et $5,50 \mathrm{~m}$, et des hauteurs maximales plus régulières, oscillant entre 6,20 m et $7 \mathrm{~m}$. Elles offrent alors l'image d'une maison de type "élémentaire », sans doute divisée en trois niveaux composant un rez-de-chaussée, un étage d'habitation et des combles.

Les façades ont toutes été reconstruites entre l'extrême fin du XVIII ${ }^{e}$ siècle et le $\mathrm{XX}^{\mathrm{e}}$ siècle, comme dans le quartier Saint-Jacques. À Saint-Mathieu, aucun élément de réponse n'a pu conforter ou infirmer l'une des deux hypothèses exposées par F. Guyonnet au terme de son étude : l'une envisageant des façades primitives en terre crue qui auraient été systématiquement remplacées par des élévations maçonnées, l'autre admettant des élévations à pans-de-bois, peut-être construites sur un rez-de-chaussée en terre (Guyonnet 2003, 397). La surélévation des maisons, aux époques modernes, 


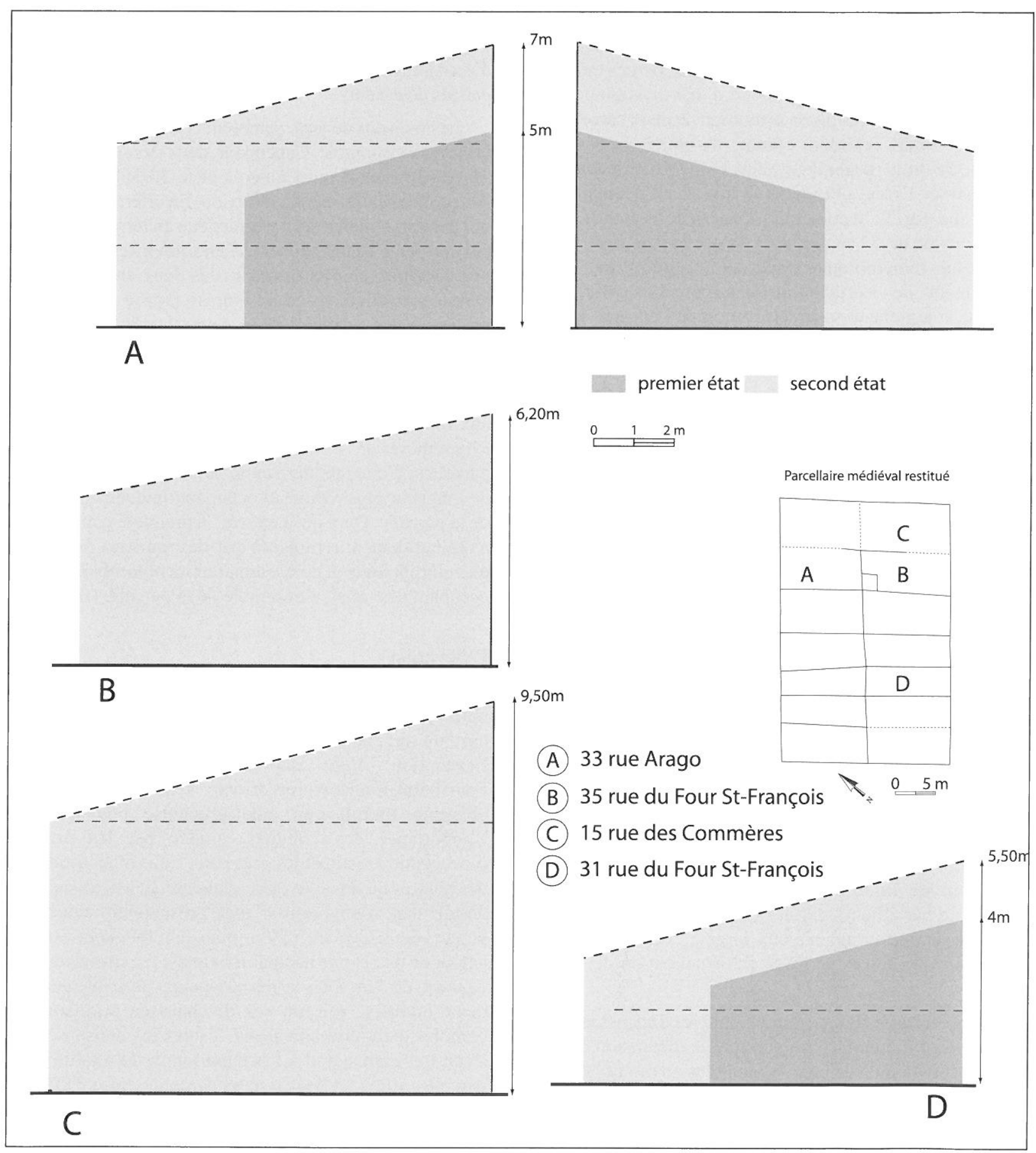

Fig. 4 : Présentation des volumes restitués des maisons médiévales diagnostiquées.

impossible sur une structure légère et a fortiori si elle est en encorbellement, aurait conduit peu à peu au remplacement des façades. L'un de ses arguments en faveur de cette dernière hypothèse est l'existence de façades en pan-de-bois dans le centre ancien de la ville, qui, bien qu'elles appartiennent à des constructions plus récentes $\left(\mathrm{XV}^{\mathrm{e}}\right.$ siècle et $\mathrm{XVI}^{\mathrm{e}}$ siècle), seraient le témoignage d'une pérennité de ce modèle d'architecture.

Les niveaux étaient séparés par des planchers, simplement formés de solives portées par des poutres, dont aucun n'est demeuré en place. Cependant, quelques négatifs identifiés comme des trous d'encastrement de poutres ou de solives montrent qu'apparemment les hauteurs des pièces ont relativement peu varié. Aux 33 et 33 bis de la rue Arago, les planchers semblent avoir été remontés de moins de $0,20 \mathrm{~m}$. Les $0,50 \mathrm{~m}$ qui séparent les ancrages du premier plancher des éléments des planchers actuels de la maison du 5 rue de l'Hôpital forment une exception et s'expliquent sans doute par la reconstruction de ce secteur de l'îlot. De manière générale, les quelques trous d'encastrement mis au jour permettent de préciser des hauteurs de plafond comprises entre $2 \mathrm{~m}$ et $2,50 \mathrm{~m}$. 
Les négatifs des solives montrent une disposition tantôt dans le sens de la longueur - de manière indiscutable au 33/33bis de la rue Arago, probablement au 35 rue du Four-Saint-François et au 5 de la rue de l'Hôpital -, tantôt dans le sens de la largeur - au 15 de la rue des Commères entre les deux étages et au 31 de la rue du Four-Saint-François. Peut-être doit-on imaginer des modes de construction variables d'une maison à l'autre, mais adoptant le plus souvent une structure formée de solives établies dans le sens de la longueur et portées par des poutres disposées dans le sens de la largeur. Dans un des cas (31 de la rue du Four-Saint-François), cette orientation des éléments porteurs pourrait être directement justifiée par une éventuelle longueur inférieure de la première maison en terre, mais la corrélation entre les négatifs et ce premier état demeure hypothétique. Peut-être peut-on prudemment avancer que cette orientation argumente en faveur de l'existence d'une façade en pan-de-bois. Parmi les multiples combinaisons connues pour les assemblages des pièces séparant chaque niveau d'une maison charpentée, celle qui génère une orientation semblable évoque plus particulièrement les encorbellements sur grosses solives observés le plus souvent entre les deux premiers niveaux.

Les sondages ouverts dans le sous-sol de quatre maisons ont permis de mettre en évidence, dans tous les cas, la présence d'une couche limoneuse peu épaisse, de même nature que le terrain naturel et très légèrement anthropisée. Elle conduit à suggérer que l'occupation, au rez-de-chaussée, s'effectuait directement sur le terrain naturel affleurant ou sur des aménagements de sol rudimentaire de type terre battue.

En revanche, la distribution des pièces demeure inconnue. Parmi les nombreuses anomalies repérées, il est ardu d'identifier celles qui ont formé les points d'ancrage d'un escalier ou d'une cloison. Aujourd'hui, les pièces s'organisent en enfilade et chaque étage est desservi par une distribution, souvent latérale, sous la forme d'un escalier droit, construit contre un des murs mitoyens. Les dimensions des parcelles ne laissent guère de liberté en ce domaine. Il est possible que cette formule, adoptée dans la majorité des cas, témoigne d'un schéma maintenu depuis l'édification des maisons en terre.

La découverte d'une saignée verticale, au 31 de la rue du Four-Saint-François, permettrait toutefois de proposer une division des volumes par des cloisons légères, mais cet exemple est unique. L'absence de toute autre trace clairement identifiée conduit à supposer que, le plus souvent, les volumes n'étaient pas cloisonnés.

De même, il est difficile d'établir si les accès étaient isolés des espaces voués à l'habitat et aux activités. Il semble toutefois possible d'exclure l'existence d'escaliers en pierre et de favoriser l'hypothèse d'escaliers en matériaux périssables.

\section{Des aménagements peu nombreux et sommaires}

Les aménagements les plus essentiels attendus dans l'habitat civil urbain n'ont que rarement été mis en évidence. Les ouvrages élémentaires liés au rangement, comme les niches par exemple, sont au nombre de deux seulement et même d'interprétation douteuse ( $1^{\mathrm{er}}$ niveau du 35, rue du Four-Saint-François, 31 de la rue du Four-Saint-François). De même, l'usage fait d'une marmite complète, intégrée en position couchée dans le mur du fond du 33 de la rue Arago, n'a pas été éclairci. Elle pourrait très bien faire simplement office de niche, mais son col resserré, soigneusement disposé au droit du mur, et sa petite contenance rendent le choix de ce dispositif étonnant, si l'on considère qu'une simple réserve dans la terre permettrait de bénéficier d'un organe de rangement plus vaste et pratique. C'est pourquoi, l'interprétation comme pot à cendres ou à sel a été évoquée. Toutefois, aucune de ces hypothèses n'est vraiment satisfaisante. La présence de suie tapissant l'intérieur de la marmite, d'abord expliquée par un usage en remploi, permet peut-être d'étayer l'hypothèse de l'installation de lampes à l'intérieur de celle-ci, bien que là encore, la faible ouverture du col réduisant sans doute un rayonnement lumineux déjà faible et la situation à près d'1,50 $\mathrm{m}$ du niveau de circulation actuel conduisent à émettre de sérieux doutes.

Pourtant, la question de l'éclairage des parties des maisons situées au fond des parcelles, loin de la lumière naturelle provenant des baies percées en façade, se pose de manière récurrente. Un seul percement a été interprété comme une lucarne, avec quelque incertitude toutefois dans la mesure où il a été impossible de tester la structure, (33 de la rue Arago). Sa situation, dans le mur longitudinal, ne peut être expliquée que par une plus grande hauteur d'élévation de cette maison par rapport à sa voisine, dans leur état initial. Ces percements dans les murs latéraux étaient donc sans doute limités en nombre et en efficacité, ceux-ci n'éclairant, au mieux, que les combles. De fait, il est encore de nos jours très facile de constater que la seule source de lumière provenant des façades est nettement insuffisante pour éclairer une grande partie de la maison. Dès lors, il paraît vraisemblable d'imaginer l'emploi de divers autres moyens d'éclairage artificiels, parfois de manière conjointe : chandeliers, torches et autres lampes, posés, suspendus ou plantés dans les murs sont autant d'équipements qui ont pu coexister dans ces maisons (Esquieu, Pesez 1998, 7-107). De manière peut-être anecdotique et tout à fait hypothétique, c'est le même type d'interprétation qui a été attribué à une clavette fichée dans le mur au second niveau d'une maison ( 15 de la rue des Commères), au niveau de l'angle formé initialement par le mur de fond et le mur latéral et à environ $2 \mathrm{~m}$ du niveau de sol présumé. La tige plantée pourvue d'un anneau permettrait, par exemple de suspendre une lampe, qui fournirait aussi un complément de lumière à l'arrière de la pièce d'habitation.

$\mathrm{Si}$ le faible nombre des baies est aussi une des protections employées pour se protéger du froid (et de la chaleur), il est tout de même nécessaire de s'interroger sur la question du dispositif choisi pour se chauffer. Car force est de constater que les éléments évoquant ce type d'aménagement font encore une fois défaut. Deux empreintes d'un conduit de cheminée ont été observées 
dans un mur latéral au 33bis de la rue Arago, mais leur relation stratigraphique n'est pas claire. Bien entendu, cette absence peut être imputée au hasard d'implantation des sondages. Toutefois, elle apparaît compréhensible si l'on retient l'hypothèse d'une édification de ces maisons antérieure au XIV ${ }^{\mathrm{e}}$ siècle ou si l'on a affaire à un milieu social modeste. L'utilisation d'autres moyens de chauffage (poêles, braseros, foyers au sol au rez-de-chaussée ?) peut être proposée avec quelque vraisemblance.

Les mêmes motifs sont susceptibles d'expliquer l'inexistence d'autres aménagements de confort tels les éviers ou les latrines. Qu'ils ne soient pas aménagés, au moins pour des périodes plus récentes (c'est-à-dire postérieure à l'édification de la maison), n'est pas moins surprenant. Peut-être faut-il imaginer, au moins pour certains, un emplacement au revers de la façade, permettant de ménager soit un écoulement direct dans la rue, soit une évacuation par un conduit vers un collecteur.

Enfin, aucun élément de décor ou d'ornementation ne permet de restituer l'ambiance intérieure de ces constructions. Ni sols, ni décors muraux, ni traitements réservés éventuellement aux plafonds n'ont été retrouvés. Les laits de plâtre ou de chaux observés sur la surface des murs en terre n'ont pas été interprétés comme un embellissement des parois mais plutôt comme un revêtement destiné à freiner leur effritement. Certaines maisons, en revanche, ont conservé sur les élévations en pisé les mieux préservées un revêtement de type badigeon coloré posé sur une couche préparatoire fine, qui pourrait être le gobetis. Celui-ci est scellé sous plusieurs couches picturales de type badigeon posé sur un enduit de chaux, souvent disparu et retrouvé, dans le meilleur des cas, piégé dans l'embrasure d'une baie oblitérée $-33 / 33$ bis rue Arago, 15 rue des Commères, 31 du FourSaint-François. S'il demeure difficile d'affirmer que ces revêtements de badigeons colorés remontent à l'édification des maisons de terre, il est toutefois assez crédible d'imaginer un décor aussi modeste.

\section{Le programme de construction de l'îlot et la qualité de ses habitants}

Les conjectures concernant l'interprétation sociale des maisons dépendent étroitement de notre capacité à déterminer la destination des différents espaces. Il est toutefois peu vraisemblable que ces maisons aient été uniquement résidentielles, détachées des fonctions de production et/ou d'échanges. Les maisons polyvalentes constituant la forme la plus répandue en cette période du Moyen Âge (Garrigou Grandchamp 1999), celles-ci abritaient donc probablement à la fois des locaux professionnels en rez-de-chaussée et un logis à l'étage. Les études documentaires confortent effectivement l'hypothèse d'activités de production et/ou de transformation au sein des maisons, comme le démontre Laure Verdon : travail du cuir, du textile et du bois, activités de transport (Verdon 2001). On sait également que le Temple possède dans le quartier des moulins, ainsi que des tanneries et un four à pain, rue Saint-François. Mais, au stade actuel de nos connaissances, on ne peut pas spécifier les usages réservés à chaque espace de ces maisons car les indices issus des sondages ouverts dans quatre d'entre elles ne révèlent guère l'activité des résidents. Seule la découverte d'un bassin maçonné, au 35 rue du Four Saint-François, évoque peut-être le travail du textile mentionné dans les archives. Si sa construction et son abandon sont attribués au $\mathrm{XVI}^{\mathrm{e}}$ siècle, il pourrait néanmoins représenter un avatar d'une activité attestée pour la période médiévale.

Au-delà des morphologies répétitives et de l'absence d'éléments de confort, qui correspondent aux normes de l'habitat urbain modeste de la fin du Moyen Âge, c'est la construction proprement dite de ces immeubles qui retient l'attention. L'utilisation quasi-exclusive de la terre dans l'édification des murs - constatée ici pour la seconde fois à Perpignan dans la même fourchette chronologique nous interroge effectivement sur les raisons de ce choix : sont-elles d'ordre économique (faible coût du matériau pris sur place par rapport à la pierre), social (condition modeste des commanditaires), culturel (modèles empruntés à la Catalogne du sud, par exemple)...? Ces trois facteurs sont, probablement, étroitement imbriqués. Il faut, en tout cas, se garder d'a priori fondés sur des critères simplistes conduisant à associer une population pauvre aux constructions en terre. Les découvertes archéologiques réalisées depuis quelques années viennent en effet à l'appui des intuitions que J.-M. Pesez formulait, il y a déjà dix ans, au sujet des qualités de ce matériau et de son usage probablement «banal » (Esquieu, Pesez 1998,49 et 68).

\section{Les éléments de datation}

Le problème qui se pose toujours, et ceci de manière plus sensible pour ce genre d'architecture, est celui des datations. Or, en l'absence d'ouvrage ou de décor caractéristique, de quels arguments chronologiques dispose-t-on?

Le premier est la pérennité du parcellaire médiéval, que révèle déjà le cadastre napoléonien. De fait, la superposition presque parfaite des limites de parcelles et des murs en terre conduit naturellement à dater ceux-ci de la mise en place du plan. Le fait, dans un cas au moins (au 35 rue du Four Saint-François) que le mur de fond de la parcelle soit bâti en terre dès le rez-de-chaussée, plaide en faveur de cette hypothèse. Par ailleurs, les études des historiens montrant que dès la fin du XIII' ${ }^{\mathrm{e}}$ siècle (v. 1280), ces espaces étaient pratiquement tous lotis, on a le sentiment que leur construction s'est opérée sur une durée assez courte (voir $\$ 1$ supra).

Le second indice de datation est la marmite découverte dans le mur du fond de la maison du 33 de la rue Arago (fig. 5) ${ }^{8}$. Il s'agit d'une marmite à pâte sableuse bicolore,

\footnotetext{
${ }^{8}$ Le profil de la marmite proposé en figure a été aimablement communiqué par Olivier Passarrius. Cet exemplaire est issu du site d'Elne et présente l'avantage d'offrir un modèle très semblable à la marmite mise au jour dans la maison de l'îlot Saint Mathieu, qui a été perdue lors de son étude.
} 


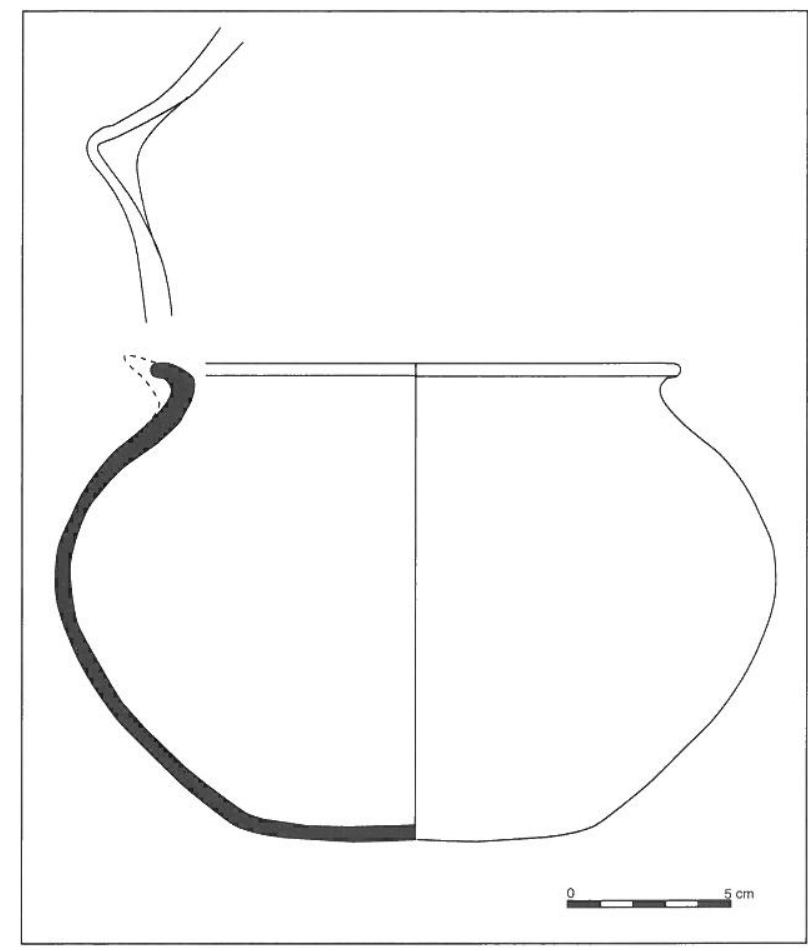

Fig. 5 : Profil d'une marmite découverte sur le site d'Elne semblable à celle qui a été insérée dans le mur du fond du 33 de la rue Arago.

nue, cuite en atmosphère réductrice dont le profil globulaire et relativement trapu est assez représentatif des productions du bas Moyen Âge (XIII'-XIV ${ }^{e}$ siècles). Elle est en cela comparable à certaines céramiques découvertes lors des fouilles de la citerne de la rue d'Iéna à Elne (Passarrius, Pezin 2003) ou de la commanderie de Bajoles, sur la commune de Perpignan (Alessandri 1993).

Enfin, une datation par le radiocarbone a été obtenue sur une pièce de bois sec extraite d'une surélévation en terre coffrée, dans sa zone de contact avec une première élévation en pisé ( $33 \mathrm{~b}$ de la rue Arago). Cependant, la fourchette de 980 à 1165 correspondant à la date d'abattage du bois interroge. Cette datation haute peut s'expliquer par l'usage d'une pièce en remploi et, quoi qu'il en soit, ne contredit pas la proposition d'édification de ces maisons au cours du XIII siècle. Seule la multiplication des échantillons aurait permis d'offrir des valeurs fiables. Toutefois, si un faisceau de présomptions incite à ne guère douter de l'appartenance de ces maisons à la période médiévale, il faudrait désormais pouvoir définir si ce parti architectural, qui fait prévaloir la terre, ne renvoie qu'à cette période ou si ce mode de construction s'étend sur une période plus longue.

\section{L'évolution des maisons}

En guise de comparaison, il est possible de faire un retour sur les maisons du quartier Saint-Jacques où existe une phase de construction datée du $\mathrm{XV}^{\mathrm{e}}-\mathrm{XVI}^{\mathrm{e}}$ siècle, qui se manifeste par le rassemblement de plusieurs parcelles, la création de cours intérieures et un programme décoratif de qualité (plafond peint) qui transforment ces maisons modestes en demeures luxueuses. Au contraire de ce qui a été observé à Saint-Jacques, les modifications reconnues à Saint-Mathieu signalent deux tendances : le remembrement dans son expression la plus simple et la surélévation des maisons.

\section{Les remembrements par réunions de parcelles}

La forte majorité des études de bâti démontre que le parcellaire, tel qu'il est fixé lors de la construction de l'îlot, reste rarement stable. Dans le cas présent, la forme et la surface des parcelles n'offrent guère d'autres choix pour le propriétaire qui veut agrandir sa maison que d'annexer une ou plusieurs parcelles voisines. L'édification d'une plus grande demeure peut alors entraîner la destruction des maisons initiales. Cette situation est illustrée par les vastes maisons du 31 rue Arago et du 37 rue du Four-Saint-François entièrement reconstruites, chacune sur la surface de deux parcelles (fig. 6). Ou bien, et c'est ici le cas le plus fréquent, les modifications observées sont d'une moindre ampleur. Elles se résument à un simple percement de murs mitoyens entre deux maisons réunies. Cette situation est attestée dans deux, voire trois cas : au 15 de la rue des Commères, aux 33 et 33 bis de la rue Arago et, avec quelques réserves, au 31 de la rue du Four-Saint-François (fig. 7). Dans un second temps, l'oblitération de ces portes

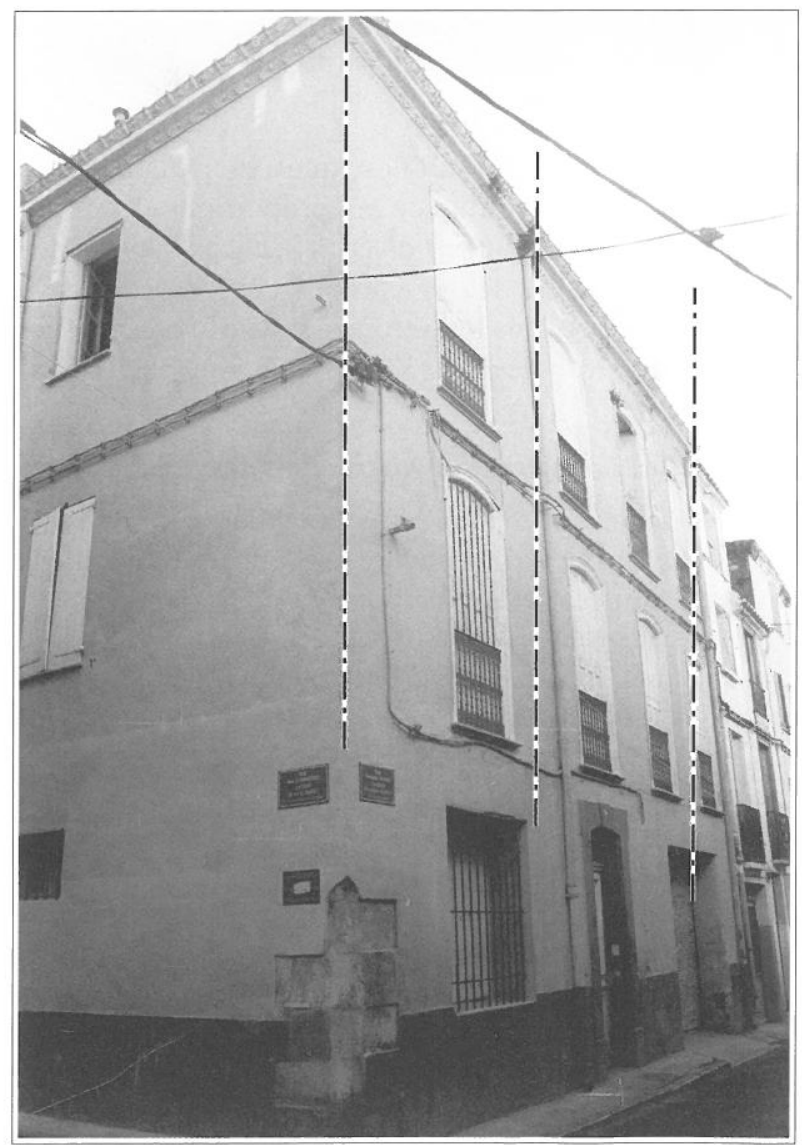

Fig. 6 : Dans deux cas seulement, la réunion de parcelles en lanière (module initial indiqué par les pointillés) est suivie d'une édification d'une maison de plus grande taille. 


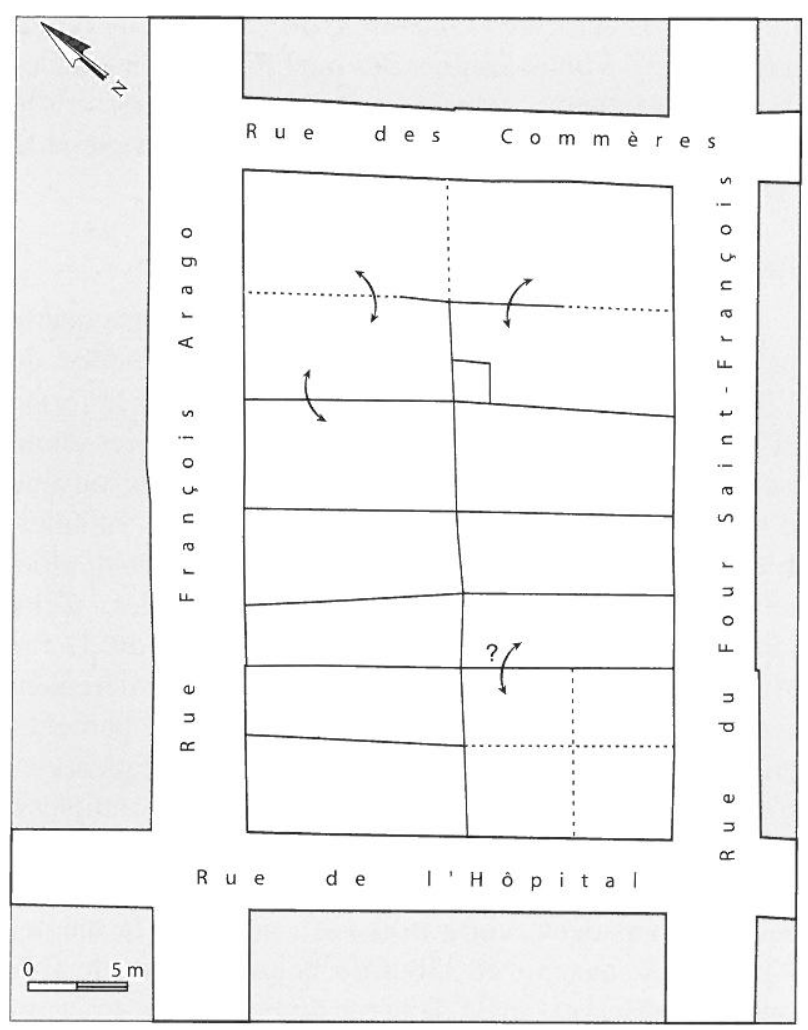

Fig. 7 : Les remembrements observés consistent essentiellement en la réunion de parcelles mitoyennes, qui se traduit le plus souvent par le percement d'une porte de communication entre les deux maisons, plus rarement par la reconstruction d'un édifice de plus grande ampleur.

indique, pour chacune d'elles, que ces parcelles sont démembrées pour retrouver les proportions d'origine. Cette évolution se poursuit dans un seul cas - les actuels 33 et 33 bis de la rue Arago - jusqu'à la subdivision de la maison en deux unités très étroites, suite à la construction d'une cloison installée dans le sens de la longueur (fig. 8).

\section{Les surélévations et la reconstruction des façades}

C'est encore l'exiguïté des parcelles qui conduit à augmenter la surface habitable par l'édification d'étages supplémentaires. Cette évolution, qui a été communément observée sur toutes les maisons, s'est accompagnée de modifications des niveaux d'occupation, illustrées par les déplacements de planchers.

Les nouvelles phases de construction se caractérisent par l'abandon de la terre au profit des maçonneries de briques et de galets. Elles ne s'accompagnent d'aucune amélioration sensible du bâtiment, en particulier dans le domaine du confort.

Cette surélévation va de pair avec d'autres travaux portés essentiellement sur les façades reconstruites en maçonnerie. Leur style tend à associer ces modifications lors de périodes très récentes : le $\mathrm{XIX}^{\mathrm{e}}$ siècle voire le $\mathrm{XX}^{\mathrm{e}}$ siècle souvent, dans un seul cas dès le XVIII' ${ }^{\mathrm{c}}$ siècle

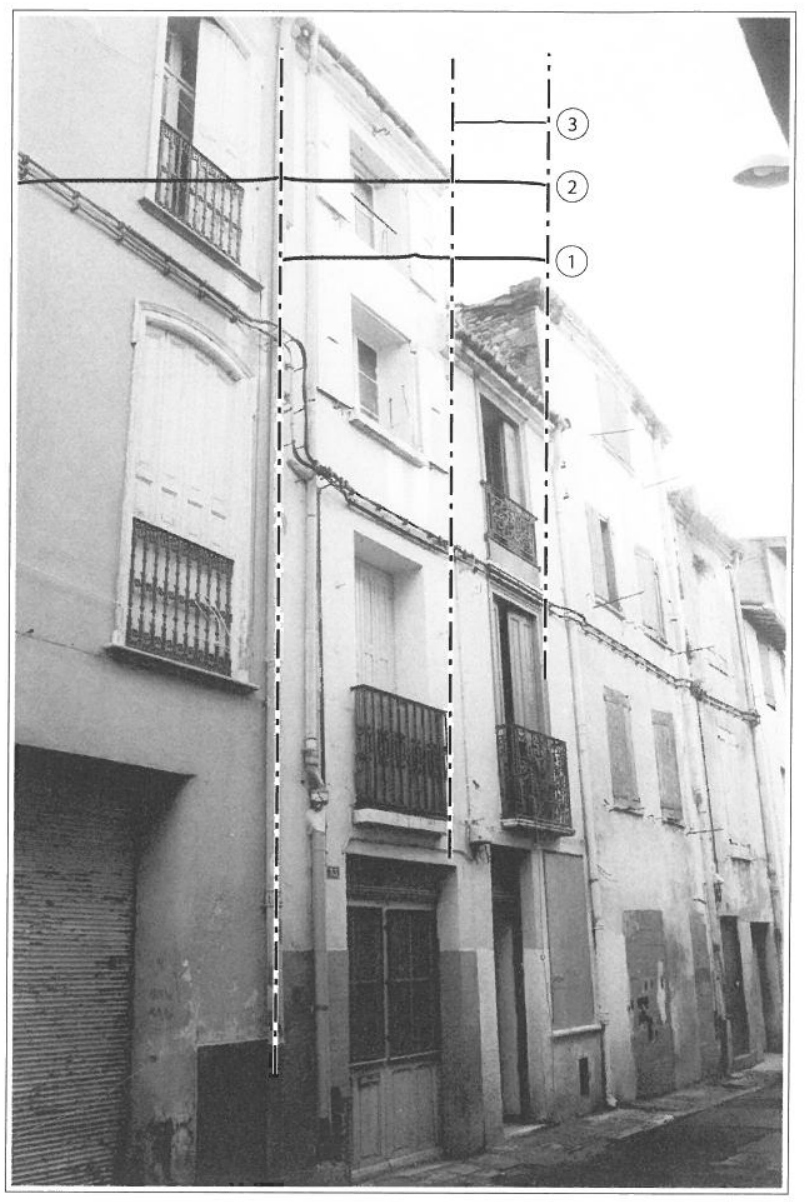

Fig. 8 : Dans le cas du 33 et 33 b de la rue Arago, la parcelle initiale (1) est réunie à la parcelle voisine (le 37) (2), puis retourne à ses proportions initiales avant d'être divisée en deux parcelles très étroites (3).

\section{LES CONSTRUCTIONS EN TERRE}

Les données recueillies sur les constructions en terre de cet îlot proviennent d'un échantillon jugé représentatif car on n'a pas pu étudier tous les murs dans le détail. Il s'agit, pour les murs en pisé, des maisons situées au 33/33bis de la rue Arago, au 31 et au 35 rue du Four-Saint-François ; pour les murs ou les reprises ponctuelles en bauge, du 5 rue de l'Hôpital, 35 du Four-Saint-François, 33/33bis rue Arago (fig.9).

Parmi les murs étudiés, quatre correspondent à des tronçons du mur médian portant le faîtage, parallèle aux rues Arago et du Four-Saint-François, qui divise l'îlot en deux séries de maisons ouvrant respectivement sur chacune de ces voies. Les six autres sont des murs séparatifs entre les habitations, perpendiculaires aux façades et au mur médian. Aucune façade en terre ne semble être conservée.

La technique de construction la plus représentée est le pisé 9 . Si la bauge est illustrée par des témoins ponctuels, rien ne permet d'affirmer qu'elle ait constitué des parois entières.

\footnotetext{
${ }^{9}$ Pour une mise au point technique et terminologique sur les modes d'utilisation de la terre crue dans le bâtiment, se reporter à l'ouvrage de référence de Houben et Guillaud, Traité de construction en terre, 1989.
} 


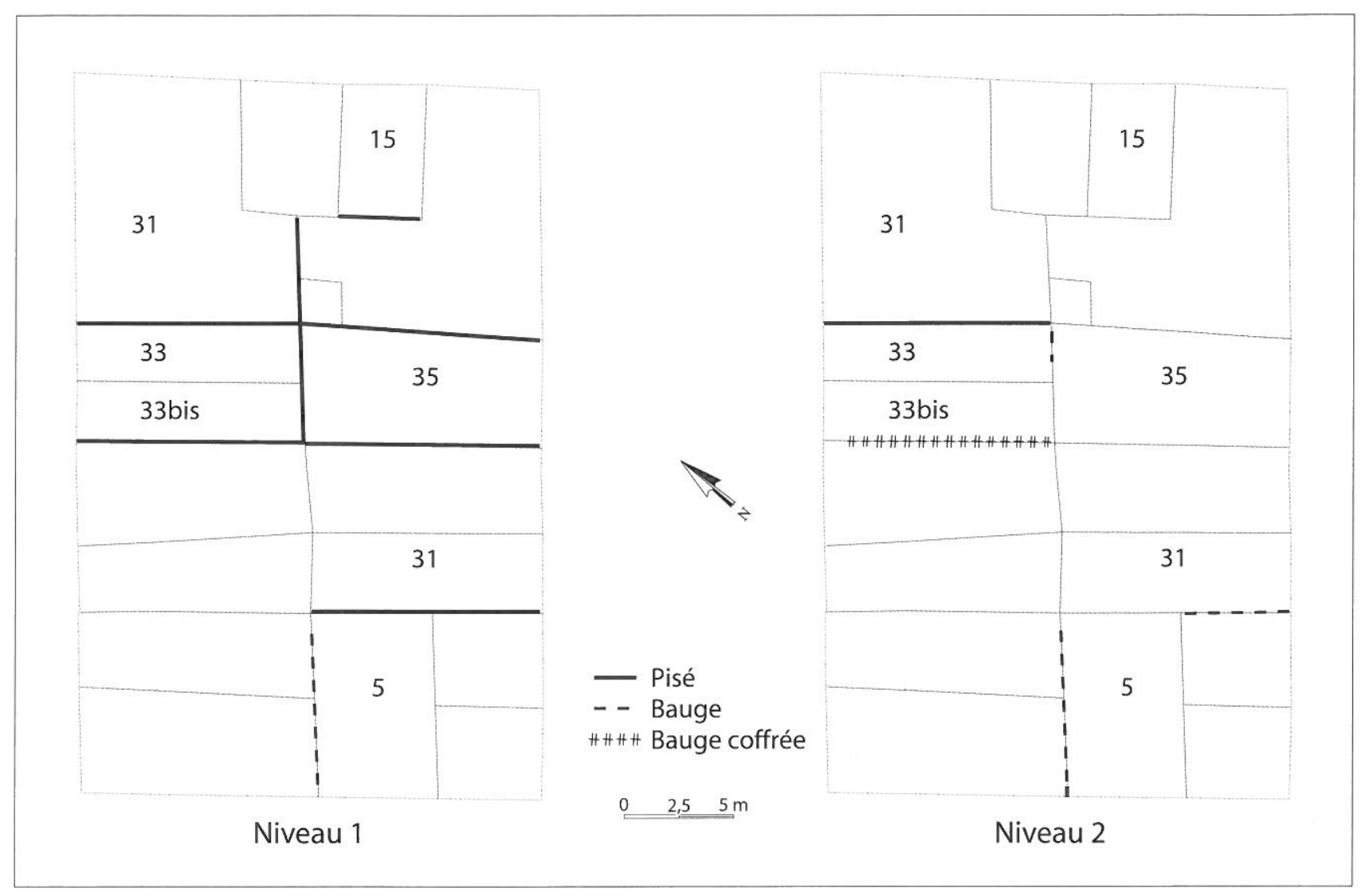

Fig. 9 : Plan de l'îlot avec localisation des murs de bauge et de pisé, par niveau.

\section{Les murs en pisé}

\section{Rappel technique}

Dans la construction en pisé, la terre est damée avec un outil spécial (le pisoir) à l'intérieur d'un coffrage en bois, constitué par de longues parois (les banches). Celles-ci sont maintenues en place à la base et au sommet par des clés transversales. Ces éléments, en bois ou en métal, sont insérés dans des rainures que l'on creuse dans l'arase supérieure du soubassement, pour la première assise de pisé, puis dans la partie supérieure de chaque assise de pisé terminée. Il est préférable que la terre comporte un mélange de particules fines et grossières afin d'obtenir le compactage optimal et qu'elle soit employée brute d'extraction c'est-à-dire avec son degré d'humidité naturel. Compte tenu de l'importance des volumes de terre à mobiliser, le matériau est généralement extrait sur le lieu de construction quand ses qualités le permettent. Au sein de chaque banchée, la terre est tassée progressivement par couches de 10-15 cm d'épaisseur ; ce sont les « lits de damage ». Les maçons procèdent par assises horizontales en déplaçant les planches latéralement dès qu'une banchée est terminée, sans attendre le séchage de la terre. L'enlèvement des clés laisse des négatifs qui sont normalement - mais pas obligatoirement - bouchés. Il n'est pas utile d'attendre le séchage d'une assise pour élever la suivante car on peut marcher sur le pisé frais.
Les dimensions des banches varient selon les régions, les époques, et en fonction des ressources en bois d'œuvre ; elles peuvent atteindre 3 ou 4 mètres de longueur, pour des hauteurs de $0,80 \mathrm{~m}$ à 1 mètre. Certains coffrages possèdent un « fond de banche », c'est-à-dire qu'ils sont fermés aux extrémités, ce qui permet de compacter la terre sur toute la longueur des planches. Dans ce cas, on observe des limites verticales entre les banchées consécutives. Ce système, le plus répandu dans le monde, s'identifie sur les parements de pisé par la reconnaissance de grands modules rectangulaires. Dans certaines régions de France (en Auvergne, Lyonnais, Dauphiné), à partir du milieu du XVIII ${ }^{\mathrm{e}}$ siècle, s'est généralisée la technique des pisés « modernes » réalisés dans des coffrages sans fond (Guibaud 2005). Avec ce procédé, les joints entre les banchées sont inclinés à $45^{\circ}$ car la longueur des lits de damage est réduite de bas en haut de manière à former un plan oblique. Les banchées dessinent donc sur les parements des parallélogrammes (fig. 10). Quel que soit le système, les joints entre les

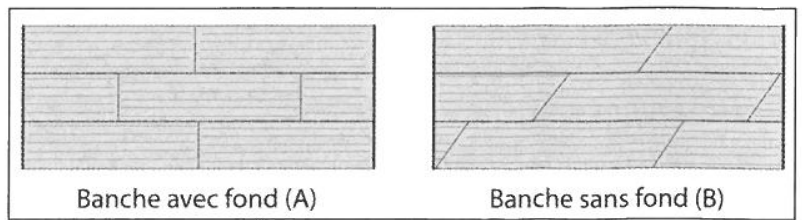

Fig. 10 : Croquis des deux types de banches : banche avec fond (A) et sans fond (B) (C.-A. de Chazelles). 
banchées (les « moraines ») sont décalés d'une assise à la suivante afin d'éviter les coups de sabre. La présence de mortier entre les banchées ou même entre les assises n'est pas systématique avant la période moderne et, quand ils existent, ces « joints », appelés cordons, se limitent en réalité à la périphérie de la banche.

Le chaînage des murs s'effectue soit en «besace » quand les banchées des deux parois sont entrecroisées comme les blocs d'une construction en grand appareil, soit au moyen de banches spéciales permettant de coffrer l'angle d'un seul bloc.

Dans les fouilles archéologiques, la mise en évidence des constructions en pisé est souvent rendue délicate par la médiocre conservation des murs : faibles hauteurs en place, longueurs réduites, dégradation des parements, etc. Cette reconnaissance est plus aisée dans les études de bâti lorsque les élévations sont préservées sur plusieurs niveaux et protégées par des revêtements. Les indices susceptibles d'être recherchés sont : les limites entre les banchées et les joints entre les assises, les empreintes de coffrage, les négatifs de clés, les lits de damage. Il faut insister sur le fait que les qualités texturales de la terre ne constituent pas à elles seules un argument décisif et que, faute d'indice probant, il vaut mieux admettre l'impossibilité de trancher entre bauge et pisé et parler de «terre massive ».

Peu de difficultés ont été rencontrées, en règle générale, sur les élévations de l'îlot Saint-Mathieu, qui présentent des hauteurs et des longueurs suffisantes. Une paroi a toutefois posé un problème d'interprétation dans la mesure où elle avait de toute évidence été coffrée alors que la teneur en eau très élevée du matériau au moment de la mise en œuvre était incompatible avec une action de compactage. Les renseignements pris auprès de spécialistes de la construction en terre et les comparaisons ethnographiques ont conduit à considérer qu'il s'agissait en fait d'un exemple exceptionnel de bauge coffrée.

\section{Les murs en pisé de l'îlot du quartier Saint-Mathieu}

Plusieurs murs séparatifs entre parcelles ont permis d'analyser les liaisons refend/mur médian de l'îlot (33-33bis rue Arago et 35 rue du Four-Saint-François) alors que les rapports avec les façades n'ont nulle part été mis en évidence. Sur les cinq maisons étudiées, des différences notables apparaissent dans la constitution des murs de séparation, certains s'élevant en pisé dès le rez-de-chaussée (au 33bis rue Arago), d'autres uniquement à partir du premier étage sur un soubassement. Quant au mur médian, s'il apparaît principalement bâti en pisé dans les étages, on a également noté en différents endroits sa construction en pisé dès le rez-de-chaussée (33bis rue Arago et 35 rue du Four-Saint-François).

\section{Fondations et soubassement}

L'existence de fondations enterrées n'a pas été démontrée dans les sondages réalisés au pied de certains murs, car des reprises de consolidation avaient été systématiquement effectuées sous les niveaux de sol (fig. 11). De même, la présence de soubassements n'est, en définitive, pas attestée non plus avec certitude pour la phase initiale de construction et les quelques solins en briques cuites liées au mortier mis au jour sous des élévations en terre paraissent plutôt résulter de réfections datant de l'époque moderne.

\section{Les banchées}

Aucune longueur complète de banche n'a été relevée, soit en raison de l'étroitesse des pièces, soit à cause de transformations postérieures. Les longueurs conservées dépassent couramment $2 \mathrm{~m}$, et même $3 \mathrm{~m}$ dans un cas (mur de fond du 33/33bis rue Arago), et les hauteurs sont ordinairement comprises entre $1 \mathrm{~m}$ et $1,40 \mathrm{~m}$. La dernière assise des murs mitoyens représente naturellement une exception compte tenu de sa forme trapézoïdale et l'on a noté, par exemple, des hauteurs de 0,70 à $0,90 \mathrm{~m}$. Les largeurs, mesurées en traversant certains murs, sont de l'ordre de $0,50 \mathrm{~m}$.

Les moules comportaient un fond de banche, comme l'indiquent les moraines verticales le long d'une même assise ainsi que les liaisons en besace laissant un « vide » de l'épaisseur d'une planche entre deux murs perpendiculaires, par exemple entre le mur de fond et les murs mitoyens du 33/33bis rue Arago (fig. 12 et 13). Dans tous les exemples étudiés, les banchées se juxtaposent latéralement sans cordon de chaux ou de mortier.

Les empreintes assez nettes des planches horizontales de la banche ont été identifiées sur le parement du mur de fond du 33 rue Arago dont le matériau est particulièrement fin.

\section{Le damage}

Les lits de damage repérés à différentes reprises indiquent des hauteurs de terre de $15 \mathrm{~cm}$ (fig. 14). Horizontaux dans la plupart des cas, ces lits présentent la particularité au sommet des deux murs latéraux du 35 rue du Four-Saint-François de suivre un plan oblique. Ce procédé, tout à fait inhabituel dans la pratique du pisé, a servi à constituer des banchées trapézoïdales qui, en se juxtaposant latéralement, forment la ligne de pente du toit sans décrochement. Pour obtenir ce résultat, les lits de terre s'épaississent peu à peu vers l'arrière de la banchée. si bien qu'on passe d'un damage sur plan horizontal à la base du coffrage à un damage sur plan incliné à mi-hauteur de la banchée (fig. 15).

\section{Les assises}

Selon les murs, une, deux ou trois assises ont pu être observées, bien que l'absence de cordon de chaux ou de mortier rende les limites horizontales difficilement perceptibles. Elles se repèrent néanmoins à travers de légères variations du matériau ou par des alignements de trous de clé. Ces négatifs correspondent à des traverses de section rectangulaire mesurant de $11 \mathrm{~cm}$ sur $9 \mathrm{~cm}$ à $15-16 \mathrm{~cm}$ sur $12-13 \mathrm{~cm}$. Dans quelques cas, la présence d'un couvrement fait de lauzes ou de fragments de tuile a été constatée au-dessus du passage de clé, ce dispositif ayant sans doute facilité son retrait (fig. 16). Les intervalles entre deux clés, ou entre un angle et une clé, varient entre $0,60 \mathrm{~m}$ et $1,20 \mathrm{~m}$. 


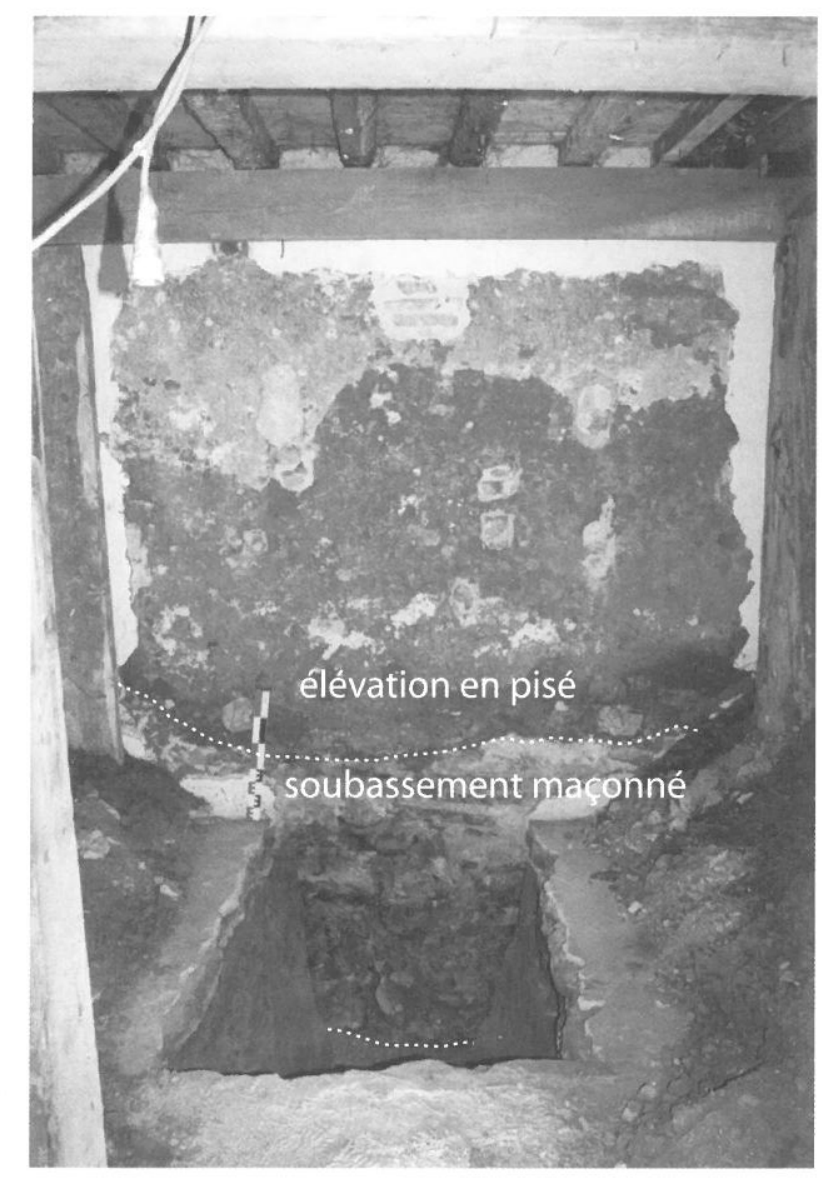

Fig. 11 : Fondation du mur de fond du 35 rue du Four Saint-François, réalisée en briques cuites. L'élévation est en pisé (P. Alessandri).

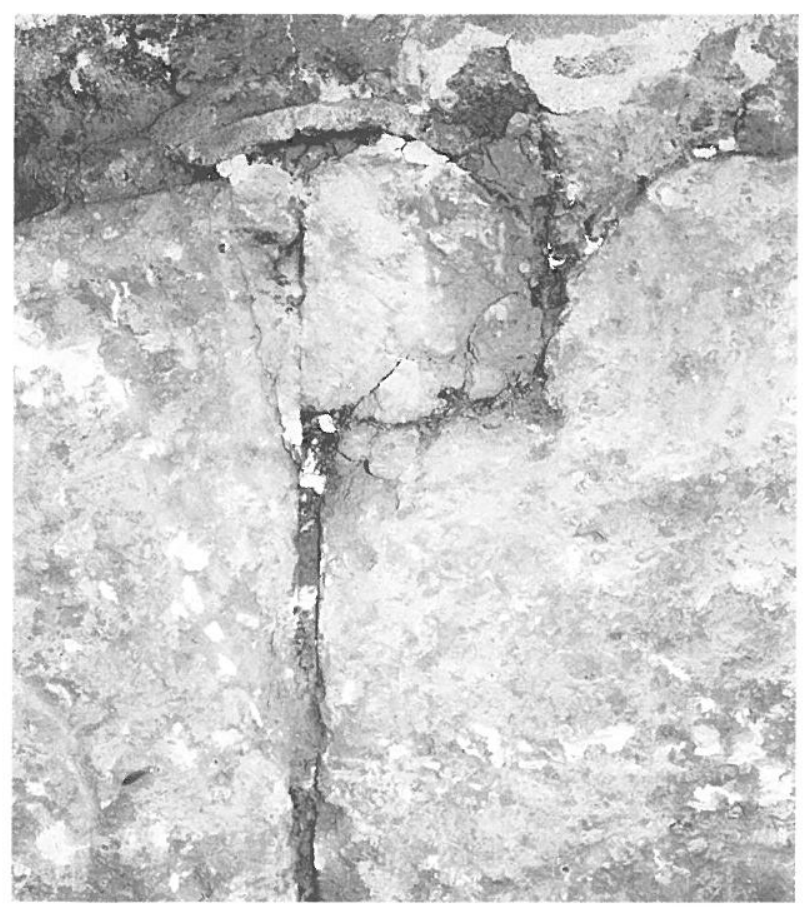

Fig. 12 : Limite verticale d'une banchée dans un mur de pisé. Le trou de clé, couvert par un fragment de tuile, est bouché avec de la terre.

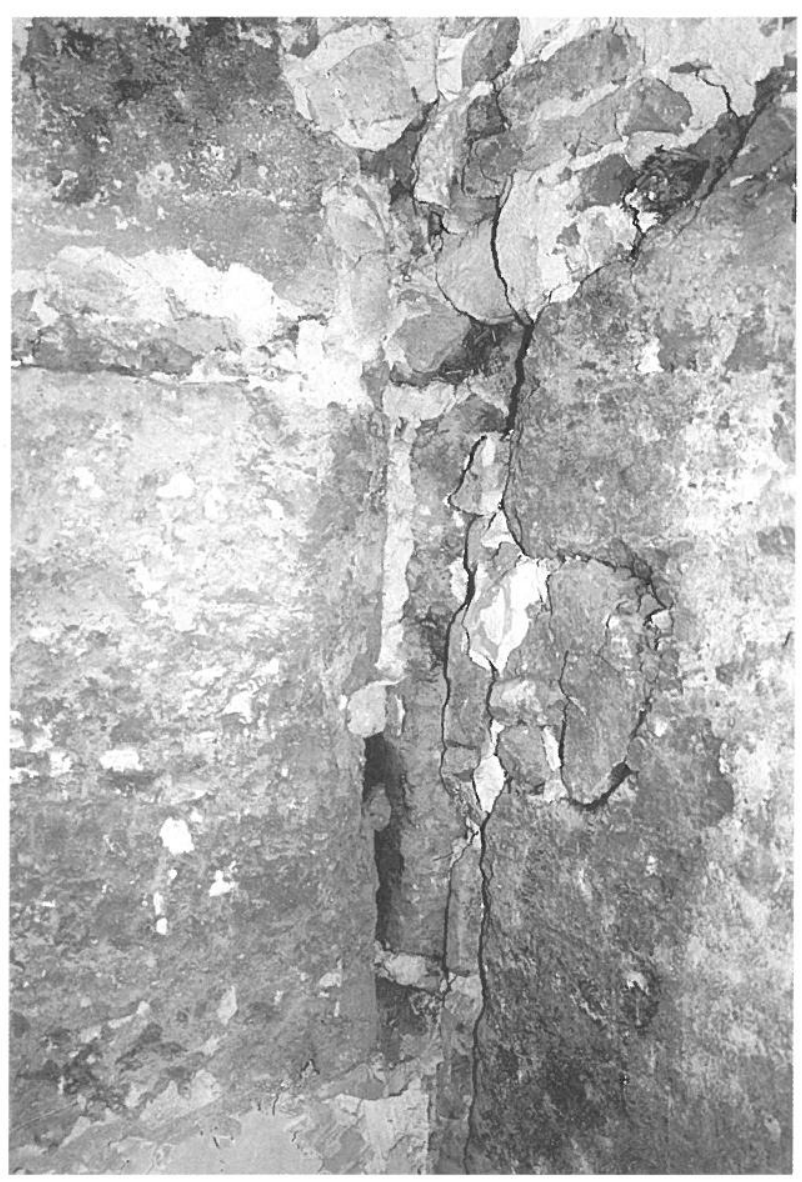

Fig. 13 : Jonction du mur médian de l'îlot avec un mur latéral, au 33 rue Arago, montrant le contact entre deux banchées perpendiculaires de pisé. Entre les deux, on distingue un angle appartenant à un mur antérieur d'une maison mitoyenne.

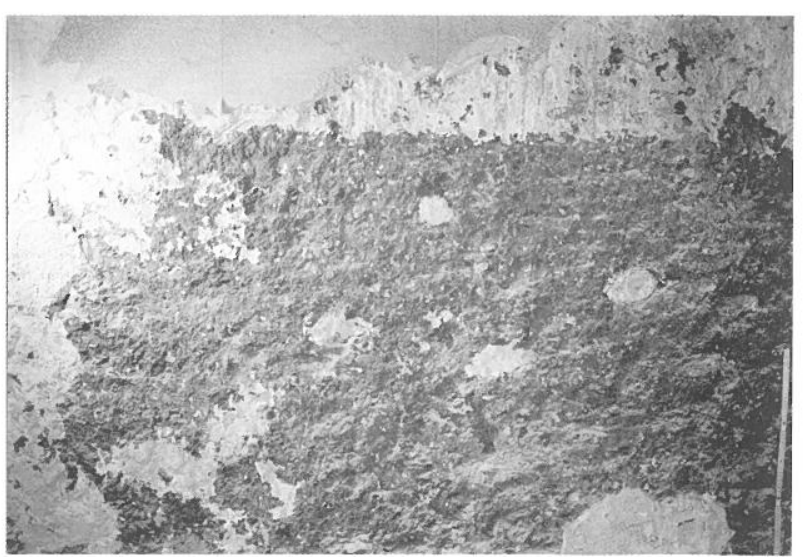

Fig. 14 : Lits de damage obliques du mur latéral en pisé de la maison située au 35 rue du Four Saint-François. 


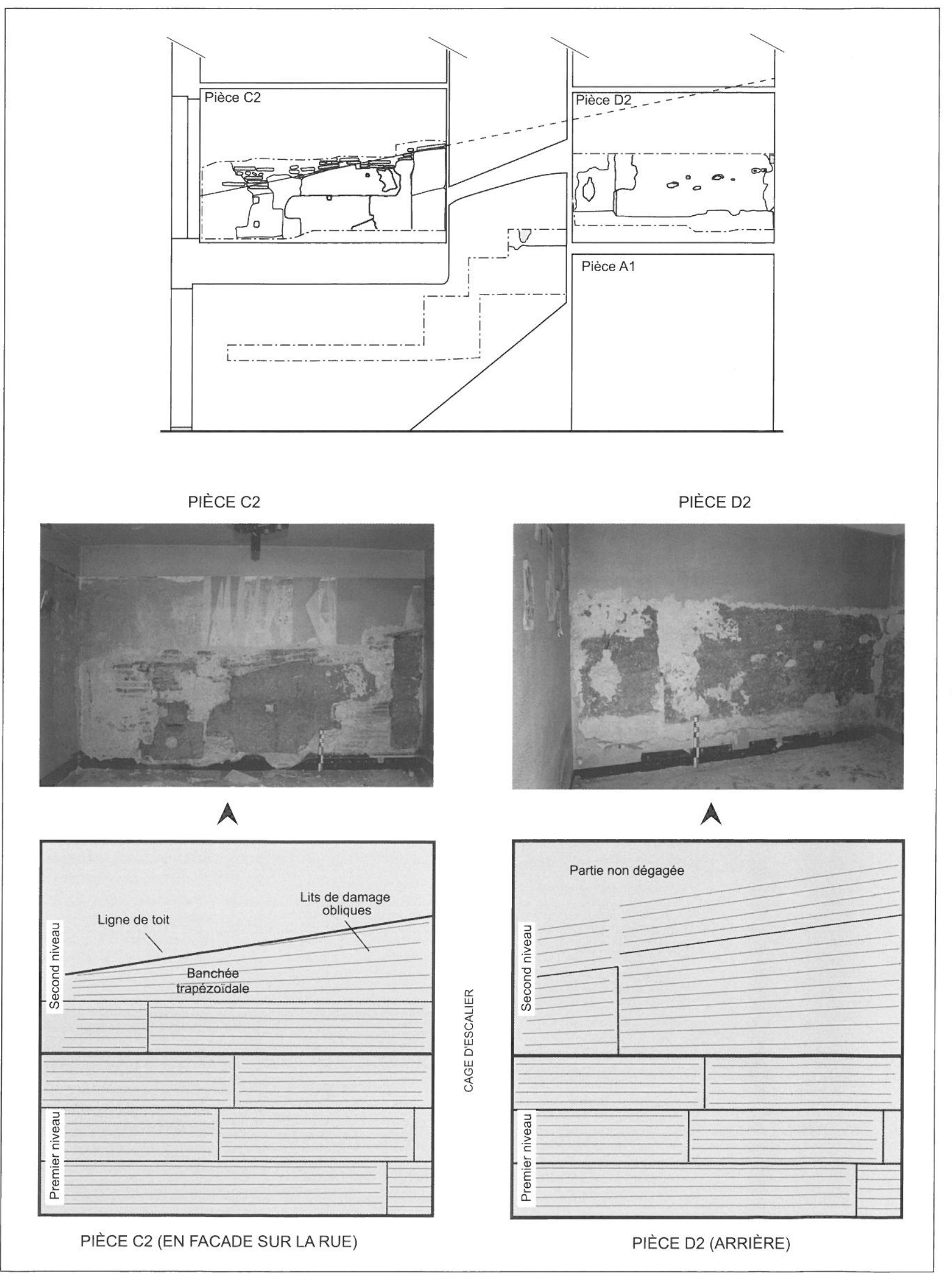

Fig. 15 : Mur latéral au 35 rue du Four Saint-François : mise en évidence du processus de damage dans des banches en forme de trapèze (C.-A. de Chazelles). 


\section{Le matériau}

À quelques différences près, le matériau des murs en pisé est toujours le même. Au toucher, la texture correspond à un mélange de limon grossier et de graviers, mais la composition doit inclure une part d'argile qui a permis, sur certains murs, la formation de la « fleur de pisé » et le moulage précis des fibres du bois de coffrage. La fleur de pisé est la surface lisse obtenue par la migration des particules de terre les plus fines vers les parements au cours du damage. La granulométrie hétérogène, très adaptée au compactage, paraît correspondre aux caractéristiques naturelles du substrat local. Les inclusions sont rares et résultent probablement de mélanges fortuits au moment de la construction : quelques fibres végétales, des tessons de tuiles ou de briques, très peu de mobilier domestique.

Il convient de noter, en raison de son originalité, la présence d'un lit de végétaux entre deux assises (fig. 17).

\section{Les traitements des parements}

Un gobetis au mortier de sable et chaux, appliqué sur le parement lisse de certains murs pour créer des aspérités avant d'appliquer l'enduit de finition, témoigne de leur traitement originel (fig. 14). D'autres parements ont soit été peints directement sur la terre avec un lait de chaux (fig. 14), soit recouverts de mortier ou de plâtre à des périodes diverses. Le plus souvent ces opérations ont imposé de strier, piqueter et même raboter la paroi pour permettre un meilleur accrochage du revêtement. Il semble que les réfections au plâtre constituent les plus récentes interventions.

Les trous de clé sont rebouchés au niveau des parements avec des matériaux divers : galets, fragments de briques cuites, terre, mortier, plâtre. Là encore, il faut sans doute distinguer les occultations contemporaines de la construction (terre, galets ou mortier), des bouchages modernes effectués lors de l'application de nouveaux enduits (fragments de tuiles ou de briques, plâtre).

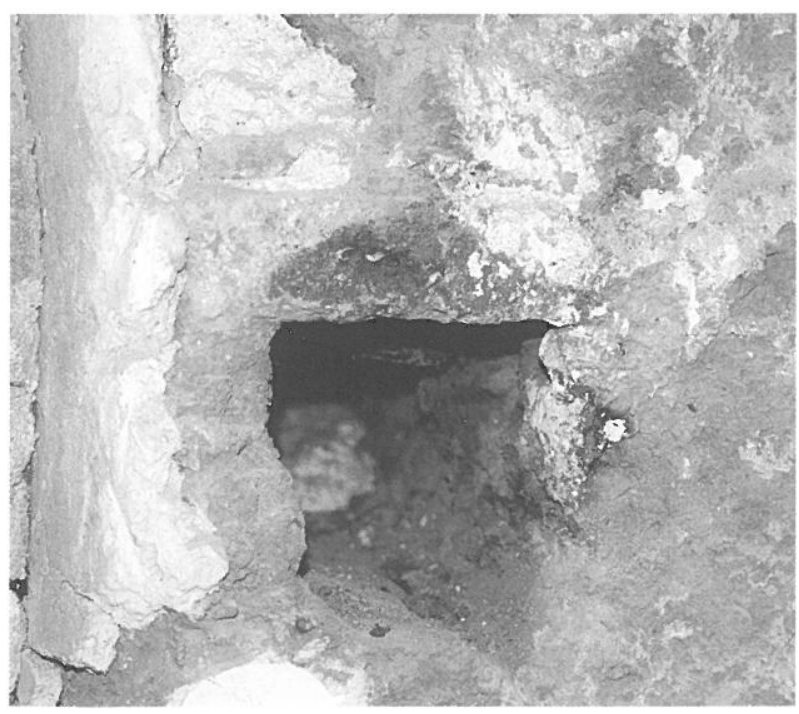

Fig. 16 : Négatif d'une grande clé de fixation de banche dans un mur de pisé. Son couvrement est fait d'une lauze.

\section{Les murs en bauge}

\section{Rappel technique}

Le terme bauge s'emploie commodément pour recouvrir différents procédés de façonnage direct élaborés à partir d'un matériau, composé de terre et souvent additionné de végétaux, à la teneur en eau telle qu'elle lui confère une bonne plasticité. Il désigne par conséquent des modes de construction en terre crue massive, dans lesquels la terre est mise en œuvre sans coffrage ni fabrication préalable d'éléments moulés (Aurenche 2003, 279).

On peut distinguer deux grandes « familles ». Dans la première, le matériau est façonné manuellement ou découpé en «mottes », « pains », « galettes », etc., qui sont assemblés directement, sans séchage. Ces masses de matériau peuvent être posées, projetées ou pressées, de manière à former des assises de hauteur généralement limitée mais continues sur toute la longueur d'un mur. Ce procédé bien connu en Midi-Pyrénées accepte des variantes en fonction de la teneur hydrique du mélange, de la forme des éléments et de leur disposition (à plat, en épis), qui se regroupent sous l'appellation de « bauge par couches filantes » (types 2 et 3 définis par Klein 2003, 425-431)

Dans la seconde famille, le matériau est manipulé avec des fourches, donc par volumes plus importants, pour élever des assises plus hautes $(0,50$ à $0,80 \mathrm{~m})$. Au cours du montage, le matériau peut être " resserré » c'est-à-dire frappé à coups de bâton ou d'autres instruments, sur le sommet de la couche ou sur les parements, afin de prévenir la formation de fissures (Klein 2003, 434). Selon la hauteur et l'épaisseur des assises, les temps de séchage sont plus ou moins longs entre deux levées de terre. La rectification des parements s'effectue soit par retaille avec un outil tranchant (bêche), soit par façonnage manuel (Klein 2003, 433 ; Scherrer 2003, 220 ; Streiff 2003, 319).

Les variantes du façonnage direct sont innombrables car ce procédé compte parmi les plus anciens de la construction en terre crue (en France méridionale, il est

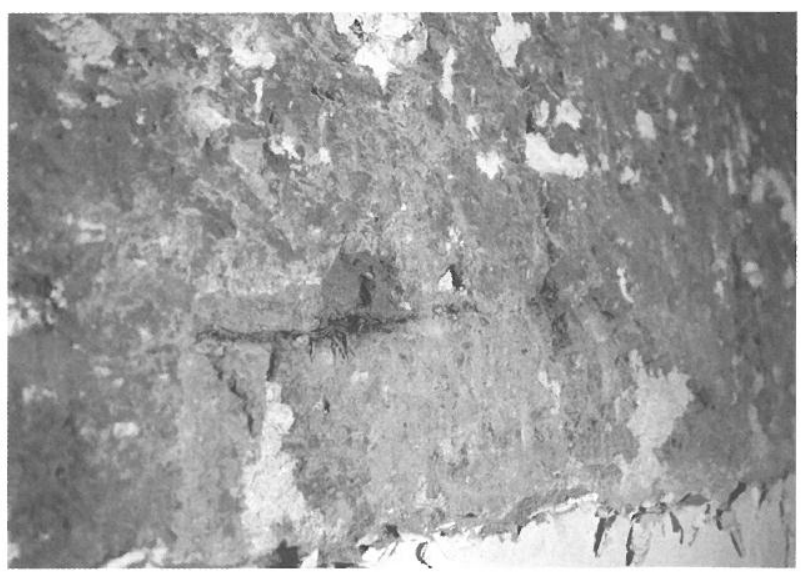

Fig. 17 : Lit de végétaux entre deux assises d'un mur de pisé au 33 bis rue Arago. 
attesté dès le Néolithique final et durant toute la Protohistoire) et les plus répandus dans le monde (il s'illustre aussi bien sous des climats froids et humides, comme celui de l'Angleterre, que chauds et secs, comme en Afrique Noire ou au Yémen).

\section{Les murs en bauge de l'îlot du quartier Saint-Mathieu}

Bien que l'échantillonnage des structures en bauge du quartier Saint-Mathieu soit restreint, il comporte des nuances.

Le mur latéral nord-ouest du 5 rue de l'Hôpital qui se développe sur deux niveaux (N1 et N2), et le mur de fond du 33bis rue Arago, qui correspond à une reprise ponctuelle au niveau N2, sont positionnés sur l'axe longitudinal séparant l'îlot en deux. En revanche, la surélévation en bauge rencontrée au 31 rue du Four-Saint-François correspond au mur latéral sud-ouest de la maison (fig. 9). Les trois constructions constituées par des lits de terre d'épaisseur variable se rattachent au Type 3 de la bauge par couches filantes selon A. Klein (Klein 2003). Dans le premier exemple (fig. 18), les lits de terre ont une certaine régularité (entre 11 et $17 \mathrm{~cm}$ ), mais les mottes ne peuvent pas être délimitées, ni mesurées. Elles ont probablement été juxtaposées de manière à se lier les unes aux autres au sein d'un même rang et il ne faut pas exclure la possibilité que chaque lit ait été «battu» ou que les parements encore frais aient été « resserrés ». Entre les couches de terre, des brindilles assez clairsemées - de bruyère à ce qu'il semble - sont disposées perpendiculairement aux parements. Le matériau matriciel est semblable à celui du pisé. Il présente à peu près la même dureté, mais il est plus friable puisqu'il n'a pas été compacté.

La surélévation, rue du Four Saint-Francois, montre des lits très inégaux (de 9 à $20 \mathrm{~cm}$ ) avec, dans les joints, de gros tessons de terre cuite (tuiles) mélangés aux végétaux (fig. 19) et celle du 33 rue Arago laisse apparaître distinctement des pains de terre.

À côté de cet appareil régulier, la bauge s'est prêtée, aussi en raison de sa grande souplesse, à des aménagements particuliers. Le rebouchage d'une brèche

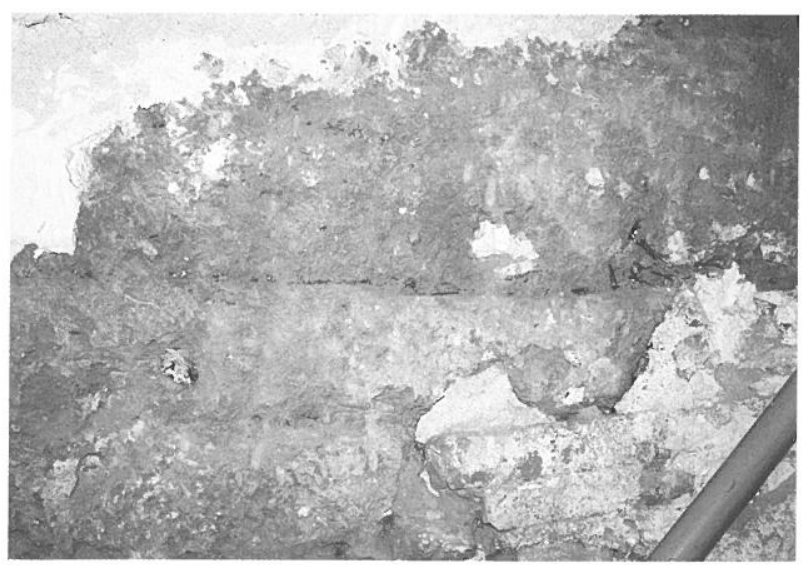

Fig. 18 : Partie du mur latéral du 5 rue de l'Hôpital, réalisé en bauge, avec des lits de bruyère. dans un mur de pisé, par exemple, est fait de mottes de terre empilées sans ordre à l'état très plastique (fig. 20). Elles sont littéralement enrobées de végétaux pour pallier la mollesse du matériau et créer un chaînage interne dans la maçonnerie. De même, des mottes assemblées sur trois rangs forment un aménagement triangulaire entre deux parties superposées d'un mur de séparation, rue Arago (fig. 21). Ce massif a permis de passer du plan d'arasement horizontal d'un mur de pisé à un plan de pose en pente servant à fixer un coffrage à l'oblique (fig. 37). La bauge a également été utilisée pour des reprises superficielles et divers rebouchages de trous et de fissures.

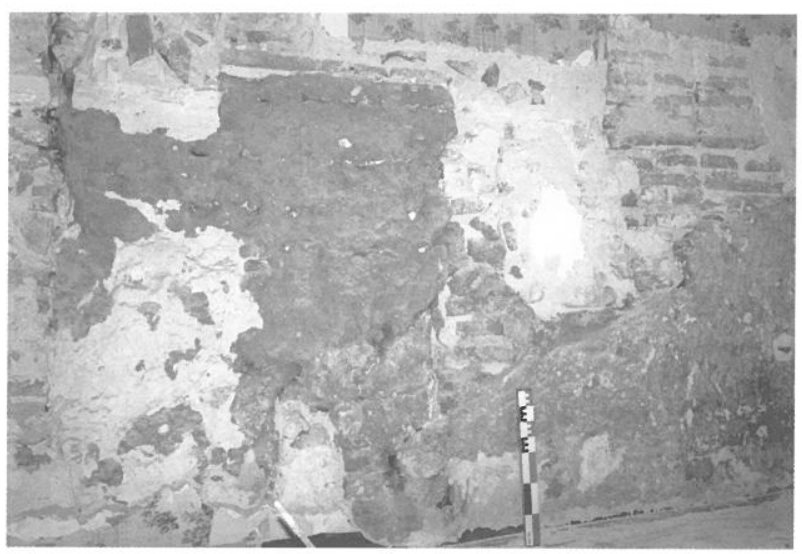

Fig. 19 : Mur latéral en bauge, au 31 rue du Four Saint-François : les lits de terre sont séparés par des végétaux auxquels sont mélangés des fragments de tuiles.

\section{Un mur en bauge coffrée}

\section{Rappel technique}

La question du coffrage éventuel de la bauge se pose régulièrement au sujet de murs en terre massive qui ne présentent ni les caractères formels du pisé ni aucune des morphologies de la bauge. Cette éventualité a été plusieurs fois évoquée pour des parois d'époque protohistorique, à l'issue d'études micromorphologiques ayant démontré un état relativement « humide » du matériau lors de sa mise en œuvre, donc peu propice à un façonnage direct sans le renfort d'un guide et incompatible avec le compactage au pisoir (Cammas 2003, 44 ; Roux et Cammas 2007, 96). Elle a également été envisagée dans le cadre d'une recherche sur le patrimoine en terre de la région Midi-Pyrénées (Klein 2003, 435) ainsi que pour certaines constructions modernes de Normandie (Streiff 2003, 321). De fait, l'interrogation porte sur la terminologie adéquate pour désigner certaines constructions qui d'une part témoignent de l'emploi de planches, au moins sur l'un de leurs parements et, qui d'autre part n'ont pas été damées. Dans l'ensemble, les praticiens des maçonneries en terre considèrent l'hypothèse de la «bauge coffrée » avec beaucoup de scepticisme car ils ne voient pas l'utilité d'un coffrage quand on maîtrise la consistance idéale de la terre pour faire de la bauge. De plus, ils objectent qu'il est très délicat de décoffrer une terre mise en forme avec une 


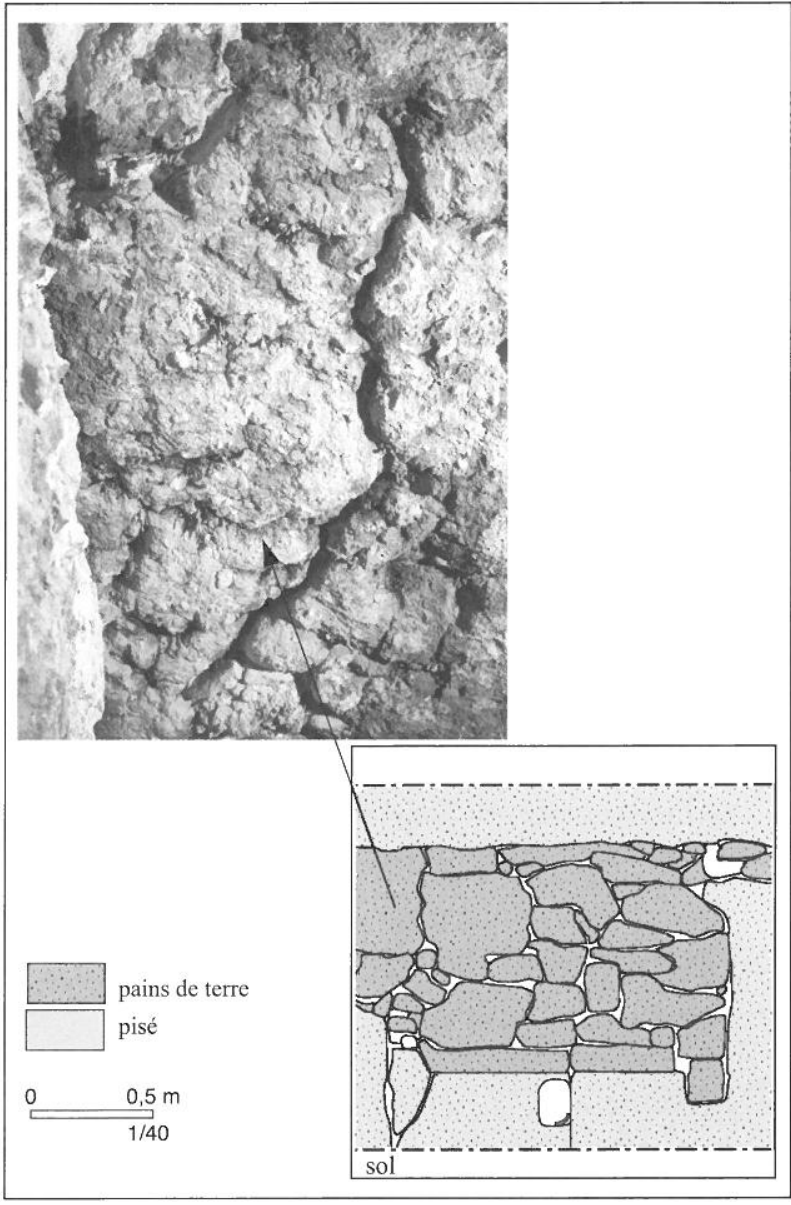

Fig. 20 : Détail d'une reprise dans un mur de pisé, faite de mottes de bauge très plastiques et enrobées de végétaux, au 35 rue du Four Saint-François.

teneur en eau élevée : l'opération ne peut s'effectuer qu'après un délai de séchage assez long et au risque de voir les banches adhérer au matériau ${ }^{10}$. Pourtant, un procédé intermédiaire entre bauge et pisé est attesté dans l'architecture actuelle de la région himalayenne Himachal Pradesh où les constructeurs utilisent des banches très basses $(0,30 \mathrm{~m})$ qu'ils fixent à l'aide de clés traversantes, mais versent le matériau très humide et le tassent très peu (Péchoux, Korbaa 2007).

\section{Le mur de bauge coffrée de l'îlot Saint-Mathieu}

L'hypothèse de la bauge coffrée est avancée à propos d'un mur de l'îlot Saint-Mathieu. Il s'agit de la partie supérieure du mur séparant les 33 et 31 rue Arago, qui correspond soit à une surélévation, soit à la réalisation dès l'origine de la partie sommitale. Quoi qu'il en soit, cette partie est montée à partir du plan incliné formé par des lits irréguliers de bauge évoqués ci-dessus. Sa base ennoie de grosses branches disposées longitudinalement sur le plan incliné.

Comme dans le cas des assises supérieures de pisé décrites pour les murs latéraux de la maison du 35 rue du Puits Saint-François (voir supra), qui d'ailleurs se trouve

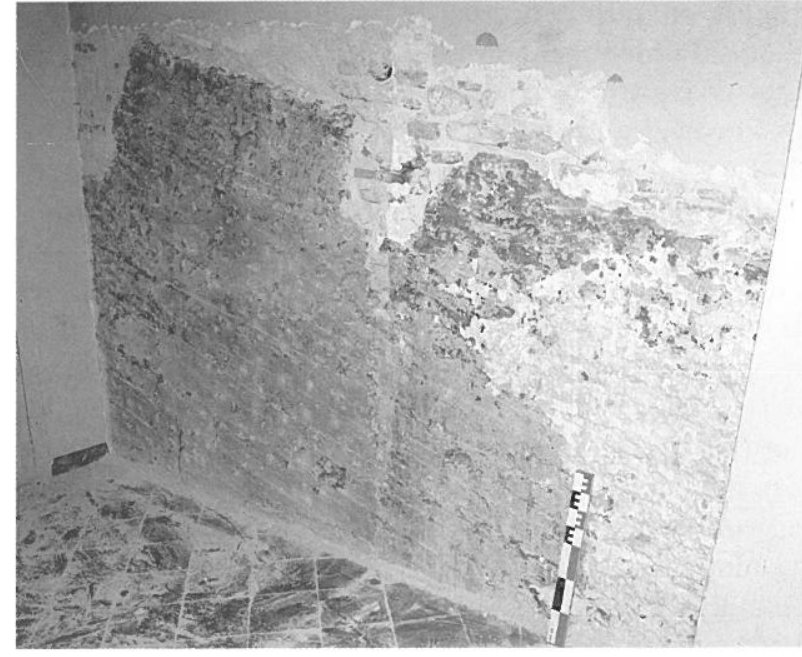

Fig. 21 : Partie supérieure d'un mur latéral, réalisée en bauge coffrée. Noter l'absence de limite d'assise ou de banche, de trou de clé et la précision du moulage des planches obliques du coffrage.

adossée à celle du 33 rue Arago, les bâtisseurs ont réalisé une haute assise trapézoïdale dont le sommet incliné correspond à la pente du toit. Mais au lieu de procéder par banchées de pisé juxtaposées, ils ont coffré une terre assez humide sans la compacter sur la hauteur non négligeable de 2,20 m et, peut-être aussi, sur toute la profondeur de la maison. Ceci ne peut être assuré puisque l'observation comporte plusieurs lacunes, mais la plus grande longueur enregistrée, dans la pièce arrière de l'étage, atteint 2,50 m. Le parement conserve les empreintes ligneuses des planches de coffrage d'une netteté remarquable, ce qui a permis de voir qu'elles étaient disposées en oblique (fig. 21). La précision de ce moulage mettant toutes les lattes en évidence ne peut être due qu'à la texture très fine du matériau et à son fort degré d'humidité. Par ailleurs, on ne distingue aucune séparation susceptible d'évoquer des lits de damage successifs, ni d'ailleurs de trous de clé. Ces empreintes évoquent celles que l'on peut voir, de nos jours, sur des structures de béton coulé « brutes de décoffrage ».

\section{Conclusion sur les aspects techniques}

Les découvertes de maisons en terre de Perpignan s'ajoutent à celles qui ont été faites dans d'autres villes languedociennes et roussillonnaises pour démontrer le rôle essentiel de la terre crue dans l'architecture domestique du Moyen Âge.

Les raisons motivant le choix technique du pisé ou de la bauge n'apparaissent pas clairement : les deux procédés ont pu offrir des solutions légèrement différentes à la nécessité de construire vite et à peu de frais, répondant peut-être à des contraintes spécifiques. L'hypothèse que ces choix traduisent les habitudes de populations ou de catégories sociales différentes n'est pas à écarter, ni celle de constructeurs disposant de bagages techniques et/ou d'outillages distincts.

\footnotetext{
${ }^{10} \mathrm{Ce}$ point a fait l'objet de longues discussions et controverses au cours d'une table-ronde. Voir la transcription des débats dans Guillaud et alii 2007.
} 
En ce qui concerne le pisé, les murs de l'îlot Saint-Mathieu se conforment aux normes propres à ce type de construction répandues jusqu'au début du $\mathrm{XX}^{\mathrm{e}} \mathrm{s}$ en Provence, dans le centre de la France, dans le Dauphiné et le Lyonnais. ${ }^{11}$. On doit cependant attirer l'attention sur certaines particularités comme les grandes dimensions des clés et le fait que les rainures qui les reçoivent sont toujours recouvertes pour faciliter leur retrait, ou encore le damage sur des plans inclinés. Alors que la grande taille des clés et le couvrement des rainures constituent désormais de véritables caractéristiques du pisé du bas Moyen Âge en Languedoc et en Roussillon ${ }^{12}$, les lits de damage obliques ne sont pour l'instant pas attestés ailleurs. Cette solution est en effet peu courante car le maniement du pisoir dans cette situation est malaisé ${ }^{13}$. Il semble que dans la maison de l'îlot Saint Mathieu où elle se distingue sur les deux murs latéraux (35 rue du Four-Saint-François), cette pratique soit associée à des banchées en forme de trapèzes rectangles (fig. 14 et 15). Plusieurs perturbations ont gêné la lecture du mur le mieux conservé, observé sur toute la profondeur de la maison (mur mitoyen entre le 35 et le 37 rue du Four-Saint-François), mais force est de constater sur une surface pourtant très étendue l'absence de limites d'assises claires ainsi que celle de trous de clé. Ce constat amène à s'interroger, dans ce cas précis, sur la forme, les dimensions et le mode de fixation des banches qui paraissent très originaux. Dans la partie avant de la maison, proche de la gouttière, la hauteur de la dernière assise de pisé était assez restreinte pour permettre d'effectuer la banchée trapézoïdale en une seule opération. En revanche, dans la partie arrière de la maison, beaucoup plus haute, il est possible qu'on ait fractionné le travail en deux étapes, pour éviter que le piseur ne se trouve à l'intérieur d'un coffrage de $2 \mathrm{~m}$ de haut, mais les traces ne sont pas suffisamment explicites pour le révéler (fig. 15). Toutefois, l'absence de démarcations nettes (qui auraient signalé des arrêts et reprises du travail) et, surtout, l'absence de trous de clé pourraient indiquer que les planches ont été montées au fur et à mesure de l'élévation avec un système de fixation extérieur, comme dans la méthode dite du Bugey qui permet de réaliser de grands panneaux d'un seul tenant ${ }^{14}$.

La présence de végétaux entre deux assises, notée dans un seul cas, est à souligner dans la mesure où les normes actuelles bannissent l'introduction de matières organiques dans la terre à pisé, alors que les enquêtes ethnographiques révèlent parfois, par exemple dans le Tarn-et-Garonne, l'alternance de lits de brindilles et de couches de terre exactement comme pour la bauge (Klein 2003, 419).
Un parallèle peut être établi entre les bâtiments de l'îlot Saint-Mathieu et ceux du quartier Saint-Jacques qui est créé à Perpignan à la même époque. En plus des similitudes formelles du plan d'urbanisme et du découpage des îlots, on observe l'usage extensif de la terre crue dans les deux cas. Les options techniques diffèrent cependant puisque, dans le quartier Saint-Jacques à l'inverse de l'îlot Saint-Mathieu, l'emploi de la bauge supplante largement celui du pisé. Plus récemment, en 2005, une fouille archéologique conduite à quelques dizaines de mètres de l'îlot Saint-Mathieu, sur le site de l'ancien couvent des Franciscains, a mis au jour les vestiges de plusieurs murs en pisé appartenant au premier état du couvent. Ceux-ci sont parfaitement datés de la fin du XIII ${ }^{\mathrm{e}}$ ou au début du début $\mathrm{XIV}^{\mathrm{e}}$ siècle par le mobilier contenu dans leur matériau ainsi que par les couches de démolition qui les scellent (fig. 22) (Bergeret, Donat 2004, 199-207 ; Bergeret et al. 2007) ${ }^{15}$.

Plus largement, les découvertes de constructions en pisé attribuées au Moyen Âge se sont multipliées au cours des dernières années en Languedoc et en Roussillon et un certain nombre de points communs se dégagent de

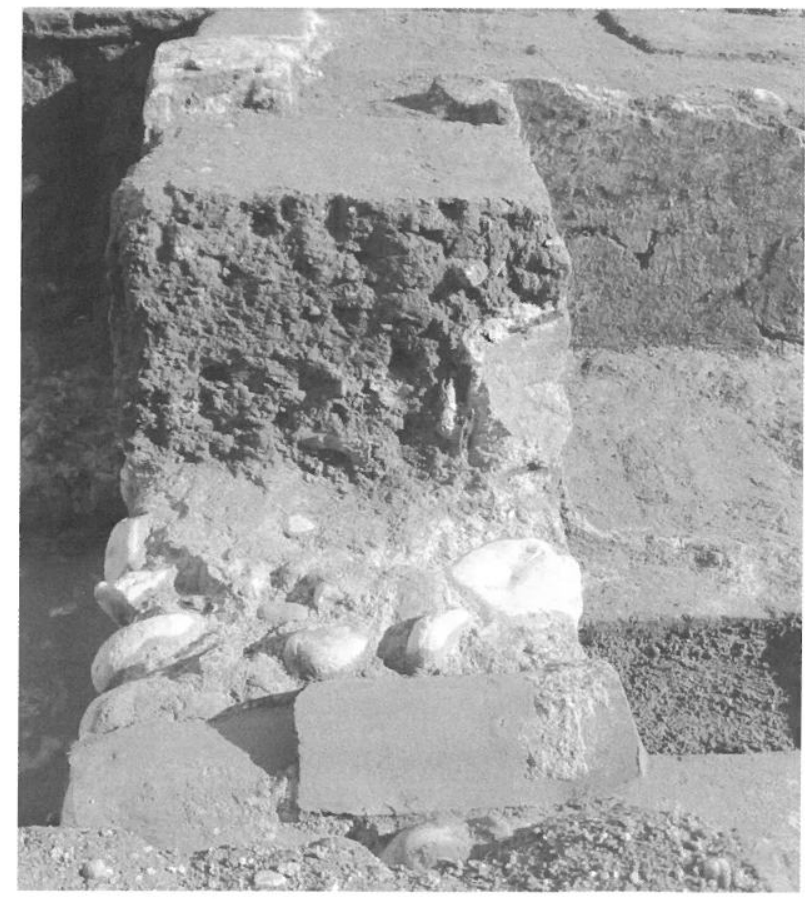

Fig. 22 : Mur de pisé sur soubassement et fondation en pierre découvert au couvent des Franciscains (Perpignan). L'arase supérieure du solin est traversée par un trou de clé recouvert par des tuiles (H. Gazzal, avec l'autorisation de A. Bergeret).

\footnotetext{
"Orientation bibliographique : Bromberger et al. 1980, CAUE de l'Ain 1983, Jeannet et al. sd.

${ }^{12}$ Ce système a été enregistré de façon systématique sur toutes les découvertes de pisé de Perpignan, Narbonne, Béziers, Montagnac, Lunel et la Digne d'Aval.

${ }^{13}$ On connaît cependant quelques illustrations modernes représentées par des murs de clôture édifiés sur des terrains en pente. Citons par exemple, à Saint-Genis-en-Laval (Ain), un mur dont les banchées et les lits de damage sont inclinés à 18\% (CAUE Ain 1983: 20 ).

${ }^{14}$ Cette méthode révélée dès le XVIII ${ }^{\mathrm{s}}$ siècle par l'architecte Cointereaux est envisagée par Alain Klein pour interpréter certaines constructions de la région Midi-Pyrénées qui ne montrent pas les repères habituels du pisé, à savoir : limites de banches, assises et trous de clés (Klein 2003, 419-424, sp. figures $2,7,9,12,14)$

${ }^{15}$ Opération INRAP, sous la direction d'Agnès Bergeret. La fouille d'un des murs, conservé seulement sur une trentaine de centimètres de haut, a néanmoins mis en évidence la présence de passages de clés au sommet du soubassement. Les deux murs fouillés possèdent effectivement des solins en pierre et, pour l'un au moins, une fondation enterrée. Nous remercions A. Bergeret qui nous a permis d'effectuer ces observations.
} 
l'analyse des situations. En premier lieu, celui de la chronologie, puisque tous les ensembles connus ont été édifiés entre le milieu du XIII' ${ }^{\mathrm{e}}$ siècle et le $\mathrm{XV}^{\mathrm{e}}$ siècle. En second lieu, les conditions d'implantation sont assez comparables car il s'agit, en règle générale, de quartiers qui entourent progressivement les noyaux primitifs des villes et se situent même souvent en dehors des enceintes d'époque romane. C'est le cas à Perpignan pour les quartiers Saint-Jacques et Saint-Mathieu (Guyonnet 2001 ; Guyonnet, Catafau 2003), à Narbonne (Aude) pour le faubourg de la Médiathèque (Mellinand et Léal 2002) ou encore à Béziers (Hérault) (Ginouvez 2002 ; Ginouvez 2008) et Lunel (Hérault) (inédit) ${ }^{16}$. On remarque avec intérêt que cette architecture de pisé (et de bauge, d'ailleurs aussi) n'est pas cantonnée à des quartiers lotis à grande échelle comme ceux de Perpignan ou de Montagnac (Hérault) (Lochard, Vayssettes, Nepipvoda $2005)^{17}$, mais qu'au contraire elle se rencontre de la même manière dans des demeures de qualité, telle par exemple la Maison dite de Philippe Le Bel, à Lunel, qui est dotée dès l'origine d'un décor architectural remarquable.

En Provence, les premiers témoins répertoriés de constructions en pisé se trouvent à Marseille, dans un contexte de la fin du XII ${ }^{\mathrm{e}}$ siècle ou du début du XIII ${ }^{\mathrm{e}}$ siècle (Thernot, Vecchione 2003). Mais ce phénomène dont l'ampleur se révèle avec l'accroissement des découvertes n'a pas concerné uniquement les régions méditerranéennes (Chazelles et Guyonnet 2007). En Languedoc, il atteint aussi l'intérieur des terres, avec une attestation sur le cours de l'Aude à la Digne d'Aval près de Limoux ${ }^{18}$. Enfin, il dépasse largement les limites régionales et l'on assiste entre la fin du XII ${ }^{\mathrm{e}}$ siècle et le début du XIVe siècle à la formidable « éclosion » d'une architecture urbaine dans laquelle le pisé occupe un rôle important, jusque dans des secteurs aussi éloignés de la Méditerranée que le Forez. Citons en particulier la chapelle Sainte-Catherine à Saint-Marcellin du Forez, édifiée au XIII ${ }^{e}$ siècle, le prieuré de Montverdun (Le Barrier 1998), ainsi que la célèbre salle de « la Diana », à Montbrison dont la construction daterait précisément de 1296 (Jeannet et alii, sans date, p. 32-33, Guibaud 2005).

Il est important de rappeler que la technique de la terre banchée et damée constitue, tout au long du Moyen Âge et au début de la période moderne, une des caractéristiques des architectures civiles et défensives de l'Afrique du Nord et de 1'Espagne. Les constructeurs musulmans l'ont employée à partir du $\mathrm{X}^{\mathrm{e}}$ siècle, sinon plus tôt, comme le prouvent de nombreux vestiges ainsi que des textes (Bazzana, Guichard 1987, Font Arellano 2007). Passée l'époque de domination islamique sur l'Espagne, la technique appelée tapia en castillan comme en catalan s'est conservée pratiquement jusqu'à nos jours dans la construction privée de plusieurs provinces - Castille-Leon, Aragon, Catalogne occidentale - ainsi que dans les fortifications jusqu'au XVIII ${ }^{e}$ siècle (Lopez Martinez 2007). En Catalogne orientale, l'emploi de la tapia est également attesté dans l'architecture médiévale, en particulier dans la région du Penedes par la muraille de Marmellar (Adell i Gisbert 1982) et par plusieurs pigeonniers (Rafel i Fontanals 1980), et, en milieu urbain, à Barcelone au XIII' siècle par des textes (Battle 1985). Les pigeonniers médiévaux décrits par Nuria Rafel i Fontanals ne prêtent pas à confusion, il s'agit de toute évidence de constructions en pisé. En revanche, J.-A. Adell i Gisbert s'appuie justement sur cet article pour interpréter comme du pisé (tapia) la partie haute disparue des murs du gisement de l'Esquerda (Masies de Roda de Ter) (Adell i Gisbert 1982, 346). Quant aux mentions utilisées par Carmen Battle dans son étude sur la maison barcelonaise, l'une concerne une clôture mesurant une tapia de hauteur, une autre un mur constitué par six tapies, les trois premières en pierre et chaux, les trois supérieures en terre et mortier (Battle 1985, 41 et 46). L'auteur précise dans les deux cas que la hauteur de la tapia est de $0,89 \mathrm{~m}$, sans indiquer l'origine de cette information, mais, pour une période plus récente, le XVII ${ }^{\mathrm{e}}$ siècle, on sait que le terme tapia a couramment servi d'unité de mesure dans l'architecture espagnole (Font 2007, 60).

La tapia est avant tout un procédé constructif fondé sur le principe du coffrage et le mot peut éventuellement s'appliquer à d'autres matériaux que la terre crue. La nature de ceux-ci est alors en général précisée. La langue castillane possède une grande variété d'expressions pour désigner toutes les variantes de la terre coffrée (Font 2007). La tapia a été utilisée par les Musulmans et par les Chrétiens dans la construction publique et privée, comme en attestent de nombreux vestiges bien conservés de châteaux et de fortifications en Espagne et au Portugal. Actuellement, dans la péninsule ibérique, en ce qui concerne le Moyen Âge et la période moderne, ni donnée archéologique incertaine, ni texte ambigu ne laisse penser que le terme tapia pourrait également désigner de la bauge, contrairement à ce que l'on constate en France (en dernier lieu : Baudreu 2007 pour le Languedoc et Chazelles, Guyonnet 2007 pour la Provence) ${ }^{19}$.

Par conséquent, envisager le transfert de ce procédé totalement maîtrisé depuis l'Espagne vers la France, à la fin du Moyen Âge, n'est pas irréaliste, quels qu'aient pu en être les vecteurs techniques et économiques, voire politiques.

\footnotetext{
${ }^{16}$ L'étude des modes de construction de cette maison a été effectuée par C.-A. de Chazelles et les datations ont été fournies par Jean-Louis Vayssettes, inventeur du site, d'après le décor des baies et la présence d'un plafond au style bien daté (Région Languedoc-Roussillon, service de l'inventaire).

${ }^{17}$ Le centre de Montagnac recèle un patrimoine en terre du bas Moyen Âge remarquablement étendu et bien conservé qui a été découvert par Thierry Lochard, Jean-Louis Vayssettes (Région Languedoc-Roussillon, service de l'inventaire) et Denis Nepipvoda (Communauté de commune de Pézénas) en 2005. Plusieurs maisons ont déjà été étudiées par C.-A. de Chazelles.

${ }^{18}$ Alors que le village de la Digne d'Aval (Aude) est entouré par une muraille en bauge par lits et rangs de végétaux, une découverte récente de D Baudreu a mis en évidence la présence d'un mur de pisé à l'intérieur de l'enceinte. Nous le remercions amicalement de nous avoir communiqué cette information et permis de voir la construction avant réfection.

${ }^{19}$ La situation est différente pour la Protohistoire : les archéologues espagnols ont du mal à mettre scientifiquement en évidence l'existence du pisé alors que celle-ci est très souvent affirmée - et commencent à envisager des emplois de la terre crue sous la forme de bauge (amasados) (Belarte, Gailledrat 2003).
} 
La mise en évidence de constructions en bauge, en 2000 sur le chantier du quartier Saint-Jacques, a constitué une étape décisive dans notre connaissance de l'architecture urbaine médiévale. Jusqu'alors, cette manière de bâtir en terre était totalement ignorée des archéologues en Roussillon comme en Languedoc méditerranéen toutes périodes considérées (après la Protohistoire), alors qu'elle commençait à être connue dans la partie intérieure du département de l'Aude (Baudreu 2002 ; Baudreu 2003) et qu'elle était par ailleurs bien cernée en Midi-Pyrénées (Klein 2003). Dans ces deux régions, la technique des lits de terre alternés avec des rangs de végétaux (bruyère le plus souvent, parfois vigne ou fougère) est incontestablement répandue dès la fin du Moyen Âge ${ }^{20}$. Elle apparaît en Carcassès et Bas-Razès dans le courant du XIV ${ }^{\mathrm{e}}$ siècle où elle se maintient au moins jusqu'au XVI ${ }^{\mathrm{e}}$ siècle (Baudreu 2003,369) et s'emploie régulièrement, par ailleurs, dans le Midi toulousain entre le XVI ${ }^{\mathrm{e}}$ et le XIX ${ }^{\mathrm{e}}$ siècle (Klein 2003, 419-420).

Enfin, à la lumière des découvertes récemment faites à Perpignan, des vestiges mis au jour à Elne à la fin des années 1980 (Kotarba, Pezin 1989) prennent leur entière signification et il est pratiquement certain que l'on avait bien affaire à ce type particulier de bauge, par lits intercalés avec des rangs de végétaux, comme cela avait été envisagé mais non démontré (Chazelles 1997, 90). Constitué par les lambeaux d'un mur de soutènement, ce dernier exemple représente aujourd'hui le plus ancien témoignage de la construction en bauge en Roussillon puisqu'il est daté du $\mathrm{XI}^{\mathrm{e}}$ ou du $\mathrm{XII}^{\mathrm{e}}$ siècle.

Si le faubourg de la Médiathèque, à Narbonne, ne fait pas état de cette technique très caractéristique (Chazelles, Leal 2003), elle a été mise en évidence à deux reprises dans des maisons urbaines de Béziers (Ginouvez 2002, Ginouvez 2008). L'étude de bâti conduite sur la Maison de Maître Gervais a permis de reconnaître, sous un chemisage de pierre datant vraisemblablement du XVI ${ }^{e}$ siècle, une façade élevée en bauge sur deux niveaux au-dessus des arcs du rez-de-chaussée, ainsi qu'un mur mitoyen atteignant aussi le faîte de la maison (Gomez 2005). Quoique les indices de datation soient moins précis qu'à Perpignan, la construction de ces murs en terre intervient en tout état de cause entre la fin du XIII ${ }^{\text {e }}$ siècle et le $\mathrm{XVI}^{\mathrm{e}}$ siècle. À Montagnac (Hérault), la bauge sous diverses formes est employée parallèlement au pisé au cours de la même fourchette chronologique. On a pu identifier des lits de terre séparés par des rangées de bruyère, des pains informes disposés en couches soit horizontales soit obliques et de la bauge beaucoup plus compacte en lits minces ou en assises plus hautes (Chazelles 2007). Même la Maison de Philippe le Bel à
Lunel, tout entière en pisé, a livré un lambeau de mur de bauge montrant les mêmes caractéristiques qu'à Perpignan. Ce témoignage inédit représente aujourd'hui l'exemple le plus oriental de ce procédé.

Il devient évident, à partir de ces cas bien répartis géographiquement et des études faites dans l'Aude par Dominique Baudreu, que la bauge en lits superposés et liés par des rangées de brindilles représente l'une des techniques de construction tardo-médiévales du Languedoc occidental et du Roussillon. L'exemple d'Elne (Pyrénées-Orientales) - bien qu'il s'agisse d'une interprétation faite a posteriori sur la base d'une description - pourrait accréditer l'hypothèse d'une tradition constructive remontant peut-être localement au $\mathrm{XI}^{\mathrm{e}}$ ou au XII ${ }^{\mathrm{e}}$ siècle. Il faut attendre l'appui d'autres découvertes pour s'en assurer. Au moins doit-on constater la remarquable homogénéité du procédé sur une vaste région qui s'étend de Carcassonne à Lunel en passant par Perpignan, entre la fin du XIII' ${ }^{e}$ siècle et la fin du $\mathrm{XV}^{e}$ siècle. Malheureusement, l'état présent de la documentation ne permet pas de préciser, non plus, si cette forme de bauge a perduré en Languedoc-Roussillon à la période moderne et au-delà. En tout cas, le patrimoine postérieur au $\mathrm{XV}^{\mathrm{e}}$ siècle conservé dans la région ne semble pas recourir à la terre crue - d'après ce que l'on en sait contrairement à ceux de l'Aude intérieure et de Midi-Pyrénées (Lhuisset 1980 ; Grandjouan 2004) ${ }^{21}$.

En guise de comparaisons extérieures, on peut évoquer des procédés très proches de celui-ci, en Grande-Bretagne (Dewar 1987,419) ainsi qu'en Belgique (Bavay 1987,21) au XIX ${ }^{\mathrm{e}}$ siècle voire au XVIII ${ }^{\mathrm{e}}$ siècle, à ceci près que les lits végétaux sont formés par de la paille au lieu de brindilles ou de branches rigides. Enfin, rappelons qu'à l'instar de la région Midi-Pyrénées, un large quart Nord-Ouest de la France a vu se développer entre le $\mathrm{XVI}^{\mathrm{e}}$ et la fin du $\mathrm{XIX}^{\mathrm{e}}$ siècle une architecture rurale en bauge qui a pris de multiples facettes en fonction des matériaux disponibles et des savoir-faire locaux ${ }^{22}$.

Il n'est pas inutile d'insister sur l'existence de la paroi en bauge coffrée de l'îlot Saint-Mathieu car cet unicum sur le site en est un également dans l'ensemble de la documentation disponible sur la bauge d'époque médiévale. Dans le cas du mur étudié, on peut avoir affaire à une construction bâtarde, éventuellement imposée par la consistance trop molle du matériau empêchant un damage correct. Ce qui retient néanmoins l'attention est la grande hauteur coffrée d'un seul tenant, sans reprise apparente, qui suggère l'utilisation d'un coffrage très haut et sans doute très long. En raison de sa position à l'oblique et de l'absence de clé, on doit restituer un mode de maintien extérieur, comme cela a été envisagé

\footnotetext{
${ }^{20}$ En Midi-Pyrénées, d'autres types de bauge sont mis en évidence par les études d'Alain Klein, mais ils sont sans rapport avec les constructions de Perpignan et, de toute façon, postérieurs au XV'siècle.

${ }^{21}$ Toutefois, avec l'expérience acquise en quelques années sur le bâti urbain médiéval, on peut légitimement se défier des affirmations reconnaissant la pierre comme matériau prédominant/ ou unique en tous contextes. Seuls les décroûtages des enduits et les sondages dans les maçonneries sont à même de révéler l'existence de parois en terre qui se dissimulent parfois même sous des chemisages de pierre.

${ }^{22}$ Pour la Normandie : Streiff 2003 ; Patte 2004, Patte 2007 ; pour la Vendée : Milcent 2004, Milcent, Renoux 2007 , ; pour la Bretagne du Sud (Ille-et-Vilaine) : Bardel, Mailland 2002, Bardel, Rioult 2007. Sur les constructions en bauge en France et en Europe, voir en dernier lieu : Patte (E.) et Streiff (F.) 2007.
} 
à propos du mur de pisé ne présentant pas non plus de démarcation ni de trou. Si l'on ne connaît pas d'équivalent dans la construction en terre, ancienne ou moderne, on peut rapprocher cette «curiosité » de réalisations contemporaines en béton coulé dans lesquelles le coffrage à l'oblique de l'arase du pignon permet de gagner du temps (fig. 23 et 24). Il limite en effet les manipulations de banches, évite la formation de «triangles vides » à l'extrémité de chaque assise de pisé (ou de parpaings) et procure directement la ligne rampante du toit ${ }^{23}$.

Ces observations nous invitent une fois de plus à considérer l'architecture domestique comme un creuset d'inventivité, les hommes adaptant sans cesse les normes de la construction «savante » aux faiblesses de leur outillage ou à la médiocrité de leurs matériaux de base. Une évocation des maisons en bauge du quartier Saint-Jacques est peut-être à même d'apporter un début d'explication à ces choix curieux. En effet, dans les parties supérieures des murs pignons, la bauge était disposée par lits obliques et non plus horizontaux comme dans les niveaux inférieurs, c'est-à-dire que les couches de terre s'inclinaient progressivement jusqu'à l'obtention de la pente voulue pour le toit. Sur la base de cette observation, on peut se demander si les différentes attestations de travail à partir de plans inclinés, relevées dans l'îlot Saint-Mathieu, ne découlent pas d'une habitude constructive liée à la pratique de la bauge. On aurait en quelque sorte réalisé un compromis entre les deux techniques usuelles, la bauge et le pisé, et perfectionné le montage en oblique en contenant la terre entre des planches.

Cet îlot progressivement loti et bâti au cours de quelques décennies du milieu du XIII' ${ }^{e}$ siècle (1240-1280) semble avoir comporté à l'origine uniquement des maisons en pisé, le doute étant permis pour la maison du 5 rue de l'Hôpital dont un des murs situé sur l'axe médian de l'îlot s'élève au moins en partie en bauge dès le rez-de-chaussée. Toutefois, la présence d'un lambeau de

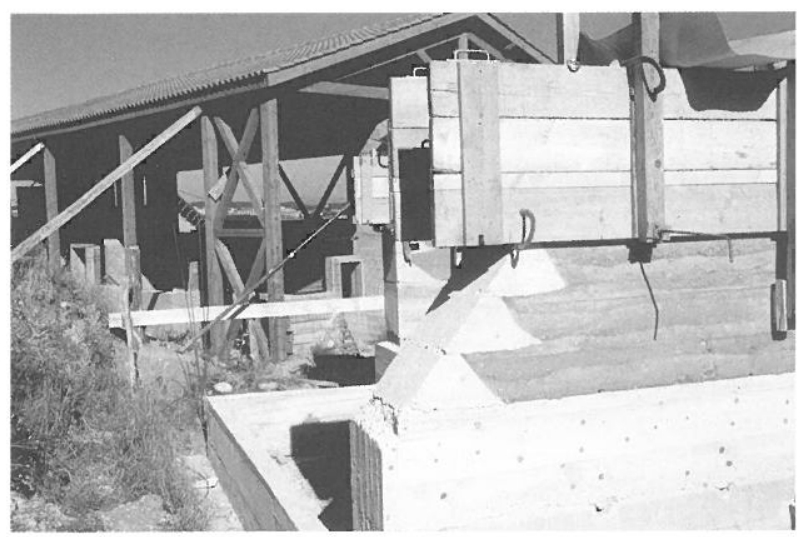

Fig. 23 : Progression « normale » de la construction d'un rampant de pignon en pisé avec consolidation au mortier de chaux. Isle d'Abeau (38), îlot J.-V. Berlottier, 1984 (H. Guillaud, CRATerre-ENSAG) pisé à l'étage laisse penser que la bauge représente seulement une reprise importante des maçonneries. De fait, la première série de reconstruction, qui ne concerne pas toutes les habitations, s'effectue également en terre, mais cette fois avec une certaine diversité des moyens mis en œuvre puisque l'on rencontre des murs de pisé, d'autres en bauge et un au moins en bauge coffrée. Les surélévations suivantes ou celles des maisons qui n'avaient pas été remontées seront réalisées en pierres, briques cuites et mortier de chaux.

Il semble effectivement que le Languedoc méditerranéen ait abandonné au profit de la pierre la plupart de ses savoir-faire constructifs à base de terre crue dès le début de l'époque moderne. Par chance, les travaux archéologiques et les études de bâti dessinent depuis quelques années une image de l'architecture médiévale urbaine du Midi de la France plus riche de nuances, dans laquelle la terre crue s'avère jouer des rôles diversifiés.

\section{LES PREMIERS ÉLÉMENTS DE COMPARAISON POUR L'ARCHITECTURE DES MAISONS EN TERRE À PERPIGNAN}

De nombreux points de comparaison peuvent être mis en évidence entre les maisons en terre du quartier Saint-Mathieu et celles du quartier Saint-Jacques, dans les domaines du parcellaire, de la morphologie et de l'évolution des maisons.

En premier lieu, les parcelles des deux quartiers montrent une organisation semblable, avec des maisons adossées inscrites sur des lots larges de $5 \mathrm{~m}$ en moyenne pour une profondeur oscillant entre 9 et $10 \mathrm{~m}$. F. Guyonnet a noté, lui aussi, des différences de mesures qu'il a également expliquées par la progression des constructions. La surface des maisons varie donc entre $45 \mathrm{~m}^{2}$ pour la plus petite et $63 \mathrm{~m}^{2}$ pour les plus importantes, la moyenne se situant entre 45 et $50 \mathrm{~m}^{2}$.

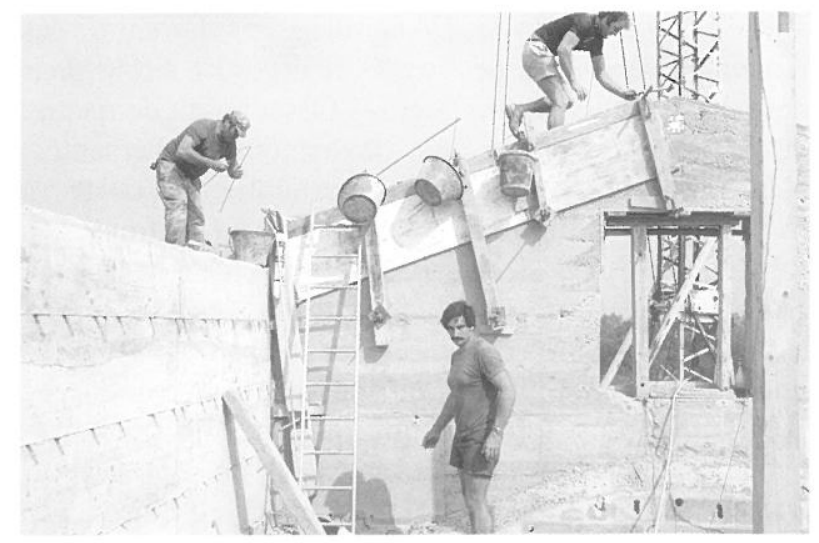

Fig. 24 : Coffrage en biais du rampant d'un pignon réalisé en béton sur un mur de pisé. Isle d'Abeau (38), îlot O. Perreau-Hamburger, 1984 (H. Guillaud, CRATerre-ENSAG)

\footnotetext{
${ }^{23}$ Nous devons ces explications ainsi que les figures 23 et 24 à Hubert Guillaud, architecte, enseignant à l'Ecole Nationale Supérieure d'Architecture de Grenoble et chercheur au CRATerre. Nous le remercions chaleureusement pour son aide dans l'interprétation de ces sommets de murs hors normes, qu'ils soient en terre damée ou seulement coffrée.
} 
En second lieu, les maisons offrent aussi une morphologie générale plutôt semblable, malgré l'existence de quelques points de distinction. En effet, si elles se présentent toutes sous la forme de maisons " élémentaires » adossées et à une pente de toit versant sur la façade, celles du quartier Saint-Jacques possèdent des épaisseurs de murs nettement supérieures $(0,70 \mathrm{~m})$ et des volumes, singulièrement plus importants, avec des plafonds restitués à des hauteurs qui atteignent 3 à $3,50 \mathrm{~m}$ pour le rez-de-chaussée et 2,50 m à l'étage. En revanche, elles ne se développent que sur deux niveaux, au lieu de trois, ce qui à Saint-Mathieu semble la formule la plus fréquente.

La structure des planchers montre de grandes similitudes dans la mise en œuvre : ils se composent de simples solives, larges de 0,15 à $0,20 \mathrm{~m}$, écartées de $0,25 \mathrm{~m}$. Elles sont installées dans le sens de la largeur, sans renfort intermédiaire, sauf dans un cas où F. Guyonnet restitue une poutre longitudinale portée par des piliers (au centre de la parcelle et en façade). Il a, par ailleurs, identifié un cas de combles en mezzanine, ce qui permettait de rendre ces espaces habitables en bénéficiant de la lumière provenant de l'étage inférieur. En revanche, comme à Saint-Mathieu, aucune information concernant la position des escaliers ou les fondations n'a été recueillie.

Les éléments de datation de ces maisons proviennent d'un ensemble de tessons de céramique commune grise et d'un tesson de céramique culinaire vernissée, recueillis dans les murs en terre. Ils sont datés de l'extrême fin du $\mathrm{XIII}^{\mathrm{e}}$ siècle ou du début du XIV ${ }^{\mathrm{e}}$ siècle.

Le principal point de dissemblance relevé concerne les réaménagements dont les maisons ont fait l'objet. En effet, alors que celles de Saint-Mathieu sont toujours restées «simples » au fil des siècles, les habitations de Saint-Jacques font état de plusieurs programmes d'amélioration. Une première phase, datée de la fin du $\mathrm{XV}^{\mathrm{e}}$ siècle ou début $\mathrm{XVI}^{\mathrm{e}}$ siècle, est illustrée par de luxueux aménagements, auquel appartient le plafond peint au $n^{\circ} 4$ de la rue de 1'Anguille. Par la suite, les remembrements effectués aux XVII ${ }^{e}$ et XVIII ${ }^{e}$ siècle, dans des proportions plus ambitieuses (association de quatre, voire six parcelles qui deviennent traversantes) s'accompagnent d'un soin particulier apporté à l'aménagement du premier étage : pose de plafonds à la française au XVII ${ }^{e}$ siècle, recouverts au XVIII ${ }^{e}$ siècle de plafonds en staff, installation de belles cheminées associant le marbre et les gypseries, etc. La qualité de ce nouveau programme est attribuée à l'arrivée d'une population plus fortunée qui remplace les premiers habitants de ce quartier. En revanche, les démembrements opérés au cours du XIX ${ }^{\mathrm{e}}$ siècle, qui ont conduit peu à peu à retrouver le parcellaire initial, témoignent d'une paupérisation croissante du quartier.

\section{CONCLUSION}

On se trouve dans le cas de figure assez connu, d'un quartier mis en place dans le cadre d'une extension de la ville, constitué d'îlots soigneusement découpés en parcelles longues et étroites, rapidement lotis de maisons adossées, couvertes d'un toit à un versant orienté sur rue. Ces maisons sont de type élémentaire, se développant sans doute sur trois niveaux et s'illustrant par un traitement du confort ou du décor réduit à la plus simple expression. En l'absence des façades, elles semblent répondre à un modèle courant, à rares variantes. Les évolutions de ces unités sont sommaires. Elles se manifestent sous forme de réunion de maisons mitoyennes, matérialisée par le percement des portes et se poursuivent souvent par un retour au parcellaire initial et même, dans un cas, à une division du module médiéval. $\mathrm{Ce}$ qui est nouveau sur le quartier Saint Mathieu, toutefois, est la mise en évidence de deux états pour deux des maisons. En effet, les deux parcelles ont, au moins dans un premier temps, été occupées par une construction déjà en pisé, mais de plus petit module et installée en fond de parcelle. Les deux unités ont sans doute été rapidement remplacées par des maisons plus grandes, semblables aux maisons voisines qui occupent l'ensemble de leur parcelle. Toutes emploient la terre selon des mises en œuvre variables : pisé, bauge et bauge coffrée, formule qui, elle aussi, est inédite dans ce secteur.

Les documents d'archives semblent désigner la plupart de ces maisons comme des propriétés d'artisans, mais les sondages n'ont pas mis au jour de vestiges témoignant d'une activité particulière, à l'exception d'un bassin daté du XVI ${ }^{\mathrm{e}}$ siècle. Par analogie avec des modèles de maisons connus ailleurs, on présume que le rez-de-chaussée pouvait être réservé à un usage commercial ou artisanal, et l'étage à l'habitation. Les combles, peut-être aménagés, pouvaient jouer un rôle mixte d'habitation et/ou de stockage. Ces hypothèses relatives à la répartition des espaces ne sont pas neuves et, à ce jour (à Perpignan), ne reposent sur aucun élément formel, que ce soit dans le registre des aménagements spécifiques ou dans celui du décor. Enfin, il semblerait que seules deux maisons aient pu occuper le fond de parcelle, précédées alors par un jardin ou une cour. La majorité semble plutôt la totalité de l'espace disponible de la parcelle, sacrifiant ainsi les espaces ouverts.

Les maisons semblent apparemment toutes d'un standard comparable, mais il est certain que la disparition des façades initiales est préjudiciable à une bonne définition du caractère de chaque unité car elles pouvaient afficher les statuts et les goûts différents des propriétaires (morphologie des fenêtres, présence/absence d'éviers, de latrines). Toutefois, il est tentant de proposer que le programme « sommaire » argumente l'hypothèse d'une construction en série : habitations modestes, associant sans doute espaces de vie et de travail, elles correspondent incontestablement à de nombreux exemples attestés dans le cadre d'autres extensions urbaines. De fait, la mise en évidence de quelques baies aurait permis de mieux caractériser cet habitat d'apparence austère et uniforme que la prédominance de la terre crue comme matériau de construction conduit, inévitablement, à attribuer à une frange modeste de la population perpignanaise. Les raisons ayant présidé au choix de ce matériau sont sans doute multiples, mais il a été souvent constaté que la terre 
répondait parfaitement, dans de nombreuses villes, au besoin de construire rapidement lors de périodes d'expansion démographique et économique, notamment à partir du XIII ${ }^{\mathrm{e}}$ siècle.

Du point de vue historique, l'implantation du quartier Saint-Mathieu de Perpignan est datée avec certitude, par les textes, des années 1240-1280. La datation est corroborée par la présence d'une marmite intégrée dans un mur de fond, caractéristique de cette même période, et, dans une certaine mesure, par l'absence de certains éléments de confort, comme par exemple les cheminées, qui incite à associer cet habitat à une période antérieure au $\mathrm{XIV}^{\mathrm{e}}$ siècle. La mise en évidence de chronologies relatives établies entre quelques murs et la présence d'un premier état pour deux des maisons concourent à démontrer une construction progressive. Il serait toutefois intéressant d'établir si cet étalement sur le XIII' siècle a pu déborder sur le siècle suivant sous la forme de reconstructions ou d'aménagements et, le cas échéant, en conservant l'usage de la terre massive.

L'étude de ces quelques maisons, que l'on pourrait à maints égards qualifier d'expéditive, avait à son heure fait progresser la connaissance d'une forme d'architecture civile urbaine médiévale qui demeurait marginale à Perpignan comme dans l'ensemble du Midi de la France. Depuis, les découvertes se sont multipliées, démontrant sans discussion un usage plus répandu de la terre qu'on ne le pensait il y a encore quelques années. Les constructions de Perpignan non seulement complètent le panel des données sur cette ville avant l'époque moderne, mais enrichissent le corpus des murs en terre du sud de la France en ajoutant un point sur la carte de répartition de la terre banchée dans un secteur où elle n'était pas attestée et en fournissant, de plus, des informations d'ordre technique indispensables pour écrire l'histoire de ce mode de construction.

\section{ANNEXE : PRÉSENTATION SYNTHÉTIQUE DES ÉLÉVATIONS EN TERRE PAR UNITÉ}

Le diagnostic réalisé sur l'îlot Saint-Mathieu a mis en évidence trois grandes phases d'évolution des bâtiments. La première phase correspond au lotissement du quartier et à la construction de maisons en terre à partir de la seconde moitié du XIII siècle. De ces maisons, seules les façades manquent. Les murs mitoyens sont presque toujours conservés ainsi que, dans de nombreux cas, les pentes de toiture, les trous d'encastrement des planchers et des pannes de charpentes. La deuxième phase se manifeste par un remembrement des parcelles médiévales. Cette étape, cependant, ne concerne pas toutes les propriétés. Enfin, la surélévation des maisons primitives, la reconstruction systématique des façades en maçonnerie et, le cas échéant, le démembrement des immeubles réunis s'accomplissent au cours d'une troisième phase, qui s'étend sur toute la période moderne ainsi que la période contemporaine, très souvent.

Cette présentation ne reprend pas les résultats observés au cours du diagnostic de manière exhaustive. Au contraire, seuls les vestiges appartenant aux deux premières phases font l'objet d'une description, ceci au détriment des ultimes étapes de construction et d'aménagement, qui ont dû être négligées.

\section{LE 5, RUE DE L'HÔPITAL}

La maison se développe dans son dernier état sur quatre niveaux (RDC $+2+$ combles inaccessibles), dont deux communiquent avec des volumes inscrits dans la maison mitoyenne située au 29 de la rue du Four-Saint-François. Les étages sont desservis par un escalier à deux volées droites continues, qui se développe contre le mur latéral nord-ouest de la maison.

L'état actuel de l'immeuble, entièrement rénové, ne paraît guère remonter au-delà de la fin du $\mathrm{XIX}^{\mathrm{e}} \mathrm{s}$, voire du $\mathrm{XX}^{\mathrm{e}}$ siècle, comme en témoigne le caractère de sa façade, les planchers refaits et le mur latéral sud-est en briques. Cependant, les sondages ont permis de mettre au jour deux élévations en terre dans le mur du fond et sur le mur latéral nord-ouest. Ces élévations offrent la particularité de former le seul exemple de maison édifiée en grande partie en bauge.

\section{La parcelle}

La maison est installée sur une parcelle orientée sud-est/nord-ouest (fig. 25 et 26). Elle est large de $5 \mathrm{~m}$ par $8,90 \mathrm{~m}$ (dimensions hors œuvre). Par son orientation et ses dimensions, elle se distingue donc très nettement des autres. Le même constat s'impose pour les deux maisons mitoyennes, ce groupe de trois maisons occupant l'équivalent de la surface de deux parcelles médiévales. Or, cette implantation opposée à ce que l'on peut observer sur le reste de l'îlot incite à émettre le postulat qu'elle est le résultat d'un remembrement de tout l'angle méridional de l'îlot. Le principal argument en faveur de cette hypothèse est le constat que les trois maisons qui occupent cet angle sont en grande partie maçonnées en briques. Ces maçonneries sont manifestement le fruit d'une reconstruction de cet ensemble, accompagnée vraisemblablement de modifications du découpage initial. Deux hypothèses peuvent

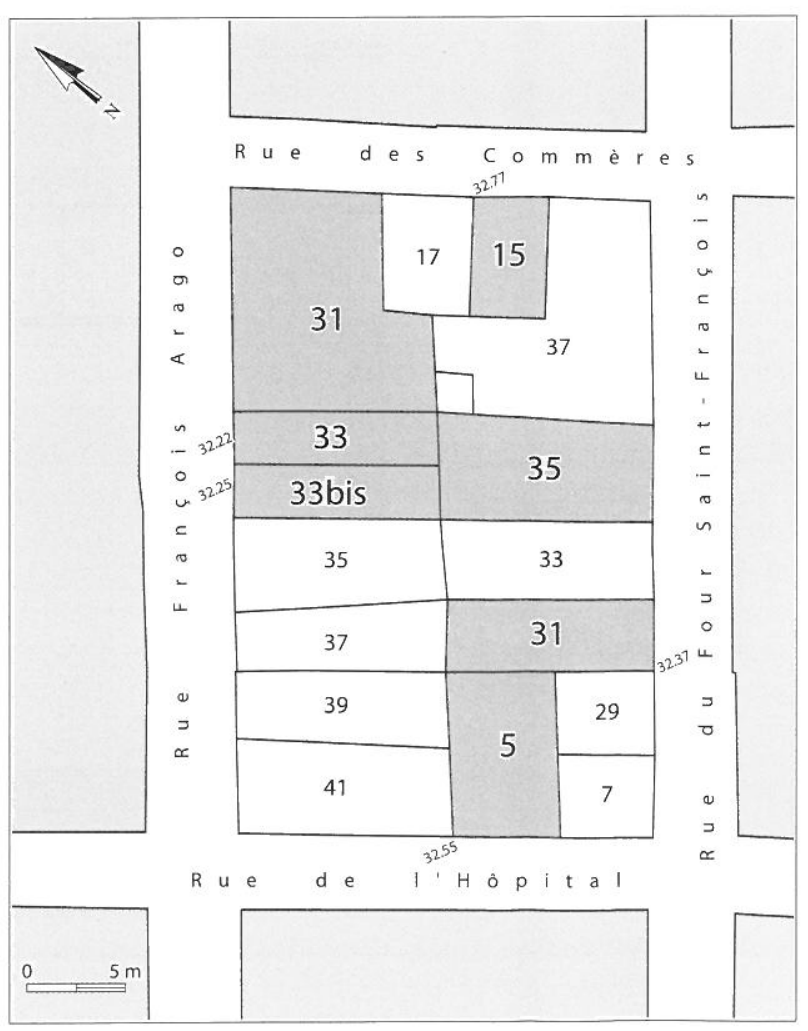

Fig. 25 : Localisation des maisons diagnostiquées au sein de l'îlot (en gris). 


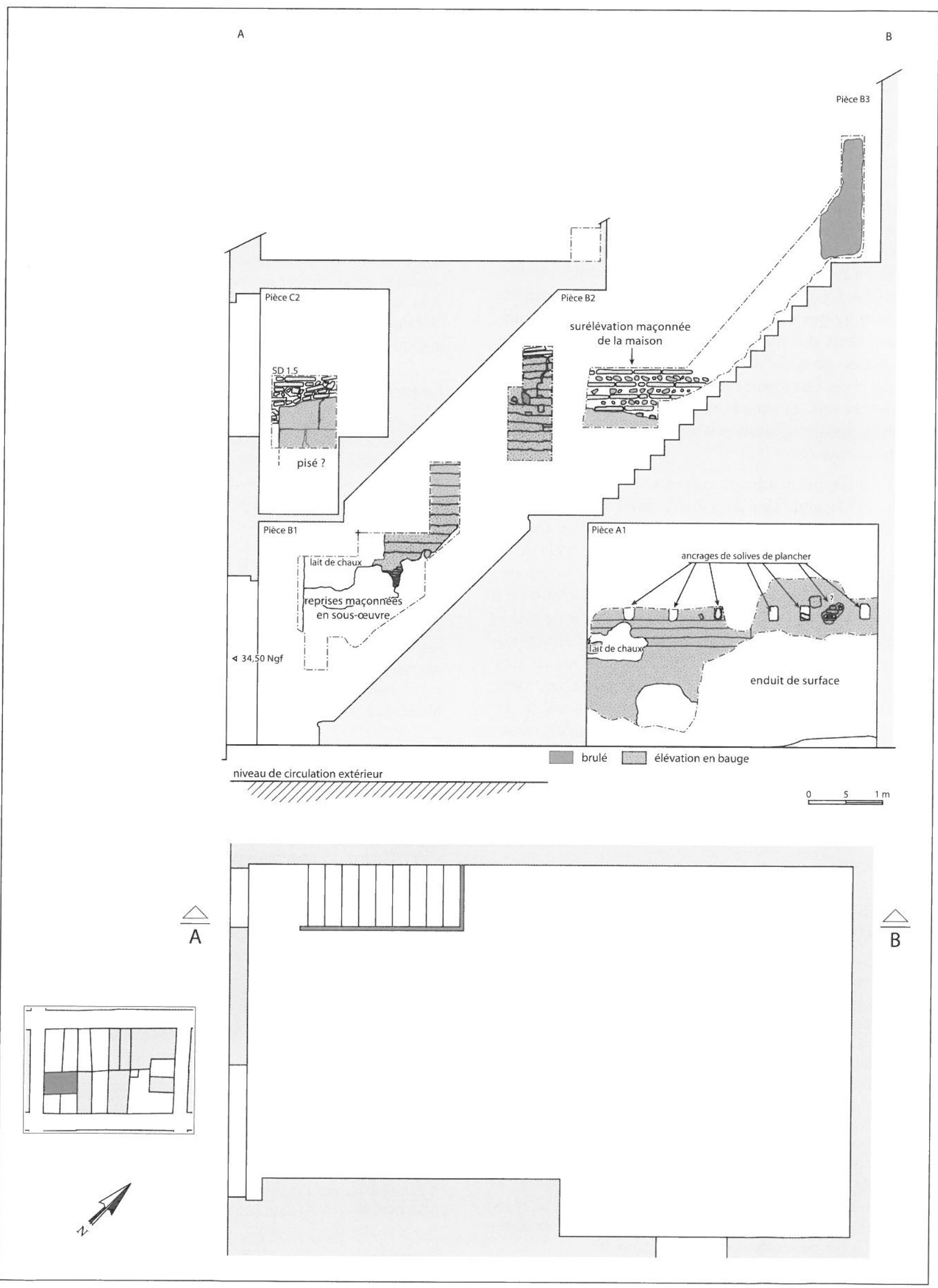

Fig. 26 : Coupe SO/NE et plan actuel de la maison située au 15 de la rue de l'Hôpital. 
dès lors être retenues : la première consiste à imaginer que cette orientation actuelle pérennise le découpage initial ; la seconde, la plus favorable, permet de restituer deux parcelles d'orientation opposée, soit nord-ouest/sud-est, mais respectant alors le découpage en lanière symétrique de l'ensemble de l'îlot.

Dans ce dernier cas, les témoins en terre dégagés dans le mur latéral et du fond correspondraient respectivement à deux murs de fond de deux maisons mitoyennes et à une section d'un mur latéral.

\section{Les élévations en terre}

\section{Les matériaux mis en ouvre}

Le mur de fond (actuel) nord-est est édifié en pisé. Cette élévation en terre se développe sur une longueur maximale de $4,20 \mathrm{~m}$ (pour une longueur maximale du mur de 5,10 m) et a été dégagée sur 2,80 $\mathrm{m}$ de hauteur.

Le mur de terre se développant dans le mur latéral nord-ouest est conservé sur une longueur maximale restituée de 7,70 m et une hauteur maximale conservée de 4,80 m (fig. 26). Il présente l'intérêt d'être entièrement, ou en grande partie, édifié en bauge. Seul l'angle supérieur de l'élévation en terre, en façade, qui est apparu dans un petit sondage établi au niveau 2 de la maison, provoque un doute sur son homogénéité apparente. Cette partie semble, en effet, bâtie en pisé (pièce C2). En témoignent un joint d'assise fin, rectiligne et parfaitement horizontal, l'absence de végétaux ainsi qu'une fissure qui peut s'interpréter comme une limite entre banchées. Toutefois, la surface limitée du sondage et la présence de bauge sur tout le reste de l'élévation conduisent à être prudent sur les conclusions à tirer de ces observations, a fortiori si cette élévation forme initialement les murs de fond de deux maisons mitoyennes.

La bauge est composée de limon sableux, de couleur brun moyen, auquel étaient mélangés quelques graviers et des fragments de tuiles, tous en faibles quantités. Elle est disposée en lits de hauteurs variables $(17 \mathrm{~cm} / 15 \mathrm{~cm} / 11 \mathrm{~cm} / 15 \mathrm{~cm}$, etc. qui semblent constitués de pains ou de mottes. Entre les assises de terre s'intercalent des lits de végétaux plus ou moins visibles, les tiges disposées perpendiculairement au parement. Enfin, la surface des murs était stabilisée par un lait de chaux.

\section{Les indices archéologiques : le plancher}

Un alignement horizontal de 7 ancrages a été mis en évidence dans le mur latéral, au premier niveau (pièce A1). Leurs petites dimensions, leur disposition à intervalles à peu près réguliers, oscillant entre $0,40 \mathrm{~m}$ et $0,60 \mathrm{~m}$ et respectant un plan à peu près horizontal permettent de les identifier comme les emplacements de solives d'un plancher contemporain de la mise en œuvre du mur en terre. Elles étaient portées par une poutre, dont l'emplacement peut être restitué à l'aide d'un négatif de $0,25 \mathrm{~m}$ de côté, apparu dans le mur du fond. Si l'on retient l'hypothèse d'une maison orientée sur la rue du Four-Saint-François, alors ces éléments de plancher invitent à proposer un solivage se développant dans le sens de la longueur et porté par des poutres disposées dans la largeur, ce qui formerait un argument supplémentaire en faveur d'un remembrement de cet angle de l'îlot.

\section{Proposition de restitution de la maison en terre}

Il apparaît hardi, en l'absence de réponses aux questions soulevées par les élévations et l'orientation de la parcelle, de proposer une restitution de la - ou les - maison(s) qui se développai(en)t sur cet espace (fig. 27). Toutefois, la présence de trous d'encastrement de solives de planchers permet quelque

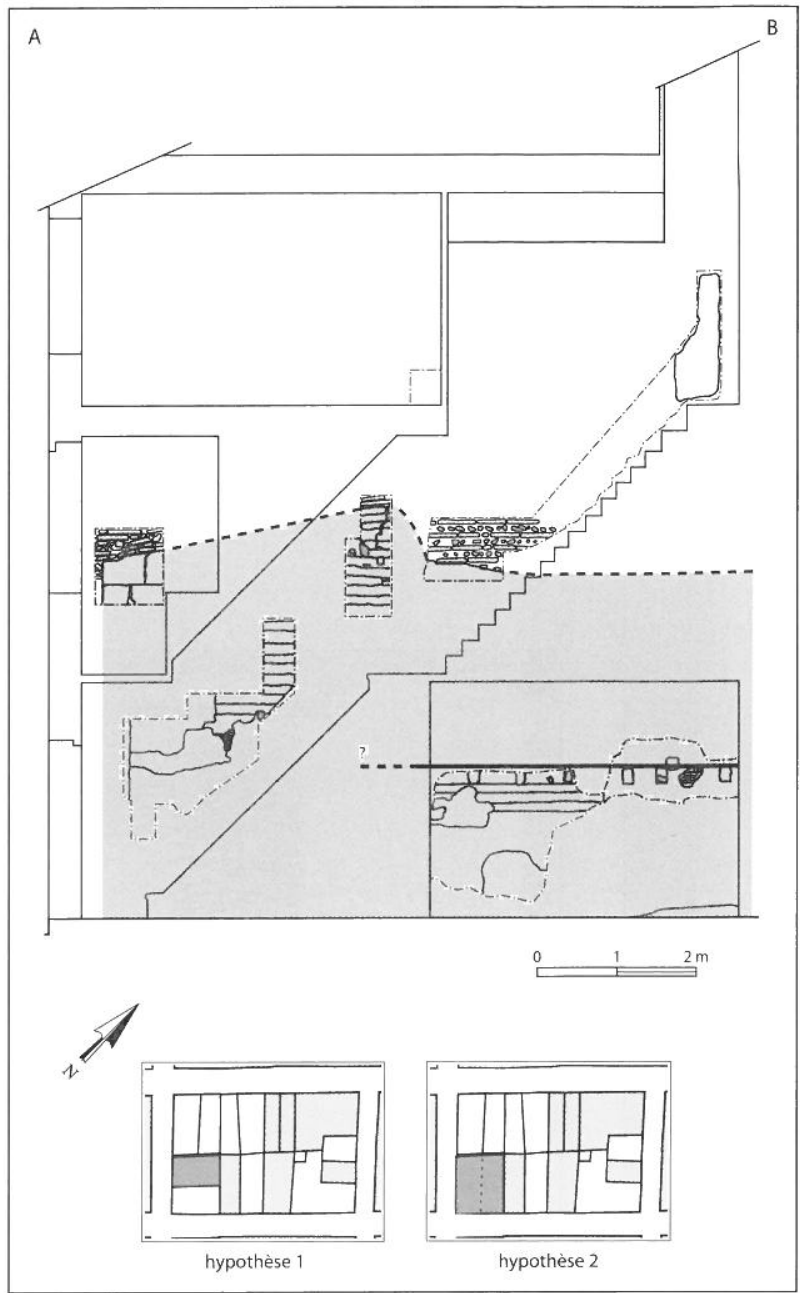

Fig. 27 : Plan et volume conservé des élévations en terre (en gris sur le relevé d'élévation de la maison). En vignette, les deux hypothèses de restitution de l'emplacement de la -ou des-maison(s) médiéval(e)s.

extrapolation : leur situation, à $2 \mathrm{~m}$ du sol actuel, corrélée à la hauteur maximale conservée du mur en terre permet de proposer une maison à 3 niveaux, soit un rez-de-chaussée et un étage surmontés de combles, dans l'hypothèse où la parcelle était tournée vers la rue de l'Hôpital, comme aujourd'hui, soit deux maisons mitoyennes se développant sur au moins deux, voire 3 niveaux, si l'on retient la seconde orientation sur la rue du Four-Saint-François. Cette dernière hypothèse est celle qui est privilégiée.

\section{Les éléments de la stratigraphie}

Sous les couches d'utilisation contemporaine se trouvent deux sols superposés non datés recouverts par de puissants remblais constitués de gravats de démolition. Ces apports comblent un espace souterrain, probablement une cave reprise en sous-œuvre, à la fin du $\mathrm{XIX}^{\mathrm{e}}$ siècle ou au début du $\mathrm{XX}^{\mathrm{e}}$ siècle, Les gravats utilisés proviennent d'un bâtiment construit et réaménagé durant le $\mathrm{XVI}^{\mathrm{e}}$ siècle et le XVII siècle. Ce bâtiment est alors détruit en totalité ou en grande partie. En témoignent les matériaux présents parmi lesquels figurent à la fois des éléments d'appareillages de murs (briques et galets), des carreaux de pavements de tailles diverses, des plâtres de plafond portant la trace de l'armature en roseaux, des fragments d'enduits muraux peints et des éléments de canalisations de terre cuite. 


\section{LE 31, RUE DU FOUR-SAINT-FRANÇOIS}

La maison s'élève sur 5 niveaux, un rez-de-chaussée surmonté de deux étages d'habitation transformés en appartements, et de combles aménagés. Chaque étage est desservi par un escalier droit à deux volées, isolé dans une cage, flanqué contre l'élévation nord-est de la maison.

Le diagnostic a permis d'enrichir notre corpus par la mise au jour, sur les murs du fond et latéral sud-ouest, d'élévations illustrant deux types de mise en œuvre : malgré un état de conservation peu satisfaisant, il a été possible d'établir que la terre se présentait sur les deux premiers niveaux de la maison sous forme de pisé et que lui succédait une élévation en bauge. Plusieurs éléments semblent indiquer que ces deux élévations résultent de plusieurs phases de construction pour cette seule maison ou de deux phases successives de constructions correspondant à l'édification de deux maisons mitoyennes. Toutefois, il semble difficile d'émettre quelque certitude en ce qui concerne cette question, le diagnostic n'ayant porté que sur un seul mur longitudinal.

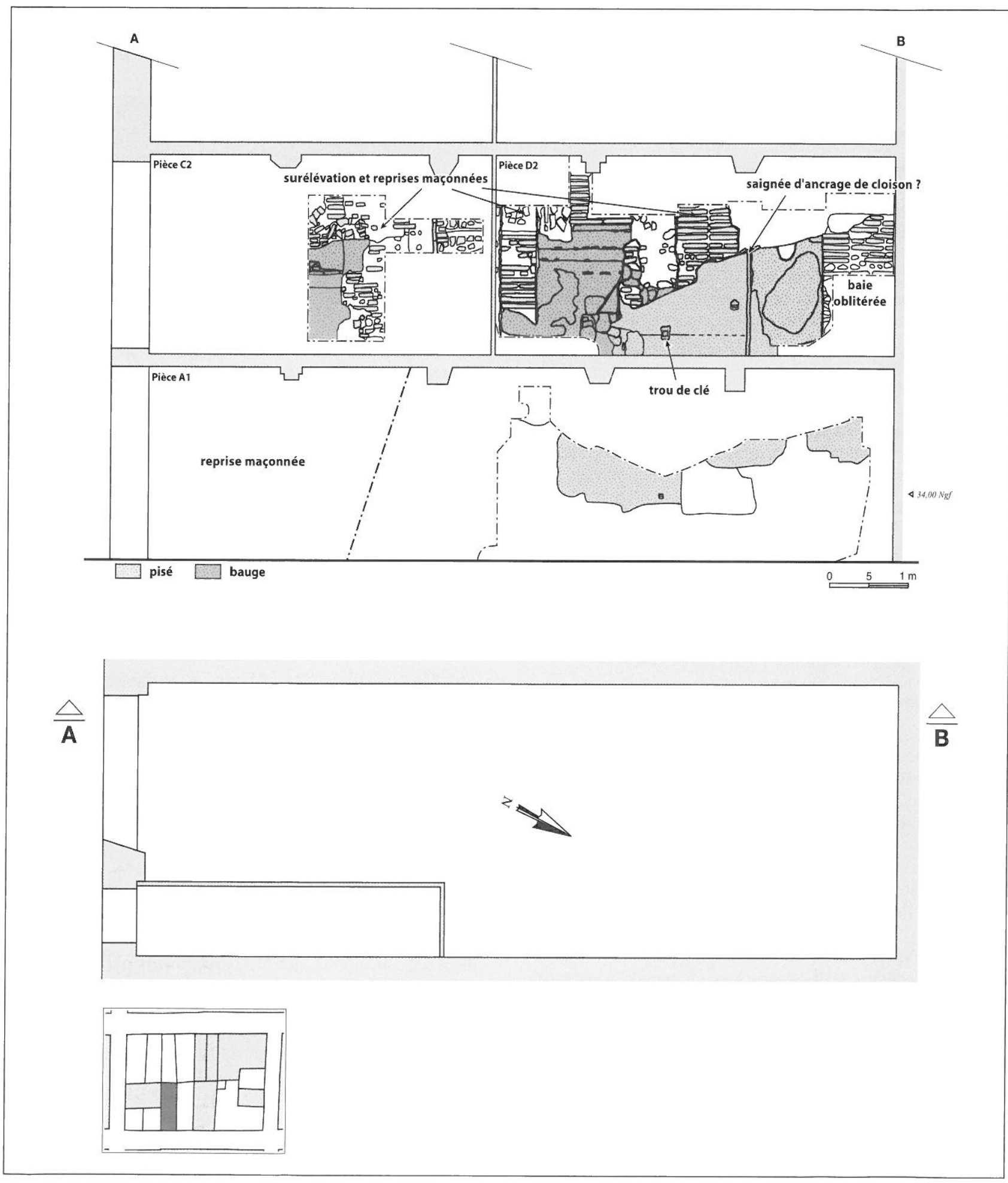

Fig. 28 : Coupe SE/NO et plan actuel de la maison du 31 de la rue du Four-Saint-François. 


\section{La parcelle}

La maison est construite sur une parcelle rectangulaire, orientée sud-est/nord-ouest (fig. 25 et 28). La largeur, réduite à $3,20 \mathrm{~m}$ hors œuvre (pour 9,65 m de longueur) fait de cette parcelle et de celle qui lui est adossée les plus étroites de l'îlot.

\section{La maison en pisé (la maison 1)}

\section{Les matériaux mis en ouvre}

Les murs du premier niveau et d'une partie du second sont constitués de terre banchée. Elle a été mise en évidence sur le mur du fond et une partie du mur latéral sud-ouest (fig. 28).

Le mur du fond est construit en pisé. Bien que très mal conservé, il a été observé sur une hauteur maximale de $4 \mathrm{~m}$ environ.

Sur le mur latéral, le pisé n'a été dégagé que sur une hauteur maximale d'environ $3 \mathrm{~m}$ et longueur maximale de $4 \mathrm{~m}$. Au-delà de cette distance, sur la moitié antérieure de la maison, l'élévation en terre laisse place à une maçonnerie appartenant soit à la reconstruction de tout l'angle sud de l'îlot soit à une reprise en sous-œuvre de grande ampleur. Une partie de la surface est altérée par un piquage puis recouverte par un lait de chaux ou de plâtre permettant de freiner son effritement, ensuite habillée par des enduits de chaux à décor de badigeon colorés. Trois ancrages, par leur situation en limite de banchée, ont pu être identifiés comme des trous de clef.

La relation stratigraphique, entre le mur du fond et le mur latéral n'est pas établie, en raison d'une reprise maçonnée localisée dans l'angle.

\section{Les indices archéologiques : les ancrages de charpente et de plancher, les divisions intérieure, une baie}

À l'étage (pièce D2), à environ 3,50 m du rez-de-chaussée actuel, le mur affecte une forme trapézoïdale à sommet oblique irrégulier, correspondant à une pente de toit de $14^{\circ}$ orientée vers la façade. En partie haute et à 1,30 m de l'angle de la maison se trouve un ancrage de panne de charpente, de forme circulaire et oblitérée à l'aide d'une maçonnerie.

À 1,80 m de l'angle, une saignée verticale, profonde de $2 \mathrm{~cm}$ (profondeur initiale qu'il faut majorer en raison de la surface piquée) et large de $4 \mathrm{~cm}$, se développe jusqu'à la pente de toit, soit sur une hauteur maximale de 1,20 m. Elle a été interprétée comme le négatif de l'ancrage d'une cloison légère.

Une baie, mise au jour à l'extrémité occidentale de l'élévation, au contact de l'angle formé avec le mur du fond, peut être interprétée soit comme une porte illustrant la réunion de deux parcelles mitoyennes soit comme une niche au sol. Son interprétation n'a pas pu être fixée, faute de moyen d'ôter une partie du bouchon maçonné qui la condamne ${ }^{24}$. L'hypothèse de la niche semble la plus vraisemblable, en raison de son apparente contemporanéité avec l'élévation de terre. Le caractère souvent discutable des relations stratigraphiques, inhérent à la nature même du matériau, permettant des découpes plus ou moins soignées, conduit toutefois à rester prudent. Le piédroit est situé à $0,93 \mathrm{~m}$ du mur du fond et présente une hauteur maximale d'1,33 m. Son niveau de seuil n'est pas repéré et la nature du linteau inconnue. Un petit test réalisé dans le bouchage maçonné a permis de mettre au jour un décor formé d'un badigeon coloré gris clair posé sur un mortier de chaux très fin, de couleur blanc-grisâtre. Conservé uniquement dans l'embrasure, il pourrait être l'ultime témoin du décor initial de la pièce.
Le reste des informations livrées par ces élévations se compose d'ancrages qui, à l'exception des trous de clef, n'ont pu être interprétés de manière toujours satisfaisante. Le mur du fond du rez-de-chaussée, par exemple, a livré la moitié inférieure d'un ancrage, situé dans l'axe du mur, au niveau d'une poutre posée en renfort sous les solives du plafond actuel. La présence, dans son colmatage, de trois briques empilées et liées au mortier, évoque les assises d'amortissement qui accompagnent les poutres portant les solives. Cependant, son orientation, dans le sens de la longueur, donne matière à discussion.

\section{La proposition de restitution}

Les vestiges appartenant à cette maison suscitent de nombreuses interrogations, en raison de leur mauvais état de conservation. Il est toutefois possible de restituer une construction au niveau du pignon de $4 \mathrm{~m}$ de hauteur, ce qui correspondrait à deux niveaux, soit un rez-de-chaussée surmonté de combles, probablement aménagés (fig. 29). Certains éléments, comme la possible cloison légère ancrée dans une saignée peu profonde permettant de diviser les volumes, et la baie, qui peut être identifiée comme une niche au sol, argumentent en faveur de cette hypothèse. Les deux niveaux étaient sans doute séparés par un plancher dont le seul témoin recueilli est un trou d'encastrement de poutre observé dans l'axe du mur du fond. Toutefois, maintenir cette interprétation induit que la poutre se développait dans le sens de la longueur. Cette orientation conduit à émettre la proposition d'un plancher établi sur un système de croisement de poutres maîtresses portant des poutres secondaires, se substituant aux solives. Ou bien, et c'est l'hypothèse qui semble la plus crédible, faut-il restituer une maison se développant sur une longueur plus réduite d'environ $4 \mathrm{~m}$. La projection de la pente de toit jusqu'à une façade en bordure de rue conduirait à restituer une maison haute de moins d'1,50 m, ce qui paraît invraisemblable. La proposition d'une maison plus petite que les maisons mitoyennes et installée en fond de parcelle est donc celle qui est privilégiée. Dès lors, l'hypothèse d'un plancher formé de poutres se développant dans le sens de la longueur et portant un solivage disposé dans le sens de la largeur ne pourrait plus être exclue.

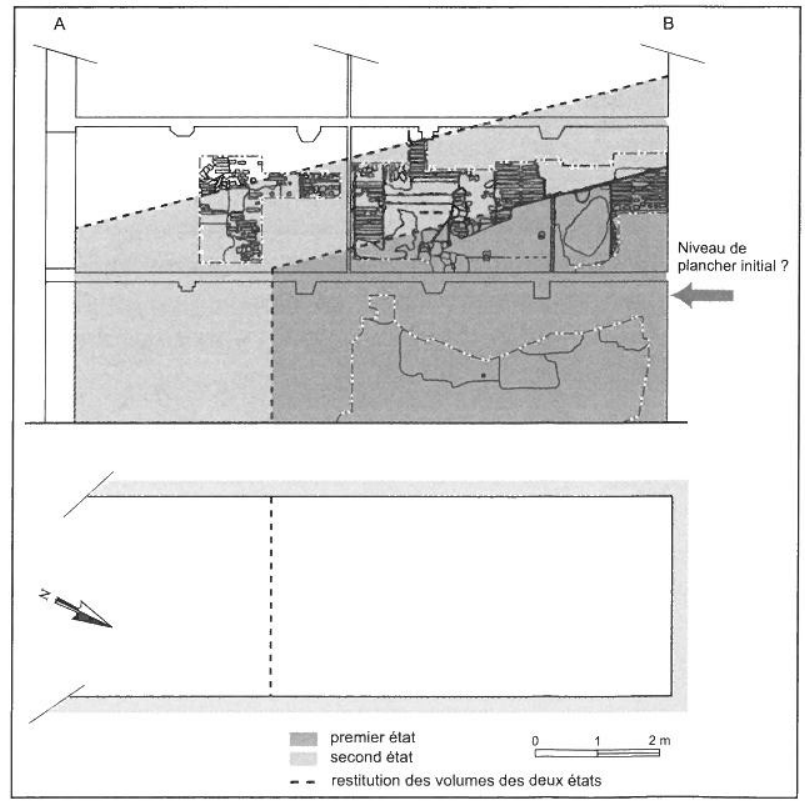

Fig. 29 : Plan et proposition de restitution du volume de la maison médiévale, dans les deux états observés. 
La surélévation en bauge : agrandissement de la maison en pisé ou construction de la maison mitoyenne ? (la maison 2)

La surface irrégulière de la pente de toit de la première maison en pisé semble conforter l'hypothèse d'une destruction précoce de celle-ci, conduisant à son remplacement par une maison de plus grande ampleur, matérialisée par l'élévation en bauge qui coiffe la première élévation en terre. Une seconde hypothèse, qui consiste à suggérer que l'élévation en bauge corresponde à l'édification de la maison mitoyenne, ne peut être exclue en l'absence de tout autre indice et en raison des reprises maçonnées importantes observées sur l'ensemble de l'élévation. De fait, le mur en bauge n'a été mis au jour qu'au niveau de l'étage, sous le forme de tronçons discontinus d'une hauteur maximale d'1,50 m.

\section{Les matériaux mis en ouvre}

La terre utilisée est un mélange de limon sableux brun soutenu et de gros éléments (cailloutis, graviers, fragments de terre cuite), de végétaux et de bois (pièce $\mathrm{C} 2$ ). Elle est disposée en lits de terre continus, de hauteurs très variables $(9 \mathrm{~cm} / 20 \mathrm{~cm} / 15 \mathrm{~cm} / 9 \mathrm{~cm}$, etc.). On ne distingue pas de pains. De gros fragments de tuiles placés horizontalement, auxquels se mêlent des végétaux (bruyère ?) et de la chaux, sont intercalés entre les lits de terre.

\section{La proposition de restitution}

Deux interprétations ont déjà été évoquées. La première est que cette construction en bauge forme une surélévation, destinée à transformer la maison en pisé à deux niveaux en maison à trois niveaux $(\mathrm{R}+1+$ combles $)$. La seconde interprétation, qui consiste à proposer que ces vestiges appartiendraient à la maison mitoyenne, légèrement postérieure à la petite maison qui occupe cette parcelle, semble contredite par son installation sur un solin partiellement détruit. C'est donc la première hypothèse qui est retenue, malgré l'absence d'arguments très convaincants.

\section{Les éléments de la stratigraphie}

Dans le sondage ouvert au rez-de-chaussée, sous les sols d'utilisation contemporaine réalisés à l'aide de briques cuites posées sur une chape de mortier de chaux figurent les restes arasés d'un dépotoir également d'époque contemporaine, ainsi qu'une fosse et un remblai non datés. Ce dernier, à base de limons contenant de rares éléments anthropiques (petits fragments de briques et nodules de mortier de chaux), est recoupé par la tranchée de fondation de deux murs aboutés, réalisés en galets liés au mortier de chaux, qui pourraient former le soubassement du mur de pisé se développant au fond de la maison. Malheureusement, l'absence de mobilier archéologique ne permet pas de dater leur fondation.

\section{LE 35, RUE DU FOUR-SAINT-FRANÇOIS}

Cette parcelle est occupée par une maison qui se distingue par la qualité et le programme de sa façade. La maison se développe sur cinq niveaux, soit un rez-de-chaussée, surmonté de trois appartements indépendants, par étage, et de combles aménagés en logement qui se prolonge en terrasse en bordure de rue. Les appartements sont desservis par un grand escalier tournant, situé au bout d'un long couloir placé au revers de la porte d'entrée. La façade s'organise sur un rythme de deux travées de fenêtres légèrement cintrées. Le premier étage est éclairé par des portes-fenêtres protégées par des balconnets que supportent de fausses consoles moulurées. Au dernier niveau, une terrasse est close par une balustrade dont la tablette et les balustres, à panse galbée en demi-cœur, sont en terre cuite. La façade témoigne du soin apporté à son ornementation, unique sur l'îlot. Elle est recouverte par une épaisse couche de mortier de chaux, dans lequel sont creusés des joints dessinant un faux grand appareil. L'enduit recouvre les piédroits et les linteaux en briques des baies pour former des encadrements moulurés. Autour des fenêtres, les moulures sont interrompues par une fausse clef en bossage. Enfin, la façade est couronnée par une corniche moulurée où l'utilisation du répertoire décoratif antique (oves, denticules, acanthes) permet de faire remonter sa construction à la deuxième moitié du XVIII' siècle.

\section{La parcelle}

La parcelle est légèrement trapézoïdale. L'immeuble se développe sur une longueur de 9,90 m et une largeur atteignant 4,95 m (dimensions hors œuvre), ce qui permet de le qualifier comme la plus spacieuse de l'îlot (fig. 25 et fig. 30 ).

\section{La maison en pisé}

\section{Les matériaux mis en cuvre}

Les élévations en terre n'ont été mises en lumière, pour l'essentiel, qu'aux niveaux des deux premiers étages, en raison d'une vaste reprise en sous-œuvre occupant tout le rez-de-chaussée (fig. 30).

Les murs longitudinaux ont été dégagés sur la totalité de la longueur du mur latéral sud-ouest et sur une seule moitié du mur opposé (pièces C2 et D2). Les élévations en terre n'ont été étudiées qu'au niveau de l'étage, les parties inférieures étant reprises en sous-œuvre tandis qu'au-dessus prennent place les surélévations modernes. Les deux murs latéraux montrent une quasi parfaite symétrie qui atteste de leur construction simultanée. En revanche, la mise en lumière des relations stratigraphiques entre les murs latéraux et le mur du fond a permis d'établir que cette maison a été édifiée postérieurement à la maison mitoyenne, contre laquelle elle prend appui.

Le pisé est composé de limon brun clair, avec quelques graviers et des petits galets. Les élévations sont recouvertes de lait de plâtre ou de chaux. Des limites de banchées, horizontales et verticales, sont visibles, notamment grâce à la présence de quelques trous de clef carrés, de $9 \mathrm{~cm}$ de côté.

L'élévation des deux murs latéraux se compose d'une première assise de forme légèrement trapézoïdale, en raison de la pente de toit. Elle comporte une limite verticale entre deux banchées (longueurs respectives : $\geq 0,38 \mathrm{~m}$ et $2,92 \mathrm{~m}$ ). Les lits de damage sont assez nets, d'abord horizontaux (vers la façade), puis s'épaississent progressivement vers le fond de la salle pour conférer à l'assise un sommet oblique. La deuxième assise accuse une forme franchement trapézoïdale (hauteur : 0,34 m à gauche, majorée à $0,78 \mathrm{~m}$ à droite). Ses lits de damage sont obliques.

Le mur du fond, qui appartient à la maison mitoyenne (le 33/33b de la rue Arago : infra), est construit en pisé jusqu'au deuxième étage, formant une élévation maximale d'un peu plus de $6 \mathrm{~m}$ de hauteur. Il se découpe en trois registres superposés.

Sur $4 \mathrm{~m}$, le pisé se compose de terre limoneuse brune, à abondantes inclusions de graviers, de cailloutis, de végétaux, de quelques fragments de terre cuite et de rares galets.

Au-delà des $4 \mathrm{~m}$ prend place une élévation en bauge très fragmentée élevée à l'aide de pains de terre, d'une hauteur maximale de $0,90 \mathrm{~m}$ et interprétée comme une reprise ponctuelle d'une zone altérée. Les pains de terre sont de formes irrégulières et de tailles variées, disposés en assises presque horizontales de hauteurs inégales (entre 8 et $13 \mathrm{~cm}$ ). Les mottes ont dû être déposées à l'état plastique assez humide, ce qui explique leur 
A
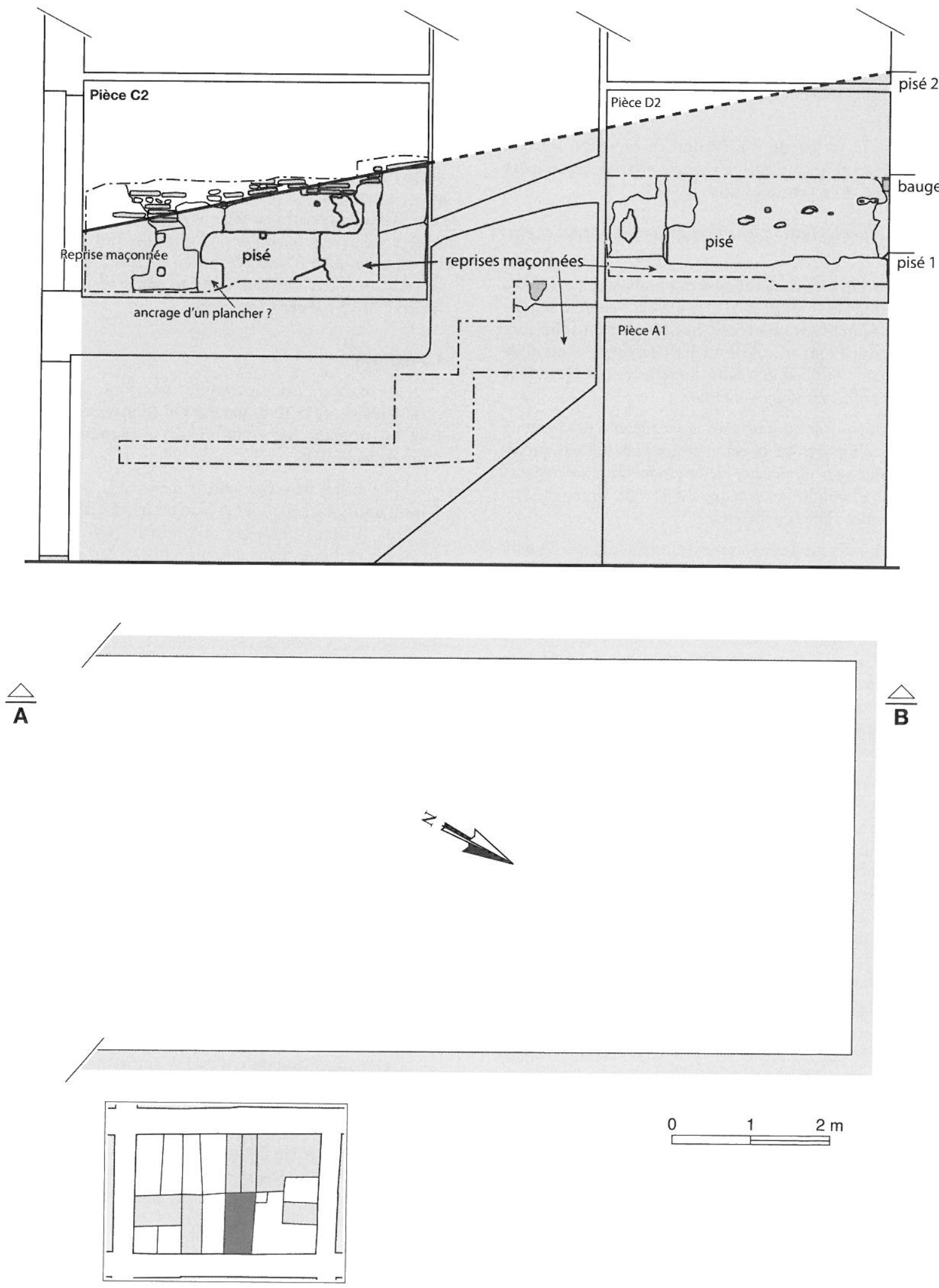

Fig. 30 : Proposition de restitution du plan et élévation de la maison médiévale située au 35 de la rue du Four-Saint-François. 
aspect «mou », l'absence de module et le fait qu'elles se soient agglomérées entre elles pour constituer les « assises ». Le retrait des argiles, qui s'est produit uniquement au niveau du parement, met les pains de terre en évidence mais, à l'intérieur du mur, ils sont étroitement soudés les uns aux autres. Des lits de végétaux s'intercalent entre les assises de terre, tiges et brindilles placées perpendiculairement au parement et sans doute retaillées (bruyère ?). Par endroits, elles forment des paquets plus fournis qui comblent les vides entre les mottes. Le matériau constitutif est un limon brun, très dur mais friable, contenant des graviers en abondance.

Au-dessus de la bauge, l'élévation se prolonge sous la forme, à nouveau, de pisé. Cette élévation conserve un parement en bon état avec deux possibles trous de clef.

\section{Les indices archéologiques: les ancrages de charpente et une baie}

Le sommet des élévations en pisé des murs latéraux affecte une pente de toit de l'ordre de $11^{\circ}$, la classant comme la plus faible parmi les maisons observées. Les traces d'un solin sont conservées sur une longueur de $0,40 \mathrm{~m}$. Il est formé d'un lit de mortier de chaux, qui habille l'arase supérieure des élévations latérales et déborde sur l'angle interne.

Deux ancrages mis au jour dans le mur latéral nord-est, en raison de leur situation sur la pente de toit, ont été interprétés comme des ancrages de poutres de la charpente. Les négatifs sont de forme circulaire de presque $0,40 \mathrm{~m}$ de large, situés à 3,60 $\mathrm{m}$ des angles situés en façade.

Parmi les nombreux autres accidents, parmi lesquels figurent en première place les abondantes reprises maçonnées qui illustrent de multiples phases d'interventions destinées à consolider ou boucher, il est difficile de retenir ceux qui livrent une information utile à la restitution de la maison en terre. Un seul bouchage, pour sa forme régulière, de $30 \mathrm{~cm}$ de côtés, et sa situation, à environ 3,50 m du rez-de-chaussée actuel, a retenu l'attention. Il a été interprété, mais de manière discutable, comme le bouchon condamnant le trou d'encastrement d'une poutre de plancher.

Enfin, sur le mur de fond du rez-de-chaussée (pièce A1), une baie oblitérée et effacée derrière une maçonnerie formant un épais placage maçonné destiné à consolider le mur de terre a été mise au jour. Elle est située à la base du mur, contre l'angle occidental. Ses piédroits ne sont pas construits. Le linteau est formé par une grande poutre équarrie, longue de 1,70 m et épaisse de $0,22 \mathrm{~m}$. Cet ouvrage, peut-être une niche, est contemporain de l'élévation en terre.

\section{La proposition de restitution}

La projection de la pente de toit dégagée sur les murs latéraux permet de restituer une maison haute d'un peu moins de $6,50 \mathrm{~m}$, au niveau du faîtage et de $4 \mathrm{~m}$ en façade. Malgré l'absence de témoins fiables permettant de restituer les niveaux de circulation intérieurs, il est possible de proposer l'existence de deux niveaux, surmontés de combles.

\section{Les éléments de la stratigraphie}

Sous les sols d'utilisation contemporaine se trouvent deux remblais limoneux successifs non datés, pouvant avoir été utilisés comme des sols. Pour la période antérieure, l'espace du sondage est occupé par un bassin maçonné, bâti au moyen de galets de rivière et de fragments de briques de terre cuite, presque entièrement creusé dans le terrain naturel et muni d'un enduit intérieur d'étanchéité. Le petit module de briques employé, qui accompagne habituellement le grand module du
$\mathrm{XVI}^{\mathrm{e}}$ siècle, permet de proposer ce siècle comme période de construction. Il est abandonné et rapidement comblé au moyen de gravats de démolition également au XVI ${ }^{\mathrm{e}}$ siècle comme en témoigne une petite série céramique comprenant des éléments de vaisselier à revêtement stannifère orné d'un décor couvrant au pinzell pinta en provenance des ateliers de Barcelone.

\section{LE 15, RUE DES COMMÈRES}

Cette maison et sa voisine, sises respectivement au 15 et au 17 de la même rue, se distinguaient très nettement des autres, tant par leur plan que par leur orientation. Cette situation et l'organisation de l'ensemble permettait de raisonnablement suspecter un remembrement et sans doute une reconstruction plus ou moins importante de la partie nord-est de l'îlot. Malgré le postulat de départ peu favorable à la découverte de murs en terre, le diagnostic a livré des informations très satisfaisantes par la mise au jour d'une élévation en pisé, trouvée dans un remarquable état de conservation, sur le mur du fond de la maison du 15 rue des Commères.

\section{La parcelle}

La maison est construite sur une petite parcelle rectangulaire, de $5,30 \mathrm{~m}$ par 3,90 $\mathrm{m}$ (dimensions hors œuvre). Elle est orientée, au contraire de la plupart des parcelles, nord-est/sud-ouest.

Elle s'insère dans une vaste parcelle en L, (le 37 de la rue du Four-Saint-François), dont le plan est le fruit d'une association de deux longues parcelles mitoyennes (fig. 25 et 31 ). Les sondages pratiqués dans un mur mitoyen ont permis d'établir l'existence d'une élévation en terre séparant deux maisons initialement installées sur des parcelles en lanière orientées vers la rue du Four-Saint-François. La morphologie actuelle des deux parcelles de cet angle de l'îlot est donc le résultat de l'association des deux maisons, dans un premier temps, suivi de leur démembrement, permettant de dissocier une petite surface correspondant à la maison orientée sur la rue des Commères.

\section{L'élévation d'une maison en pisé}

\section{Les matériaux mis en ouvre}

L'élévation en pisé est observée sur une hauteur maximale conservée de près de 7,80 m et sur la totalité de la largeur de la maison (fig. 31 et 32). Malgré un indéniable excellent état de conservation, elle montre sur la toute la hauteur des traces de forte combustion, produites par un incendie. Ces traces sont particulièrement nettes au deuxième niveau (pièce $\mathrm{D} 2$ ), où la terre est brûlée. C'est sans doute ce qui a favorisé l'excellente conservation du parement : les négatifs des planches du coffrage utilisé pour la mise en œuvre sont parfaitement lisibles en surface et le gobetis dont elle était recouverte est préservé.

La longueur, toutefois, n'est pas suffisante pour livrer toutes les informations nécessaires à la bonne lecture de la mise en œuvre de la terre. Ainsi une seule limite verticale entre deux banchées a-t-elle été repérée à mi-distance du mur, au second niveau. En revanche, la hauteur des assises peut être restituée à $1 \mathrm{~m}$, car leurs limites sont indiquées par des trous de clef, trois ayant pu être observés sur la totalité de la hauteur grâce au soin apporté à leur ouvrage.

Les indices archéologiques: les ancrages d'un plancher et d'un élément de la charpente, une clavette plantée dans la terre

Quatre ancrages alignés, situés à $0,60 \mathrm{~m}$ de la limite supérieure (pièce C3) de l'élévation en terre, ont été identifiés comme les trous d'encastrement de solives d'un plancher 


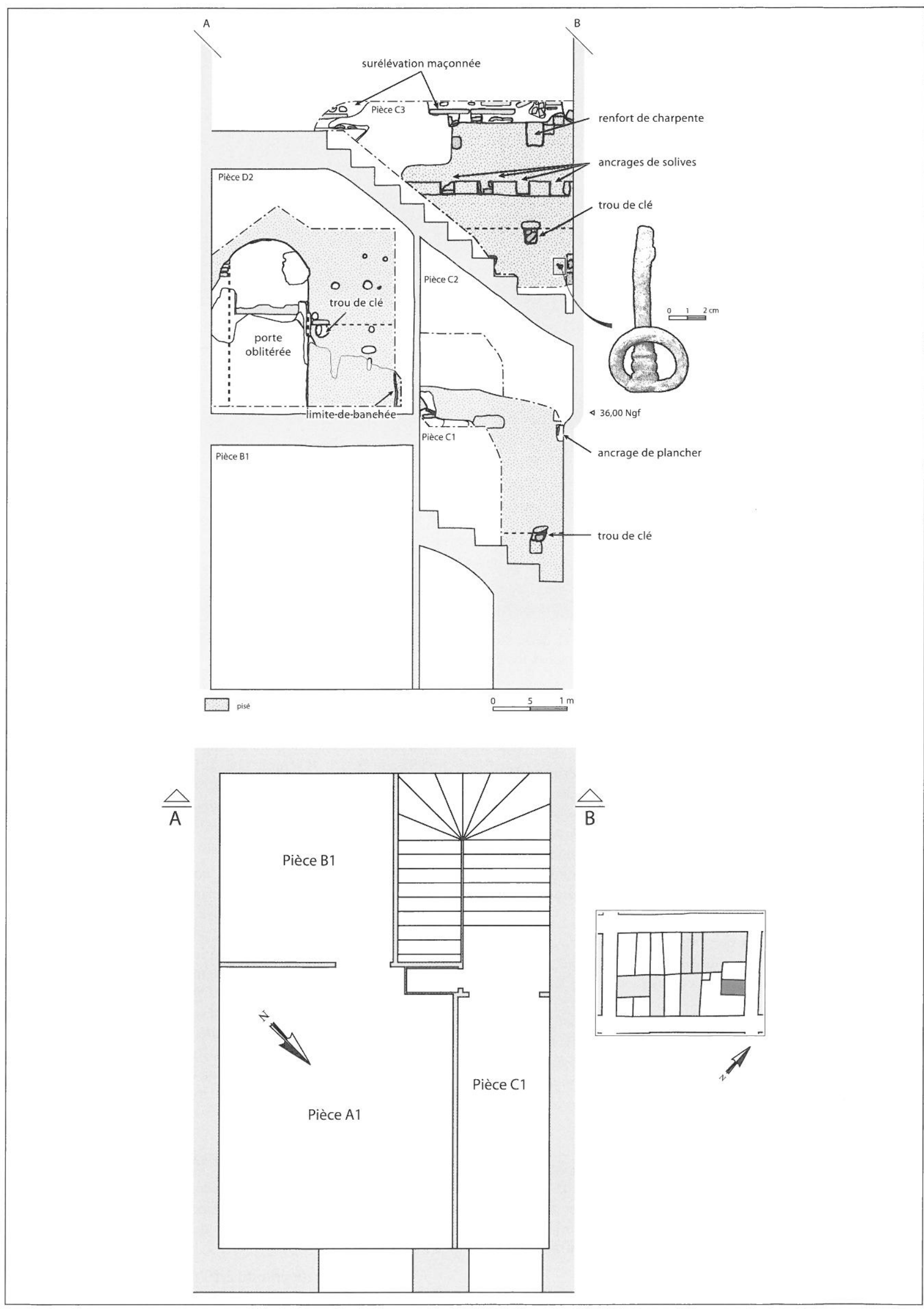

Fig. 31 : Plan et coupe SE/NO de la maison située au 15 de la rue des Commères. 


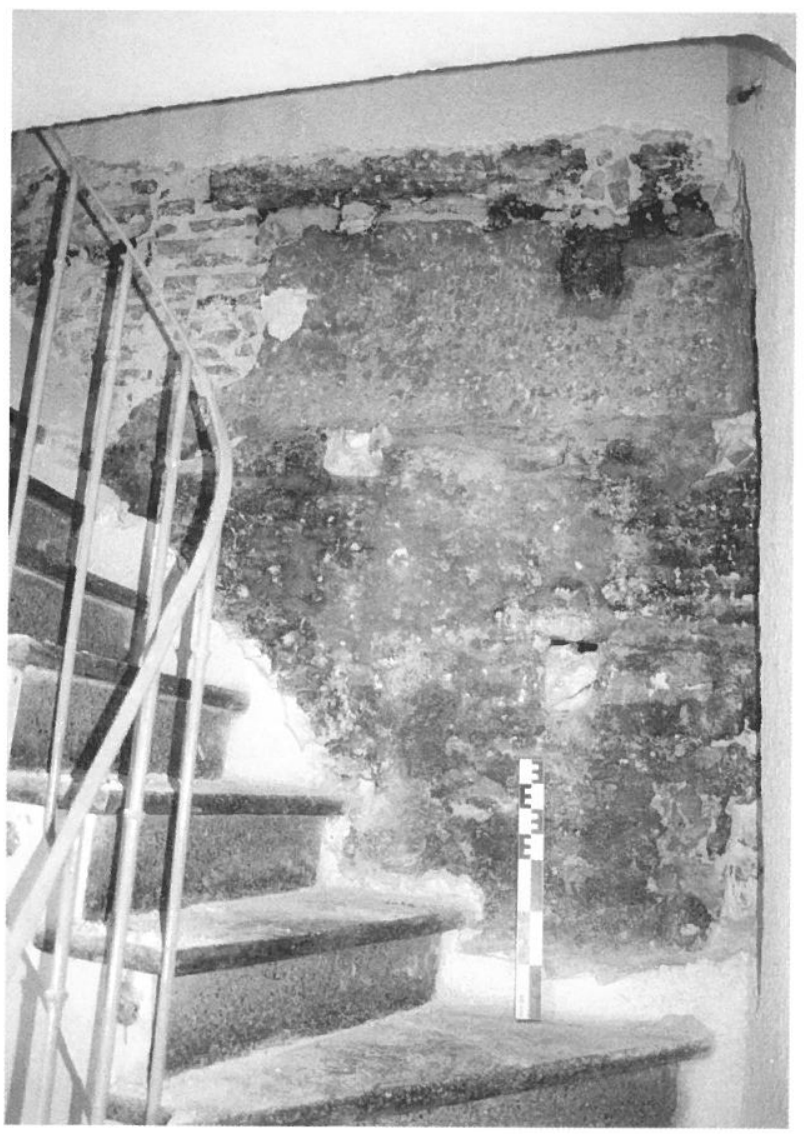

Fig. 32 : Vue de l'élévation en pisé de la maison du 15 de la rue des Commères. Les bouchons appartiennent aux trous de clé.

séparant deux étages, probablement un niveau d'habitation et des combles.

Un autre ancrage a été découvert à la limite supérieure de la partie en terre. Sa faible profondeur de $2 \mathrm{~cm}$ peut être majorée de $0,20 \mathrm{~m}$, en raison du démaigrissement accompli sur la partie supérieure de l'élévation en terre. Il mesure $0,30 \mathrm{~m}$ de hauteur pour $0,15 \mathrm{~m}$ de largeur. La carbonisation du fond atteste qu'il appartient à un aménagement antérieur à l'incendie et sa situation conduit à l'interpréter comme l'ancrage d'un renfort de la charpente.

Une clavette en fer a été dégagée à l'étage, à quelques centimètres de l'angle occidental. Elle a été trouvée grossièrement à plat, la tige fichée dans la terre, pliée et brisée à $9 \mathrm{~cm}$. À son extrémité, elle portait un anneau retourné et écrasé contre le parement. Cet objet pourrait avoir été accidentellement mélangé à la terre, mais sa position, tige plantée dans la terre et rabattue contre la paroi de terre, évoque assez un objet en place et écrasé lorsqu'il n'est plus d'utilité avant d'être noyé dans le nouvel enduit de recouvrement.

\section{La proposition de restitution}

Le mur découvert au 15 de la rue des Commères forme sans doute un vestige du mur séparatif entre les deux longues parcelles occupant à l'origine l'angle oriental de l'îlot, avant leur rassemblement (fig. 33). Les différents témoins mis au jour permettent de préciser l'élévation de cette maison possédant deux façades sur rue.

La largeur de la parcelle, qui se situait initialement entre $5 \mathrm{~m}$ et $5,50 \mathrm{~m}$ pour une longueur de l'ordre de $10 \mathrm{~m}$, la classe parmi les plus grandes. C'est aussi le cas si l'on considère l'élévation,

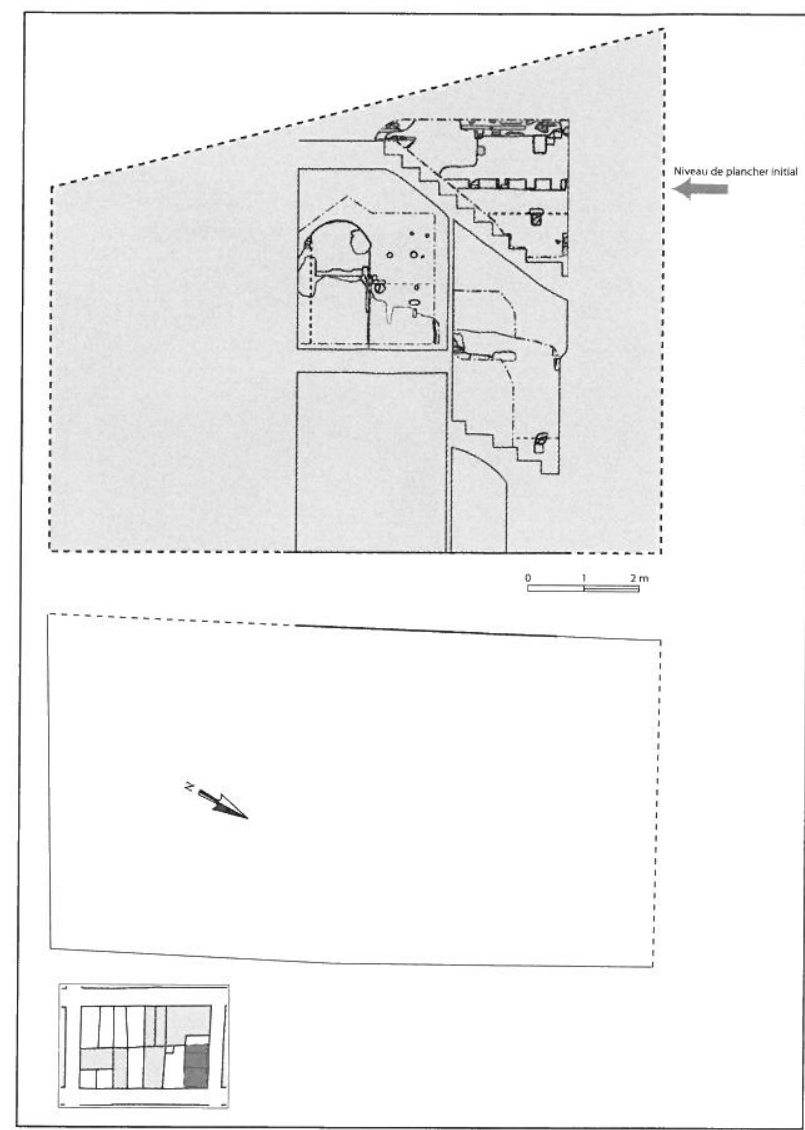

Fig. 33 : Plan et proposition de restitution du volume de la maison médiévale.

qu'il faut majorer de près d' $1,50 \mathrm{~m}$, ce qui porte la hauteur maximale à environ $9 \mathrm{~m}$ au niveau du pignon, pour une hauteur en façade de $6 \mathrm{~m}$. Il semble plus difficile, en absence de témoins associés aux niveaux de circulation inférieurs, de déterminer l'emplacement exact des planchers divisant le reste du volume de la construction. Il semble toutefois possible de suggérer que les hauteurs de planchers, bien que refaits, aient peu évolué.

La situation des ancrages des solives démontre qu'ils appartiennent à un plancher séparant un étage d'habitation et des combles. Dans une telle hypothèse, le solivage est orienté dans le sens de la largeur et sans doute porté par des poutres orientées dans le sens de la longueur. C'est le second cas où l'on observe cette orientation singulière des éléments de plancher. Quant aux niveaux inférieurs, qui n'ont livré aucune trace semblable, il est possible de proposer l'hypothèse d'un développement sur niveaux d'environ 2,30 $\mathrm{m}$ de hauteur. L'unique indice est offert par la porte cintrée dont la position milite en faveur d'un plancher proche de l'état actuel, en admettant que son percement ne se soit pas accompagné de mouvements importants des niveaux de circulation.

\section{Le rassemblement de deux parcelles mitoyennes}

La présence d'une porte percée dans le mur, au second niveau, témoigne d'un remembrement, à une date indéterminée, se matérialisant par la réunion de cette maison à la voisine (fig. 34).

Elle est haute de près de $2,50 \mathrm{~m}$ pour une largeur qu'il est possible d'estimer à $1 \mathrm{~m}$. Elle se caractérise par un linteau à engravement segmentaire, légèrement asymétrique, simplement taillé dans la terre. Le bourrage maçonné, sondé, donne une 


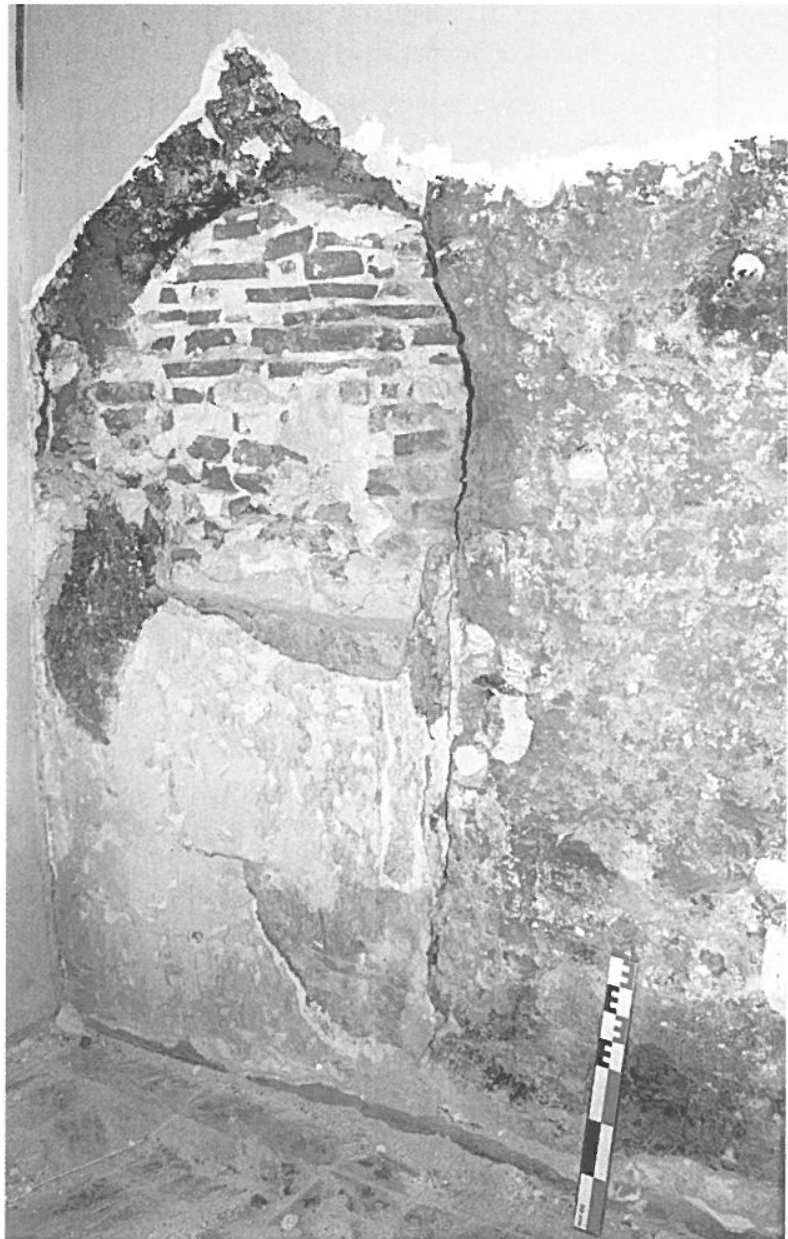

Fig. 34 : Le percement de la porte indique le rassemblement de cette parcelle avec la voisine et son bouchage correspond à un retour au parcellaire initial.

épaisseur du mur de $0,50 \mathrm{~m}$. Par ailleurs, le dégagement de l'embrasure a permis de mettre en lumière un décor, composé par un badigeon bleu-gris posé sur un enduit préparatoire semi-grossier, blanc.

\section{Le retour au parcellaire d'origine}

La porte, dans un troisième temps, est condamnée par une maçonnerie de briques assisées. L'oblitération de cette porte témoigne d'un retour au parcellaire d'origine, là aussi à une date indéterminée.

Ce bourrage a conservé sur sa surface des vestiges d'un second décor, composé d'un badigeon coloré gris clair.

\section{LE 31, RUE ARAGO}

Cette maison, située dans l'angle septentrional de l'îlot, a été sondée en raison de sa morphologie en tout point semblable à l'ensemble adossé. Elle permettait d'imaginer un scénario identique, malgré les limites imposées à l'enquête par la présence de locataires aux étages.

L'organisation de cette parcelle reflète celle des immeubles occupant l'angle oriental (fig. 25). La maison se développe donc sur un plan en L, d'une longueur de $10 \mathrm{~m}$ pour une largeur en façade de $10,15 \mathrm{~m}$, dans laquelle s'insère une petite maison, orientée sur la rue Arago.

Les trois sondages réalisés ont permis de mettre en lumière l'existence de pisé sur le mur du fond et le retour qui est mitoyen

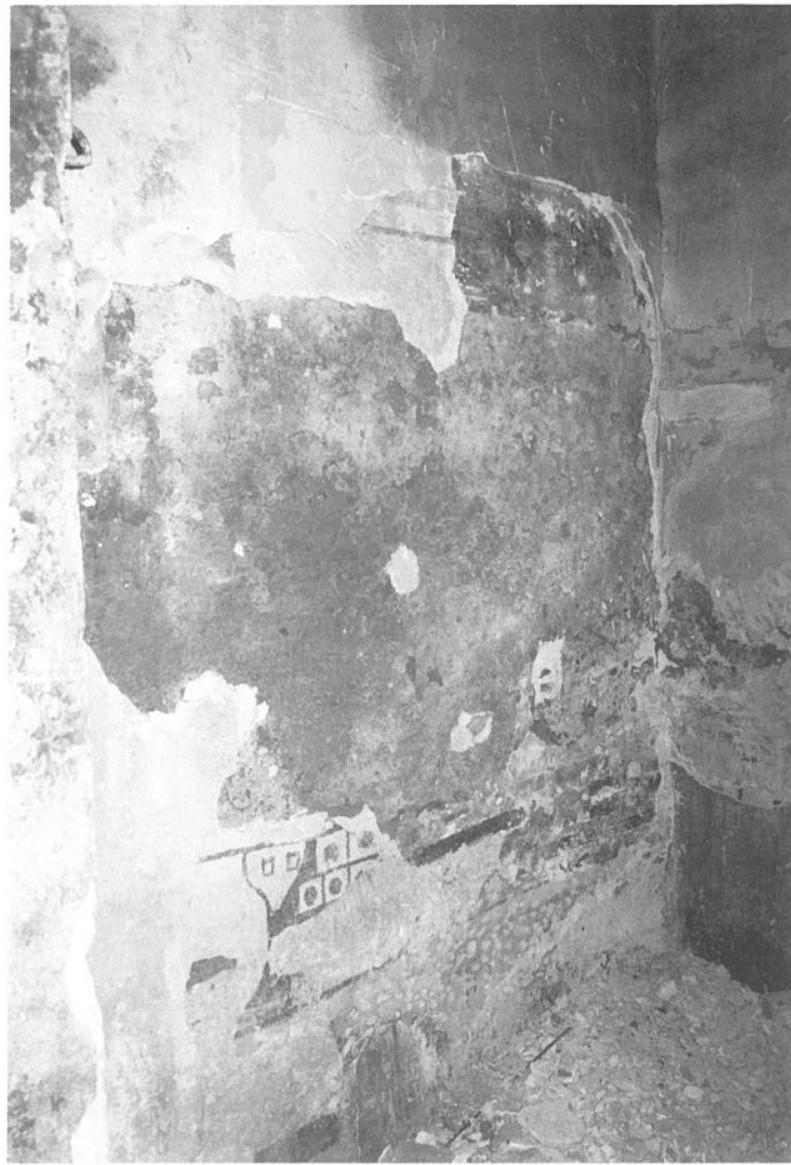

Fig. 35 : Élévation en pisé de la maison du 31 de la rue Arago.

avec la maison du 17 de la rue des Commères (fig. 35). Comme dans le groupe de maisons adossées, l'existence de ces murs de terre permet de proposer une évolution formée depuis deux longues parcelles orientées nord-ouest/sud-est, associées puis démembrées jusqu'à leur configuration actuelle.

\section{LE 33 ET 33BIS, RUE ARAGO}

Les deux bâtiments formaient à l'origine une seule et même maison, tardivement divisée par un mur en briques continu sur les trois premiers niveaux. Cet ensemble a livré des élévations en terre d'une exceptionnelle qualité en matière de conservation et d'indications concernant leur mise en œuvre. Les informations, abondantes, sont extraites du mur de fond et des murs latéraux, dégagés de manière la plus étendue que possible, exception faite toutefois du rez-de-chaussée du 33b, entièrement habillé d'une épaisse couche de ciment extrêmement compacte. Les murs sondés ont permis de mettre en lumière deux états édifiés en terre, offrant l'intérêt d'illustrer diverses formules de mise en œuvre.

\section{La parcelle}

L'immeuble primitif s'inscrit à l'intérieur d'une parcelle longue de 9,90 m environ pour une largeur de $5 \mathrm{~m}$ (dimensions hors œuvre) (fig. 25), ce qui permet de la remarquer comme étant l'une des plus grandes de l'îlot.

\section{Les matériaux mis en œuvre}

Dans l'angle oriental, les murs de fond et latéral nord-est prennent appui contre un angle de mur en terre appartenant à 
une maison mitoyenne. L'antériorité de cette dernière est avérée, mais il n'est pas possible d'établir de quelle maison il s'agit. En revanche, l'angle opposé montre un chaînage en besace témoignant de la contemporanéité du mur de fond et du mur latéral sud-ouest.

\section{Le mur de fond}

Ce mur se développe en trois parties distinctes : elles se composent pour l'essentiel de deux élévations en pisé, entre lesquelles s'intercale une partie en bauge, observée lors du diagnostic de la maison adossée (le 35 de la rue du Four-Saint-François).

La première élévation en pisé, appartenant à l'état initial de la maison, est constituée de trois assises. Le matériau est composé de limon grossier brun clair avec inclusions de graviers; dur, très compact, homogène pour les trois assises. Les limites horizontales et verticales des banchées, de même que les trous de clef, sont visibles. Le parement intact conserve la «fleur de pisé » qui forme une surface lisse blanchâtre, ainsi que les traces du coffrage. On distingue en effet très bien les empreintes des planches disposées horizontalement, plus serrées dans la partie droite (où elles sont de plus faible hauteur) que sur la gauche. Une mince couche de gobetis a été appliquée sur le parement, au moyen d'une taloche en bois qui a aussi laissé des traces nettes en tous sens, avant le crépissage au mortier de chaux.

La première assise est haute de 0,35 à $0,58 \mathrm{~m}$. Elle comporte deux banchées juxtaposées, de longueurs respectives de 0,62 m et $1,43 \mathrm{~m}$. Deux trous de clef rectangulaires $(13 \times 11 \mathrm{~cm})$, espacés d' $1 \mathrm{~m}$ et bouchés avec de la terre, ont été trouvés au contact de la seconde assise.

La deuxième assise, haute de $1 \mathrm{~m}$ à $1,20 \mathrm{~m}$, occupe toute la largeur de la pièce $(2 \mathrm{~m})$. Le joint avec la première assise est pratiquement imperceptible. Deux trous de clef, de $14-15 \mathrm{~cm}$ par $12 \mathrm{~cm}$ et espacés de $0,60 \mathrm{~m}$, ont été identifiés dans la partie supérieure. Le premier est bouché avec de la terre, le second avec un galet et du mortier. Le sommet de la seconde assise est horizontal et un joint de mortier, d'une épaisseur comprise entre 0,5 et $2 \mathrm{~cm}$, assure la transition avec la suivante.

Le revêtement le plus « ancien » de cette élévation se compose d'un mortier de chaux épais d' $1 \mathrm{~cm}$, souple, gris, truffé de nodules de chaux millimétriques ; il est recouvert par plusieurs couches de badigeons colorés en gris, beige et blanc.

\section{Le mur longitudinal nord-est}

Les observations sont issues des deux premiers niveaux, jusqu'à une pente de toit, parfaitement bien conservée. Le mur se découpe en deux registres correspondant à deux élévations qui se superposent (fig. 36).

La première élévation se distingue par un sommet oblique que l'on peut identifier comme une pente de toit (pièce D2). Elle prend naissance à environ $5 \mathrm{~m}$ du sol (actuel du rez-de-chaussée), au niveau du faittage et s'observe sur une longueur de $5 \mathrm{~m}$ environ. La pente est de l'ordre de $16^{\circ}$.

Le pisé est composé de limon grossier, sableux, homogène sur toute la hauteur. Les inclusions, peu nombreuses, se composent de graviers de taille variable $(2 \mathrm{~mm}$ à $3 \mathrm{~cm})$ et de nodules de mortier provenant peut-être du revêtement. Les inclusions de taille inférieure à $3 \mathrm{~mm}$ sont assez abondantes. Il est à noter la présence assez peu commune d'un lit de végétaux entre deux assises en partie haute.

Au-dessus de ce premier solin prend place une seconde élévation de pisé, qui présente un sommet oblique que l'on reconnaît comme une nouvelle pente de toit, que l'on peut restituer d'environ $15^{\circ}$. Il est couvert par un solin réalisé à l'aide de tuiles fragmentées et noyées dans un mortier de chaux.

Cette élévation correspond à un exhaussement du mur en terre antérieur, sur une hauteur de $2 \mathrm{~m}$. La matrice de ce pisé se distingue de celle du mur sous-jacent par son mélange plus grossier, avec de gros éléments type cailloutis, une couleur plus sombre et une plus grande compacité.

Dans la partie antérieure de la maison, le mur se développe sur une hauteur de 3,30 m en façade (depuis le sol actuel), que la pente de toit majore à 5,30 $\mathrm{m}$ au niveau du faitage. Trois assises ont été observées. Dans la partie basse, le parement est dégradé, sans trace de coffrage, les lits de damage imperceptibles. Les limites horizontales entre les assises ne se repèrent pas non plus : elles sont indiquées par de légers changements dans la composition des matériaux et par les trous de clef.

La première assise est visible sur 0,50 à $0,60 \mathrm{~m}$ de hauteur et $1,60 \mathrm{~m}$ de longueur. Elle comporte une fissure verticale bouchée au plâtre qui peut être une limite de banchée. Le sommet horizontal se distingue par la présence d'un trou de clef rectangulaire. La deuxième assise, complète, est d'une hauteur d'1,05 m. Elle a été dégagée sur une longueur de 2,30 m. Le sommet horizontal présente deux trous de clef distants de $0,90 \mathrm{~m}$. La troisième assise, enfin, présente une hauteur de $0,60 \mathrm{~m}$, vers la façade, qui augmente en raison de la pente vers l'arrière de la maison. Un seul trou de clef a été identifié, par sa position en limite de deux banchées.

\section{Le mur longitudinal sud-ouest}

Cette élévation se découpe en trois parties distinctes, formée de deux élévations en pisé entre lesquelles s'intercale un triangle composé de bauge (fig. 37).

Dans sa partie inférieure (pièces C2 et B3), le mur présente une structure compacte, homogène, très dure, formée de limon grossier de couleur brun clair contenant des graviers peu abondants. Quelques tessons de céramique à pâte sableuse bicolore et un morceau de toile ont été trouvés mélangés à la terre. Les lits de damage sont peu nets. Le parement originel n'est pas conservé, car il a subi un piquetage destiné à faciliter l'accroche d'un enduit de mortier. Deux assises sont conservées, mais la séparation n'est indiquée que par la ligne des trous de clef (pas de joint ni de limite horizontale visible). La première assise, dont la base se situe plus bas que le plancher actuel, mesure 0,70 à $0,72 \mathrm{~m}$ de hauteur. La seconde, dont le sommet est en légère oblique, mesure $1,10 \mathrm{~m}$ à l'endroit le plus haut. Trois (voire quatre) trous de clef rectangulaires $(14 \times 11 \mathrm{~cm})$ signalent le sommet de la première assise de pisé. Un seul d'entre eux possède une couverture aménagée à l'aide d'un galet. L'absence de trous au sommet de la seconde assise indique probablement que celui-ci correspond au sommet du mur. En revanche, une limite verticale entre deux banchées se distingue à 2,80 $\mathrm{m}$ de l'angle de la maison.

Au-dessus, dans la zone de contact avec le mur du fond et à partir de $1,75 \mathrm{~m}$ se remarque un triangle en bauge, sur une hauteur maximale observée de $0,65 \mathrm{~m}$ et une longueur de $2,60 \mathrm{~m}$. Il se compose de trois lits de terre, plus épais à l'extrémité gauche du mur qu'à droite, séparés par des végétaux. Un fragment de corde a été trouvé mélangé à la terre. La présence de ce triangle de bauge semble destinée à créer un plan oblique de démarrage pour la partie supérieure. La jonction avec la partie supérieure à nouveau en pisé est soulignée par une série de grosses branches posées sur la limite supérieure de la bauge et noyées dans le pisé.

La partie supérieure se développe sur une hauteur maximale de 2,20 $\mathrm{m}$ vers l'angle puis décroît vers la façade, en raison d'une pente de toit, de $15^{\circ}$, dégagé sur $6,50 \mathrm{~m}$ de longueur. Elle 


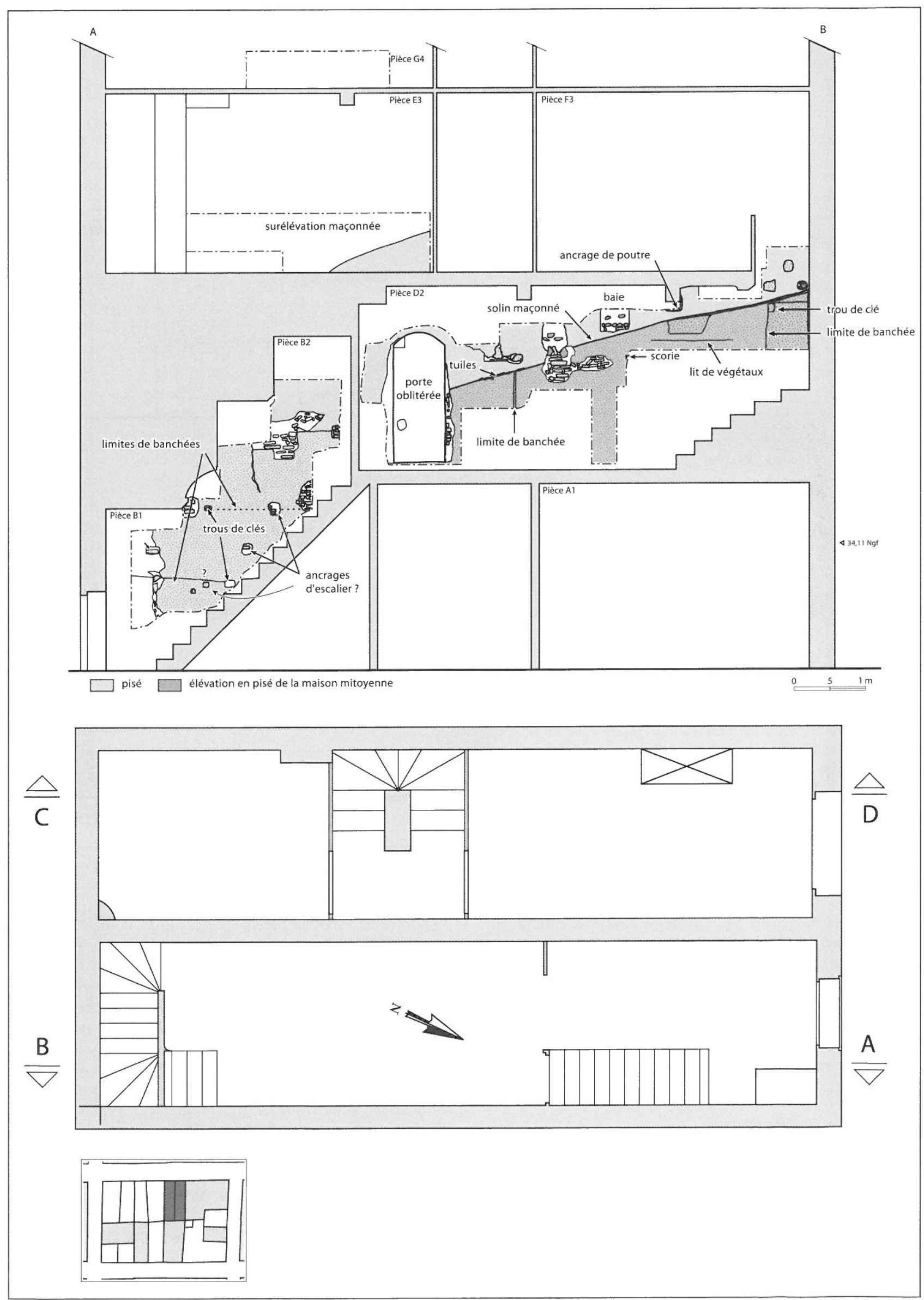

Fig. 36 : Plan et coupe de la maison située au 33 de la rue Arago. 


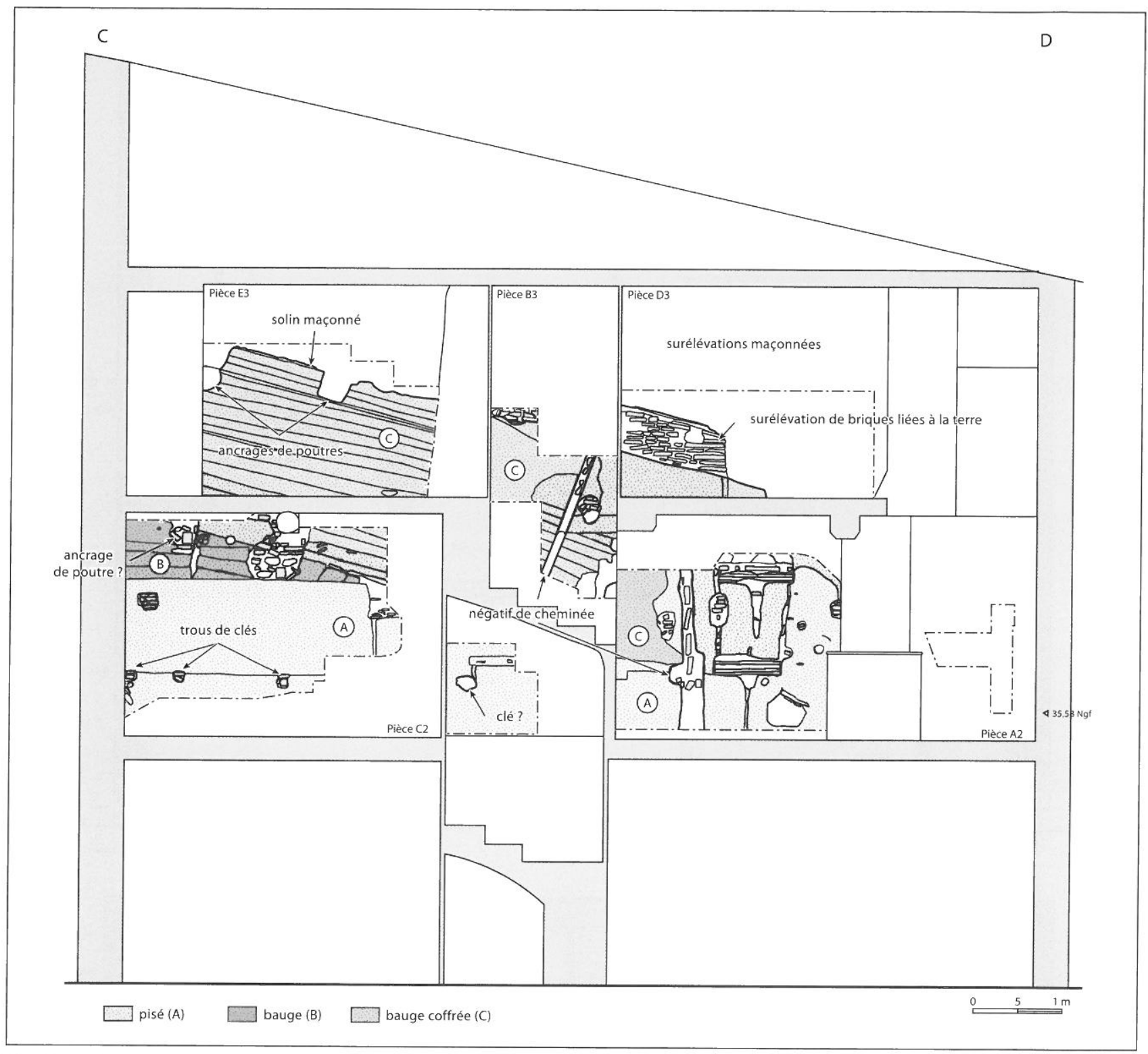

Fig. 37 : Plan et coupe de la maison située au 33b de la rue Arago.

se distingue nettement dans la pièce du fond et le couloir, en raison de son exceptionnel état de conservation. Les lits de terre, bien visibles, conservent l'inclinaison de départ amorcée par le triangle de bauge. Le parement, très lisse, présente sous un éclairage rasant des traces nettes de planches, elles aussi obliques. Le matériau utilisé est un limon grossier, semblable à celui de la partie basse, coloré en rouge par un effet de chauffe ${ }^{25}$. Il est à noter que les inclusions grossières s'orientent obliquement.

\section{Une marmite en guise de niche}

Cette maison a offert l'exemple le plus remarquable d'ouvrage contemporain de la construction de la maison, sous la forme d'un vase inséré dans le mur du fond, au premier niveau, à environ 1,50 m du sol actuel et à mi-distance de l'élévation (fig. 38). Le pot est en position couchée, la panse dans la terre, la lèvre au droit du parement. Sa forme, complète, permet d'identifier une marmite en remploi (traces de suie sur la paroi extérieure et intérieure), de forme très globulaire et à bord évasé. Elle ne possédait pas d'anse, mais elle se distinguait par la présence d'un bec verseur pincé. La pâte est brune, bicolore, légèrement micacée. Cependant, son usage n'est pas éclairci. Diverses interprétations ont été proposées : pot à sel, à cendre, etc., mais peut-être faut-il retenir simplement celle d'une petite niche rudimentaire d'usage polyvalent. La présence de suie, à l'intérieur, permettrait d'imaginer qu'elle a abrité une lampe, bien que son ouverture étroite rende cette hypothèse discutable.

\section{Une baie interprétée comme une lucarne}

Une structure rectangulaire de $0,40 \mathrm{~m}$ pour une hauteur maximale observée de $0,30 \mathrm{~m}$, a été mise au jour dans la partie exhaussée du mur longitudinal sud-ouest (pièce D2). Elle semble

\footnotetext{
${ }^{25}$ Divers indices conduisent à penser, en effet, qu'une partie de cette maison a subi un incendie. S'il n'a visiblement pas entraîné de destruction de la maison, il a vraisemblablement favorisé la bonne conservation de l'élévation, par la cuisson de la terre notamment.
} 


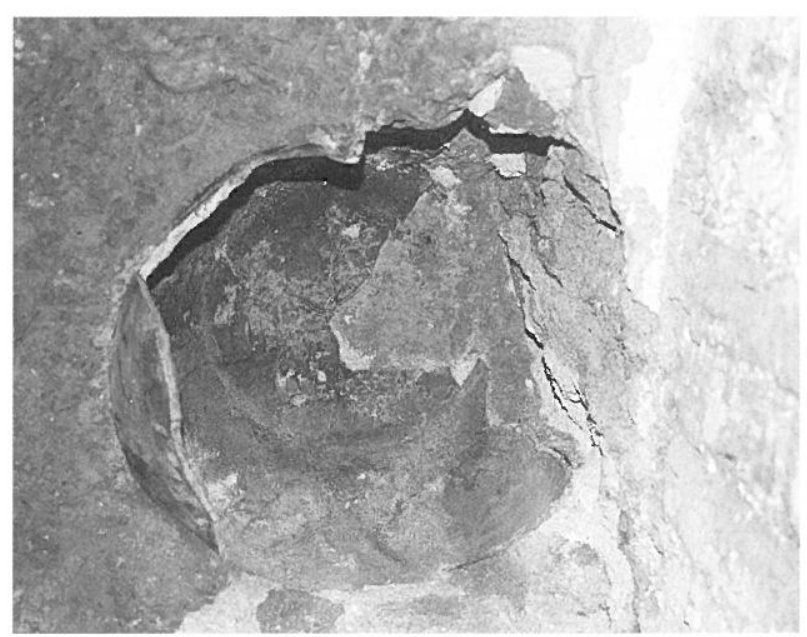

Fig. 38 : La marmite (en cours de démontage), insérée dans le mur du fond, sert vraisemblablement de niche.

découpée dans la terre après édification du mur. Malgré l'impossibilité de lever toute ambiguïté sur son interprétation ${ }^{26}$, sa situation et sa forme régulière conduisent à proposer l'hypothèse qu'il s'agit d'une petite baie, interprétée comme une lucarne.

\section{Les ancrages d'un plancher}

Deux séries de 12 ancrages alignés et à entraxes réguliers, mises au jour dans le mur du fond, sont interprétées comme les trous d'encastrement des solives de deux planchers séparant les étages. Ils semblent pouvoir être mis en relation avec un ancrage isolé, trouvé sur le mur latéral sud-ouest. Il est d'un diamètre de $0,30 \mathrm{~m}$ et situé à $0,65 \mathrm{~m}$ du mur du fond. La cote de son sommet étant sensiblement la même que celle de la base des solives, son orientation et sa position conduisent à l'interpréter comme l'emplacement d'une poutre destinée à soutenir ces dernières. La brique posée à plat au fond du bouchage, pourrait former une assise d'amortissement.

Le mur du fond a livré de nombreux ancrages contemporains de son édification. Ils ont été fermés à l'aide d'une motte de terre molle, mêlée de fragments de tuiles et enrobée de végétaux, qui forme un bouchon superficiel, tandis que le reste de la cavité est totalement rempli de paille. Toutefois, la plupart d'entre eux n'a pas reçu, dans le cadre de cette intervention, d'interprétation satisfaisante.

\section{Les ancrages de la charpente}

Seuls deux ancrages peuvent indiscutablement être identifiés comme les trous d'encastrement d'éléments de charpente. Ils appartiennent à la couverture du dernier état, ceux-ci se situant au niveau du sommet oblique du mur latéral sud-ouest. Le premier ancrage, situé à $0,90 \mathrm{~m}$ de l'angle, est de forme irrégulière. Le second, situé à 1,50 $\mathrm{m}$ de l'angle, dessine un négatif carré de $0,30 \mathrm{~m}$ de côté. Ils accompagnent les vestiges de solin formé d'un lit de plâtre, conservé sur la tête du mur sur une longueur d' $1,10 \mathrm{~m}$.

\section{La proposition de restitution}

Deux états ont été identifiés. Le premier est matérialisé par la première élévation en pisé du mur latéral nord-est, à pente de toit conservée. Elle permet de restituer une maison de petites dimensions, sans doute de deux niveaux, et qui pourrait n'occuper qu'une partie de la parcelle.

Un second état, qui s'illustre par une surélévation de pisé dans le mur nord-est et de bauge coffrée dans le mur sud-ouest, peut être le produit de multiples phases d'intervention opérées sur cette maison (ou sur les voisines). L'hétérogénéité des matériaux et des mises en œuvre tendraient à conforter cette hypothèse. Quoi qu'il en soit, ces élévations composent l'enveloppe de la maison, comme en témoignent la symétrie des deux élévations latérales ainsi que les ancrages des poutres ou de plancher. La maison, de plus grandes dimensions, occupe l'ensemble de la parcelle et possède une hauteur évoluant entre 4,50 $\mathrm{m}$ en façade et $7 \mathrm{~m}$ au niveau du faîtage, avec une pente estimée à $15^{\circ}$ (fig. 39). Ce volume, corrélé avec les indications fournies par les trous d'encastrement du plancher situés à $4,50 \mathrm{~m}$ du sol actuel, permet de proposer une maison de deux niveaux de 2,20 m environ, chacun surmonté de combles.

Une dernière indication qui suscite un intérêt est la présence d'une baie, interprétée comme une lucarne dans le mur latéral sud-ouest. Son existence, en effet, appuie l'hypothèse que les maisons ne sont pas, du moins dans un premier temps, toutes standardisées dans leurs volumes.

\section{Les remembrements : réunion de deux parcelles mitoyennes et retour au parcellaire d'origine}

Une porte, large de $0,71 \mathrm{~m}$ pour une hauteur maximale observée de $1,77 \mathrm{~m}$, percée dans le mur latéral nord-est, permet de mettre en relation la maison de cette parcelle avec la voisine, située au 31 de la rue Arago (fig. 40).

Le niveau de seuil n'a pas été repéré. Les piédroits sont en partie repris à l'aide de petites briques verticales. Le linteau de tracé segmentaire est engravé dans la terre. S'il n'a pas été possible de rouvrir la porte ${ }^{27}$, un sondage, situé au départ de l'arc, a révélé la présence de deux badigeons colorés successifs, de couleur gris-noir et brun clair, conservés dans l'embrasure.

Le retour au parcellaire initial se manifeste par l'oblitération de la porte qui reliait les deux maisons mitoyennes. Ce bourrage maçonné a conservé en surface un mortier de chaux préparatoire fin, beige, peu compact, destiné à supporter de multiples badigeons colorés en jaune moutarde, brun, bleu-gris, bleu puis vert-de-gris.

\section{Les éléments de la stratigraphie}

La superposition des sols d'époque contemporaine repose sur un remblai limoneux faiblement anthropisé. Aucun niveau de circulation n'a été mis en évidence.

\footnotetext{
${ }^{26}$ En raison de la présence de locataires dans la maison mitoyenne qui interdisait toute intervention intrusive sur cette structure.

${ }^{27}$ Pour la même raison que celle qui a été évoquée dans la note précédente.
} 

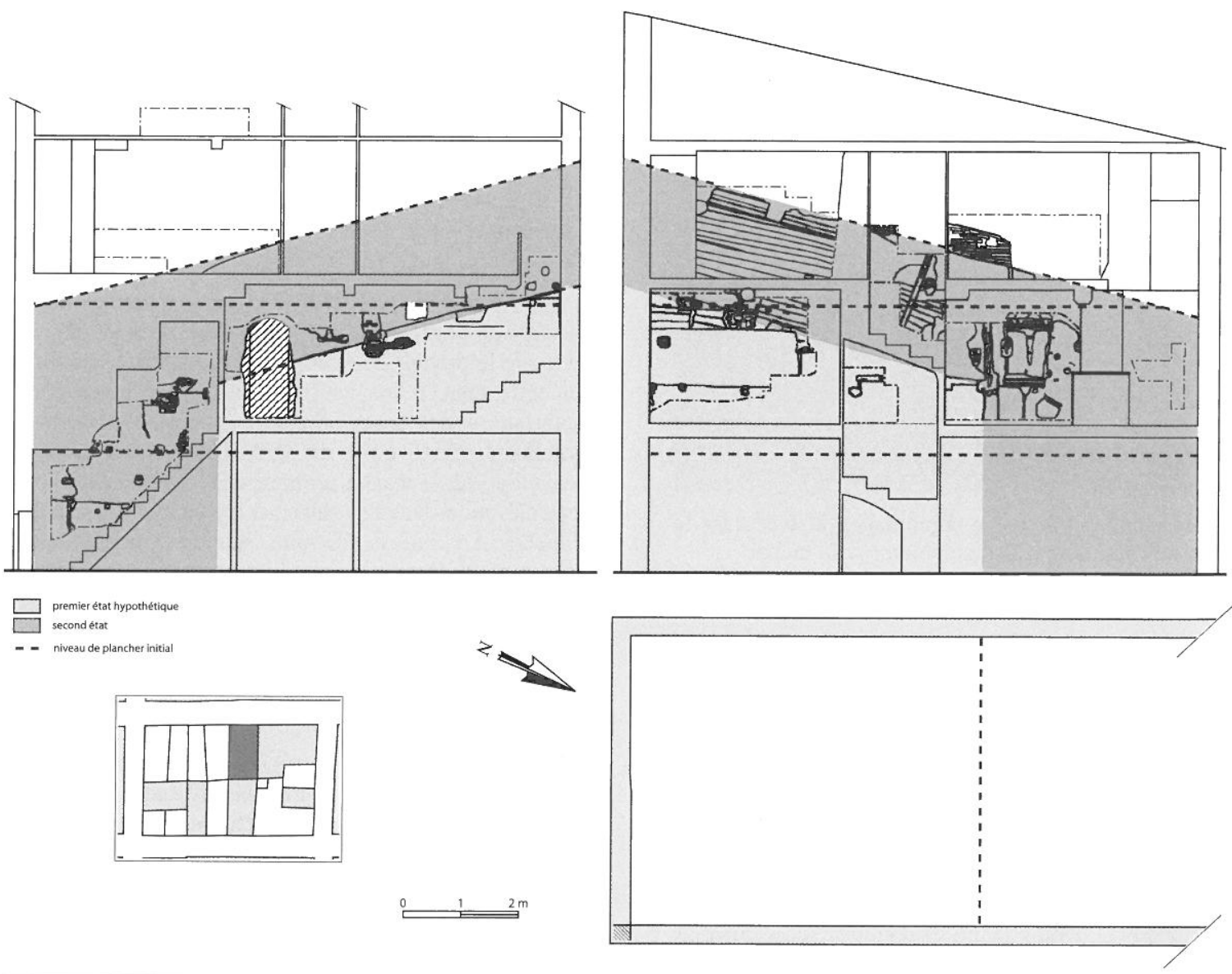

Fig. 39 : Plan et proposition de restitution du volume de la maison médiévale, dans les deux états observés.

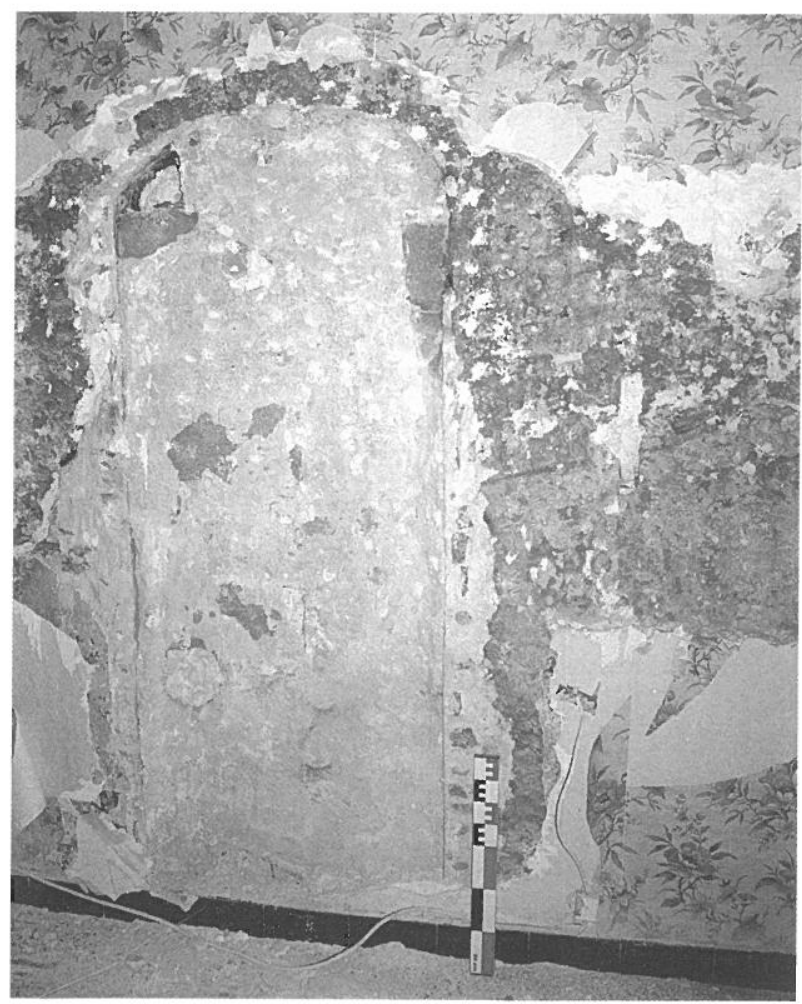

Fig. 40 : Le percement de la porte témoigne du rassemblement de cette parcelle avec la voisine et son bouchage correpond à un retour au parcellaire initial.

\section{BIBLIOGRAPHIE}

Adell i Gisbert 1982 : ADELL I GISBERT (J.), Notes per a l'estudi de la tecnologia constructiva de l'habitat en el poblament medieval de l'Esquerda. Ausa, X/102-104, 1982, p. 345-352.

Alessandri 1993 : ALESSANDRI (P.), « Perpignan, le site de Villa-Gothorum à Malloles », Études roussillonnaises, t. XIII, p. 85-89.

Aurenche 2003 : AURENCHE (O.), Propositions de terminologie pour les modalités de mise en œuvre de la terre comme matériau de construction, dans : CHAZELLES (C.A. de) et KLEIN (A.) dir., Échanges transdisciplinaires sur les constructions en terre crue. I. Terre modelée, découpée ou coffrée. Matériaux et modes de mise en æuvre. Actes de la table-ronde de Montpellier, 17-18 novembre 2001, Montpellier, Éditions de l'Espérou, 2003, p. 279-282.

Battle 1985 : BATTLE (C.), La maison barcelonaise au XIII ${ }^{e}$ siècle : caractéristiques, techniques et matériaux, Cahiers de la Méditerranée, 31, 1985 (La construction dans la Péninsule ibérique (XI'-XVI $I^{e}$.), approche économique et sociale). Université de Nice, p. 35-53.

Bardel, Maillard 2002 : BARDEL (P.), MAILLARD (J.-L.), Architecture de terre en Ille-et-Vilaine. Éditions Apogée, Écomusée du Pays de Rennes, 2002, 159 p.

Bardel, Rioult 2007 : BARDEL (P.), RIOULT (J.-J.), Les premières formes de construction en bauge dans le bassin de Rennes, dans : PATTE (E.) et STREIFF (F.) dir., 
L'architecture en bauge en Europe, Actes du colloque d'Isigny-sur-Mer, 12-14 octobre 2006, Parc des marais du Cotentin et du Bessin, 2007, p. 151-171.

Baudreu 2002 : BAUDREU (D.), Observations sur les constructions en terre crue dans l'Aude (Moyen Âge et époque moderne), Bulletin de la Société d'études scientifiques de l'Aude, t. CII, 2002, p. 57-64.

Baudreu 2003 : BAUDREU (D.), Habitats et fortifications en terre crue d'époque médiévale, dans le Midi de la France, dans : CHAZELLES (C.-A. de) et KLEIN (A.) dir., Échanges transdisciplinaires sur les constructions en terre crue. I. Terre modelée, découpée ou coffrée. Matériaux et modes de mise en auvre, Actes de la table-ronde de Montpellier, 17-18 novembre 2001, Montpellier, Éditions de l'Espérou, 2003, p. 359-375.

Bavay 1987 : BAVAY (G.), Le patrimoine bâti en terre dans le Hainaut belge et français. Bilan de l'enquête de restitution et état clinique des traces conservées, dans : Le patrimoine européen construit en terre et sa réhabilitation, coll. internat. ENTPE, 18-20 mars 1987, 1987, p. 1-30.

Bazzana et Guichard 1987 : BAZZANA (A.), GUICHARD (P.), La construction en terre dans l'Espagne musulmane : les TABIYA/S, dans : Le patrimoine européen construit en terre et sa réhabilitation, Colloque international ENTPE, Vaulx-en-Velin, 18-20 mars 1987, p. 99-119.

Belarte, Gailledrat 2003 : BELARTE (M.-C.) et GAILLEDRAT (E.), Murs protohistoriques de terre massive, sur la côte orientale de la péninsule ibérique $\left(\mathrm{VII}^{\mathrm{e}}-\mathrm{III}^{\mathrm{e}} \mathrm{s}\right.$. av. J.C.) : l'exemple de Guardamar del Segura (province d'Alicante), dans : C.-A. de CHAZELLES et A. KLEIN dir., Échanges transdisciplinaires sur les constructions en terre crue. 1. Terre modelée, découpée ou coffrée. Matériaux et modes de mise en auvre, Montpellier, Éditions de l'Espérou, 2003, p. 283-297.

Bergeret et Donat 2004 : BERGERET (A.), DONNAT (R.), en coll. avec CHAZELLES (C.-A. de), Le couvent des Franciscains à Perpignan, premiers résultats et perspectives, Archéologie du Midi Médiéval, 22, 2004, p. 199-207.

Bergeret et al. 2007 : BERGERET (A.) et collaborateurs, Le couvent des Franciscains - ancien hôpital militaire à Perpignan (Pyrénées-Orientales), Tranche 1. Rapport final d'opération de fouille archéologique, Inrap-SRA Languedoc-Roussillon, Montpellier, 2007, 201 p.

Bromberger, Lacroix, Raulin 1980 : BROMBERGER (C.), LACROIX (J.), RAULIN (H.), La Provence, collection «L'architecture rurale française», Paris, Éd. Berger Levrault, 1980.

Brutails 1891 : BRUTAILS (J.-A.), Étude sur la condition des populations rurales du Roussillon au Moyen Âge, Paris, Imprimerie nationale,1891, Réimpr. Slatkine, Genève, 1975.

Catafau 1998 : CATAFAU (A.), Les Celleres et la naissance du village en Roussillon, $X^{e}-X V^{e}$ siècle, Perpignan, 1998.

Cammas 2003 : CAMMAS (C.), L'architecture en terre crue à l'Âge du fer et à l'époque romaine : apports de la discrimination micromorphologique des modes de mise en œuvre, dans : C.-A. de CHAZELLES et A. KLEIN dir., Échanges transdisciplinaires sur les constructions en terre crue. 1 . Terre modelée, découpée ou coffrée. Matériaux et modes de mise en cuvre. Actes de la table-ronde de Montpellier, 17 18 novembre 2001, Montpellier, Éditions de l'Espérou, 2003, p. 33-53.
CAUE de l'Ain 1983 : L'architecture de terre, bâtiments caractéristiques de la région Rhône-Alpes, SME, Résonances, CAUE de l'Ain, Bourg-en-Bresse, 1983, $159 \mathrm{p}$.

Chazelles 1997 : CHAZELLES (C.-A. de), Les maisons en terre de la Gaule méridionale. Montagnac, Monographies Instrumentum, 2, 1997, $229 \mathrm{p}$.

Chazelles, Leal 2003: CHAZELLES (C.-A. de), LEAL (E.), Les murs en terre crue d'un faubourg médiéval de Narbonne (XIII ${ }^{-} \mathrm{XIV}^{\mathrm{c}}$ siècles), dans : CHAZELLES (C.A. de) et KLEIN (A.) dir., Échanges transdisciplinaires sur les constructions en terre crue. I. Terre modelée, découpée ou coffrée. Matériaux et modes de mise en œuvre, Actes de la table-ronde de Montpellier, 17-18 novembre 2001, Montpellier, Éditions de l'Espérou, 2003, p. $247-261$.

Chazelles 2007 : CHAZELLES (C.-A. de), La bauge dans les constructions du Languedoc et du Roussillon d'après les témoignages archéologiques du Néolithique à la fin du Moyen-Âge. Essai de synthèse, dans : PATTE (E.) et STREIFF (F.), L'architecture en bauge en Europe, Actes du colloque d'Isigny-sur-Mer, 12-14 octobre 2006, Parc des marais du Cotentin et du Bessin, 2007, p. 211-231.

Chazelles, Guyonnet 2007 : CHAZELLES (C.-A. de), GUYONNET (F.), La construction en pisé du LanguedocRoussillon et de la Provence, du Moyen Âge à l'époque moderne (XIII ${ }^{\mathrm{c}}-\mathrm{XIX}^{\mathrm{e}} \mathrm{s}$.), dans : GUILLAUD (H.), CHAZELLES (C.-A. de) et KLEIN (A.) dir., Les constructions en terre massive : pisé et bauge. Echanges transdisciplinaires sur les constructions en terre crue. 2, Actes de la table-ronde de Villefontaine (38), 28-29 mai 2005, Montpellier, Éditions de l'Espérou, 2007, p. 109-139.

Dewar 1987 : DEWAR (P.), Construction traditionnelle en terre en Angleterre, dans : Le patrimoine européen construit en terre et sa réhabilitation, colloque international ENTPE, 18-20 mars 1987, 1987, p. 417-468.

Esquieu, Pesez 1998 : ESQUIEU (Y.), PESEZ (J.-M.), Cent maisons médiévales en France ( $d u X I I^{e}$ au milieu $d u X V I^{e}$ siècle). Un corpus et une esquisse, Paris, CNRS Éditions, 1998, $449 \mathrm{p}$

Esquieu 2001 : ESQUIEU (Y.), La ville au Moyen Age. L'exemple français, Gloucestershire, Éd. Alan Sutton, 2001, 159 p.

Fabre, Lochard 1992 : FABRE (G.), LOCHARD (T.), Montpellier : la ville médiévale, Paris, Imprimerie Nationale, 1992, 309 p.

Font Arellano 2007 : FONT ARELLANO (J.), La tapia dans les textes hispaniques, dans : GUILLAUD (H.), CHAZELLES (C.-A. de) et KLEIN (A.) dir., Les constructions en terre massive : pisé et bauge. Échanges transdisciplinaires sur les constructions en terre crue. 2, Actes de la table-ronde de Villefontaine (38), 28-29 mai 2005, Montpellier, Éditions de l'Espérou, 2007, p. 53-70.

Garrigou Grandchamp 1999 : GARRIGOU GRANDCHAMP (P.), Demeures médiévales. Couur de la cité, Paris, 1999, $127 \mathrm{p}$

Ginouvez 2002 : GINOUVEZ (O.), Béziers. Habitations médiévales et modernes sur les vestiges de l'amphithéâtre antique. Deux nouvelles études de cas, DFS, INRAP-SRA Languedoc-Roussillon, Montpellier, 2002 (inédit). 
Ginouvez et al. 2008 : GINOUVEZ (O.), avec la coll. de CHAZELLES (C.-A. de) et la participation de COLOMER (G.) et GAZZAL (H.), Maisons médiévales sur le site de l'amphithéâtre antique de Béziers (Hérault). Contribution à l'étude de l'architecture de pierre et de terre en Languedoc, Archéologie du Midi Médiéval, 26, 2008, p. 167-197.

Gomez 2005 : GOMEZ (E.), Rue Tourventouse, Béziers, Rapport d'intervention, Service archéologique de Béziers, 2005 (inédit).

Grandjouan 2004 : GRANDJOUAN (M.-S.), Le patrimoine rural en Languedoc-Roussillon : acquis et perspectives du travail d'inventaire, In Situ, revue en ligne, Ministère de la Culture, 2004.

Guibaud 2005 : GUIBAUD (C.), L'architecture en pisé dans le canton de Boën (Loire), In Situ, revue en ligne, Ministère de la Culture, 2005.

Guillaud et alii 2007 : GUILLAUD (H.), CHAZELLES (C.A. de) et KLEIN (A.) dir., Les constructions en terre massive : pisé et bauge. Echanges transdisciplinaires sur les constructions en terre crue. 2, Actes de la table-ronde de Villefontaine (38), 28-29 mai 2005, Montpellier, Éditions de l'Espérou, 2007, 328 p.

Guyonnet 2001 : GUYONNET (F.), Rue de l'Anguille. Étude des élévations à Perpignan (Pyrénées-Orientales), DFS, AFAN. SRA Languedoc-Roussillon, 2001, 101 p.

Guyonnet et Catafau 2003 : GUYONNET (F.) et CATAFAU (A.), La construction urbaine en terre aux $\mathrm{XIII}^{\mathrm{e}} \mathrm{s}$. et $\mathrm{XIV}^{\mathrm{c}}$ s. : l'exemple de la rue de l'Anguille (Perpignan), dans : CHAZELLES (C.-A. de) et KLEIN (A.) dir., Echanges transdisciplinaires sur les constructions en terre crue. I. Terre modelée, découpée ou coffrée. Matériaux et modes de mise en œuvre, Actes de la table-ronde de Montpellier, 17. 18 novembre 2001, Montpellier, Éditions de l'Espérou, 2003, p. 389-411.

Houben et Guillaud 1989 : HOUBEN (H.), GUILLAUD (H.), Traité de construction en terre, L'encyclopédie de la construction en terre, vol. 1. Marseille, Éd. Parenthèses, $1989,355 \mathrm{p}$

Jeannet et alii. sans date : JEANNET (J.), POLLET (G.), SCARATO (P.), Le pisé. Patrimoine, Restauration, Technique d'avenir, Les Cahiers de construction traditionnelle, Éd. CREER, Nonette.

Klein 1999 : KLEIN (A.), Éloge de la terre en Midi-Pyrénées. Architectures de terre crue : patrimoine et modernité, Les Cahiers de l'ANAH, n 89, juin 1999, p. 15-21.

Klein 2003 : KLEIN (A.), Le patrimoine architectural en terre crue de Midi-Pyrénées $\left(\mathrm{XV}^{\mathrm{e}}-\mathrm{XX}^{\mathrm{e}} \mathrm{s}\right.$.), dans : CHAZELLES (C.-A. de) et KLEIN (A.) dir., Échanges transdisciplinaires sur les constructions en terre crue. I. Terre modelée, découpée ou coffrée. Matériaux et modes de mise en œuvre, Actes de la table ronde de Montpellier, 17-18 novembre 2001, Montpellier, Éditions de l'Espérou, 2003, p. 417 437.

Kotarba, Pezin 1989 : KOTARBA (J.), PEZIN (A.), Place de l'église, Elne, (P.-O.), rapport de fouilles. SRA Languedoc Roussillon, 1989 (inédit).

Le Barrier 1998 : LE BARRIER (C.), Montverdun (Loire). $\mathrm{XIII}{ }^{e}$ siècle. Logis du prieur, construit partiellement en pisé, dans : ESQUIEU (Y.) et PESEZ (J.-M.) dir., Cent maisons médiévales en France (du XII au milieu du XVI siècle). Un corpus et une esquisse, Paris, C.N.R.S. Éditions, 1998, p. 179-180.
Lopez Martinez 2007 : LOPEZ MARTINEZ (F.-J.), Les maçonneries de pisé : signification et restauration (Tapiera : significado y restauracion), dans : GUILLAUD (H.), CHAZELLES (C.-A. de) et KLEIN (A.) dir., Les constructions en terre massive : pisé et bauge. Échanges transdisciplinaires sur les constructions en terre crue. 2 , Actes de la table ronde de Villefontaine (38), 28-29 mai 2005, Montpellier, Éditions de l’Espérou, 2007, p. 71-81.

Lhuisset 1980 : LHUISSET (C.), L'architecture rurale en Languedoc, en Roussillon, Éd. Les Provinciades, 1980, $399 \mathrm{p}$.

Lochard, Vayssettes, Nepipvoda 2005 : LOCHARD (T.), VAYSSETTES (J.-L.), NEPIPVODA (D.) avec la coll. de C.-A. de CHAZELLES, Inventaire du patrimoine. Commune de Montagnac, inventaire de l'îlot Saint-Michel. Rapport de synthèse, Rapport DRAC-LR, Montpellier, 2005 (inédit).

Mellinand et Leal 2002 : MELLINAND (P.) et LEAL (E.), La Médiathèque, une occupation suburbaine antique et médiévale à Narbonne (Aude), DFS, AFAN - SRA LanguedocRoussillon (inédit).

Milcent 2004 : MILCENT (D.), Construire en terre, couvrir en roseaux. Catalogue de l'exposition Terres d'architecture, Regards sur les bourrines du marais de Monts. Écomusée du marais Breton Vendéen Le Daviaud, 10 septembre - 5 décembre 2004, p. 25-33.

Milcent, Renoux 2007 : MILCENT (D.) avec la coll. de RENOUX (B.), Architecture rurale en bauge et couverture végétale dans le Nord-Ouest vendéen : les bourrines du marais de Monts, dans : PATTE (E.) et STREIFF (F.), L'architecture en bauge en Europe, Actes du colloque d'Isigny-sur-Mer, 12-14 octobre 2006, Parc des marais du Cotentin et du Bessin, 2007, p. 17-35.

Patte 2004 : PATTE (E.) avec la collaboration de E. MARIERAFFRAY, Entre Sèves et Taute. De terre et de pierre dans les marais du Cotentin, Inventaire général des monuments et des richesses artistiques de la France. Région BasseNormandie, Éditions Cahiers du Temps, Cabourg, 2004, $64 \mathrm{p}$.

Patte 2007 : PATTE (E.), L'architecture en bauge dans les marais du Cotentin et du bassin à l'époque moderne, dans : PATTE (E.) et STREIFF (F.), L'architecture en bauge en Europe. Actes du colloque d'Isigny-sur-Mer, 12-14 octobre 2006, Parc des marais du Cotentin et du Bessin, 2007, p. 133-149.

Rémy, de Chazelles, Alessandri, Catafau 2003 : REMY (I.), DE CHAZELLES (C.-A.), ALESSANDRI (P.), CATAFAU (A.), Des maisons en terre sur un îlot du quartier SaintMathieu à Perpignan (P.-O.), DSF de diagnostic de bâti, SRA de Montpellier, 2003, $87 \mathrm{p}$.

Patte, Streiff 2007 : PATTE (E.), STREIFF (F.), L'architecture en bauge en Europe, Actes du colloque d'Isigny-sur-Mer, 12-14 octobre 2006, Parc des marais du Cotentin et du Bessin, 2007, 335 p.

Pays d'Aigues (Le) : COLLECTIF, Cantons de Cadenet et de Pertuis, Inventaire topographique du Pays d'Aigues, Paris, Ministère de la Culture et de la Communication, 1981.

Péchoux, Korbaa 2007 : PÉCHOUX (M.), KORBAA (M.), L'architecture en pisé des déserts de haute altitude en Himachal Pradesh (Inde) : le village de Tabo dans la vallée du Spiti, dans : GUILLAUD (H.), CHAZELLES (C.-A. de) et KLEIN (A.) dir., Les constructions en terre massive : 
pisé et bauge. Échanges transdisciplinaires sur les constructions en terre crue. 2, Actes de la table-ronde de Villefontaine (38), 28-29 mai 2005, Montpellier, Éditions de l'Espérou, 2007, p. 203-216.

Rafel i Fontanals 1980: RAFEL I FONTANALS (N.), Contribucio a l'estudi de diverses restes arquitectoniques publicades com a columbaris romans, Fonaments, 2, 1980 , p. $117-125$.

Roux et Cammas 2007 : ROUX (J.-C.), CAMMAS (C.), La bauge coffrée : appréhension d'un mode de construction inédit dans la ville protohistorique de Lattes, Hérault (deuxième quart du $\mathrm{IV}^{\mathrm{e}} \mathrm{s}$. av. n. è.), dans : GUILLAUD (H.), CHAZELLES (C.-A. de) et KLEIN (A.) dir., Les constructions en terre massive : pisé et bauge. Échanges transdisciplinaires sur les constructions en terre crue. 2, Actes de la table ronde de Villefontaine (38), 28-29 mai 2005, Montpellier, Éditions de l'Espérou, 2007, p. 87-98.

Scherrer 2003 : SCHERRER (O.), Actualité de la construction en bauge en Afghanistan : la technique du "pakhsa», dans : CHAZELLES (C.-A. de) et KLEIN (A.) dir., Échanges transdisciplinaires sur les constructions en terre crue. 1. Terre modelée, découpée ou coffrée. Matériaux et modes de mise en ceuvre, Actes de la table ronde de Montpellier, 17 18 novembre 2001, Montpellier, Éditions de l'Espérou, 2003, p. 213-230.

Streiff 2003 : STREIFF (F.) avec la collaboration de F. LAHURE, Le patrimoine en bauge de Haute et de BasseNormandie. Caractéristiques et développement actuel des savoir-faire de la filière bauge en Normandie, dans : CHAZELLES (C.-A. de) et KLEIN (A.) dir., Échanges transdisciplinaires sur les constructions en terre crue. 1 . Terre modelée, découpée ou coffrée. Matériaux et modes de mise en cuvre, Actes de la table ronde de Montpellier, 1718 novembre 2001, Montpellier, Éditions de l'Espérou, 2003, p. 315-330.
Thernot et Vecchione 2003 : THERNOT (R.), VECCHIONE (M.), Les murs en pisé banché dans l'habitat de Marseille au Moyen-Âge (fin XII ${ }^{e}$ s. - début XIII ${ }^{\mathrm{e}}$ s.). Fouilles de la place Villeneuve-Bargemon, dans : CHAZELLES (C.-A. de) et KLEIN (A.) dir., Échanges transdisciplinaires sur les constructions en terre crue. I. Terre modelée, découpée ou coffrée. Matériaux et modes de mise en cuvre, Actes de la table ronde de Montpellier, 17-18 novembre 2001, Montpellier, Éditions de l'Espérou, 2003, p. 439-450.

Tréton 2007 : TRETON (R.), Recueil des chartes de la maison du Temple du Mas Déu en Roussillon (1001-1329), Paris I la Sorbonne, 2007, 5 vol., 1700 pages.

Verdon 1995 : VERDON (L.), Quelques aspects de la démographie en Roussillon au XIII siècle, dans : SÉNAC (P.) dir., Histoire et archéologie des terres catalanes au Moyen Âge, Perpignan, PUP, 995, p. 253-268.

Verdon 2000 : VERDON (L.), Le quartier Saint-Mathieu de Perpignan : un exemple de la croissance d'une ville au XIII ${ }^{e}$ siècle, dans : ASSIER-ANDRIEU (L.) et SALA (R.) dir., La Ville et les pouvoirs, Perpignan, 2000, p. 99-107.

Verdon 2001 : VERDON (L.), La terre et les hommes en Roussillon aux XII et XIII siècles. Structures seigneuriales, rente et société d'après les sources templières, Publications de l'Université de Provence, 2001, 249 p.

Vinas 1961 : VINAS (R.), Les Templiers en Roussillon d'après le cartulaire de la commanderie du Mas Déu, DES, Montpellier, 1961.

Vinas 2001 : VINAS (R.), L'Ordre du Temple en Roussillon, Éditorial Trabucaïre, Perpignan, 2001, 219 p. 
